\title{
TURNING WITH SHALLOW CUTS AT HIGH SPEEDS
}

\author{
By H. J. French and T. G. Digges
}

\begin{abstract}
A method is described for testing lathe tools under shallow cuts and fine feeds. The relations were determined between the cutting speed, feed, depth of cut, and tool life for carbon and high-speed tool steels. Comparisons were made of tools of different forms and of tool life when cutting dry and with water or lard oil. Heat treatment and chemical composition of the tools were also studied, including, in the case of high-speed tool steels, the effects of cobalt, nickel, molybdenum, arsenic, antimony, phosphorus, sulphur, copper, tin, aluminum, titanium, and tantalum. The results obtained under shallow cuts and fine feeds with these steels are compared with those obtained under heavy duty.
\end{abstract}

\section{CONTENTS}

I. Introduction

II. Previous investigations

III. Preliminary tests with a dynamometer............. 833

IV. The method of test used under shallow cuts _........... 833

1. Equipment.

2. Procedure

3. How carbon and high-speed steel tools failed

V. Effect of cutting speed on tool life

1. For high-speed steel tools

2. For carbon steel tools _....... 844

VI. Effect of feed and depth of cut on cutting speed

1. For high-speed steel tools

2. For carbon steel tools _... 849

VII. Variations in tool form

1. Shape of the nose of the tool

2. Back slope and side slope in broad-nose tools........... 852

VIII. Effect of lard oil and water on cutting speed of high-speed steel tools_ $\quad 853$

IX. Effect of heat treatment of tools on cutting speed

1. High-speed steel tools _._.

2. 1.3 per cent carbon steel tools

X. Performance comparisons of different carbon and low-alloy tool steels under shallow cuts. . .

XI. High-speed steel tools of different compositions used under shallow and deep cuts...-...-.

1. Preparation of the steels and tools

2. Hot working and machining properties

3. General comments on lathe tests

4. Steels with molybdenum

5. Steels with cobalt

6. Steels with arsenic, antimony, copper, or tin $\ldots$

7. Steels with aluminum

8. Steels with titanium

9. Steels with tantalum

10. Steels with high phosphorus or sulphur.....

11. Steels with nickel

XII. Summary and conclusions 


\section{INTRODUCTION}

Most studies of turning have been made with relatively coarse feeds and deep cuts, and it is now possible to predict, with an accuracy sufficient for many practical purposes, the cutting speeds which can be used economically in the rough turning of metals. Comparable information is not yet available for the shallow cuts used in finish turning.

The experiments described in this report relate primarily to a new method of test for lathe tools taking shallow cuts, and it was first used in a study of the effects of feed, depth, cutting liquids, and tool form upon the cutting speed to give a broad background for useful interpretation of results. The new test was then used in a study of the effect of composition and heat treatment upon the performance of carbon and high-speed steel tools and results compared with those obtained in the customary rough turning tests.

While there has recently been a tendency in machine-shop practice to replace finish turning by grinding, the discussion of a recent paper relating to the rough turning of alloy steels ${ }^{1}$ indicated active industrial interest in test methods applicable to turning tools working at high speeds with shallow cuts and fine feeds. This is, perhaps, natural since the bulk of industrial machining does not involve cutting conditions as severe as those obtaining in the usual rough turning tests of high-speed tool steels.

\section{PREVIOUS INVESTIGATIONS}

It is generally believed that the methods of test developed for heavy cuts with high-speed tool steels can not be applied successfully to the shallow cuts used in finish turning. For example, Taylor ${ }^{2}$ cautioned investigators against using "cuts lighter than $3 / 16$ inch depth by $1 / 16$ inch feed," and stated further that "as a result of our experience we should consider practically worthless for determining laws (of cutting) all cuts that are as shallow as $1 / 16$ inch, and we should much prefer a $3 / 16$-inch depth to a $1 / 8$-inch depth."

Among the reasons for these recommendations were the difficulty of maintaining constant cutting conditions with shallow cuts, and the fact that when high frictional temperatures played only a minor part in the wear of the tools, as with shallow cuts, failure was not abrupt and complete, but, instead, the tools showed a gradual wearing away of the nose. This, of course, was reflected in a gradually changing depth of cut and raised the question of what should be considered as tool failure. Wear of the tool nose, which reduces the depth of cut by $0.001 \mathrm{inch}$, is a relatively small part of the total depth usually encountered in rough turning and is of secondary importance,

1 H.J. French and T. G. Digges, Rough Turning With Particular Reference to the Steel Cut, Trans. Am. Soc. Mech. Engrs., 48, p. 533.

F. W. Taylor, On the Art of Cutting Metals, Trans. Am. Soc. Mech. Engrs., 28, par. 252, p. 66; 1907. 
since close adherence to dimensions is not ordinarily required. Such a change is of much greater importance in finish turning where the cuts are shallow, of the order of 0.005 to 0.010 inch or less, and where close adherence to dimensions is usually required.

The methods of test used by previous investigators for studying the gradual wear of lathe tools taking shallow cuts may be grouped under two headings: (1) Direct measurements of tool wear and (2) indirect methods of measurement.

Direct measurements of wear have been reported by Ripper and Burley ${ }^{3}$ and Herbert. ${ }^{4}$ In the experiments of Ripper and Burley the wear was determined by a microscope with vernier attachment. The tests, which were made in a lathe, were interrupted repeatedly to remove the tool from the holder and measure the wear.

Herbert's tests were made with a special tool-steel testing machine in which a tool was applied at the bottom end of a rotating tube placed in a vertical position. A heavy weight pressed the tube against a dead stop and regulated the amount of the cut. The vise in which the tool was held was mounted on knife-edges and tilted as the tool wore. The tilting angle of the vise was proportional to the wear of the tool and was measured by a micrometer.

Indirect methods of measuring the wear of lathe tools have been described by Poliakoff, ${ }^{5}$ Smith and Hey, ${ }^{6}$ and Smith and Leigh. ${ }^{7}$

In the method used by Poliakoff, and also by Smith and Jinoya, ${ }^{8}$ the wear of the tools was determined from the corresponding increase in the diameter of the work (the bar being cut). An indicator was mounted on the tool rest immediately behind the tool and kept in continuous contact with the work. The tests were continued until the wear was greater than that selected to represent failure of the tool and the carriage moved back by hand, after stopping the test, to permit checking the changes in the depth of cut.

Smith and Hey and Smith and Leigh made use of a dynamometer for measuring the vertical forces on the tool when cutting. Tool comparisons were based on the time required for the vertical force to increase 10 per cent above its initial value. This increase was found to correspond approximately to a tool wear of 0.0015 inch and was stated to bear a distinct relation to the breakdown of the tool. In selecting the pressure on the tool as a measure of tool life these investigators disregarded the recommendations of Taylor and his associates who specifically stated that "no law can be established or

${ }^{3}$ W. Ripper and G. W. Burley, Cutting Power of Lathe Turning Tools, Proc. Inst. Mech. Eng., pts. 3 and 4 , p. 1067; 1913.

${ }^{4}$ E. G. Herbert, The Cutting Properties of Tool Steel, J. Iron and Steel Inst., 81, p. 206; 1910.

5 F. Poliakoff, Cutting Tools, The Engineer, 119, p. 275; 1915.

${ }^{6}$ D. Smith and I. Hey; Report of the Lathe Tools Research Committee, Department of Scientific and Industrial Research, published by His Majesty's Stationery Office; 1922; also, The Engr., 137, p. 366; 1924.

7 D. Smith and A. Leigh, Lathe Tool Experiments with Fine Cuts, Proc. Inst. Mech. Eng., pt. 1, p. 383; 1925, also, The Engineer, 139, p. 318; 1925.

8 See footnote 5 . 
formulated for cutting steel which expresses the relation between cutting speed and the pressure on the tool."

Some of the conclusions drawn from tests made by these different methods are compared in Table 1, which also gives a general idea of the conditions under which the tests were made. The investigators have taken different criteria for failure of the tools and have obtained what, at first glance, seem to be contradictory results. For example, Ripper and Burley found that the life of both carbon and high-speed steel tools, when represented by wear of 0.005 inch, increased as the cutting speed decreased. Most of the other investigators referred to in Table 1 found "peaks" in the cutting speed-"tool life" curves which showed that under some conditions increase in cutting speed resulted in an increase in the "tool life." Apparently, however, such critical speeds were found only when the working portions of the tools were kept at low temperatures by means of very shallow cuts and fine feeds, the use of cutting liquids, or both.

TABLE 1.-Summary of some of the results obtained by different methods of test for lathe tools taking flne cuts

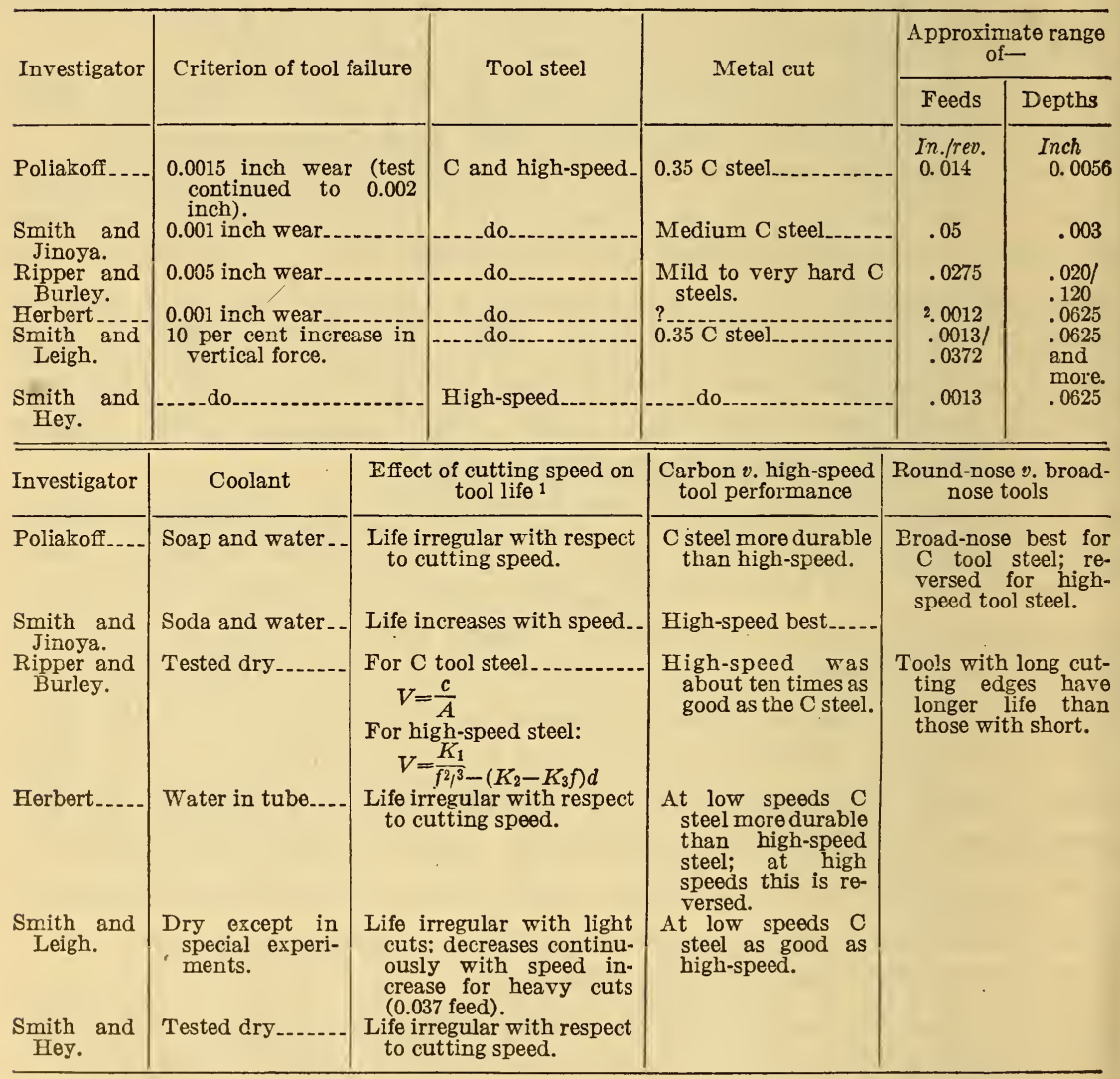

$1 \mathrm{~V}=$ cutting speed, $f=$ feed, $d=$ depth of cut, $A=$ area of cut, and $c, K_{1}, K_{2}$, and $K_{3}$ are constants.

' Maximum obtainable. 


\section{PRELIMINARY TESTS WITH A DYNAMOMETER}

Tests were first made with a dynamometer with the view of correlating the changes in pressure on the tools with tool wear. The dynamometer used was similar in design and construction to that employed by Stanton and Hyde ${ }^{9}$ and is shown in Figure 1.

One of the disadvantages of such equipment, which was noted by earlier investigators, was the lack of rigidity of the test tools. Measurements of the diameter of the test forgings, subsequent to the tool tests, showed variable depths of cut from start to finish in nearly all tests. The variations were not progressive changes in one direction but appeared at irregular intervals and could be detected readily from the changes in the appearance of the cut surfaces. "Stepped cuts" were obtained in nearly all cases.

It is probable that such effects could have been minimized by refinements in the construction of the dynamometer, but since there did not seem to be any consistent relation in the preliminary tests between the vertical or horizontal forces on the tools and the tool wear the use of the dynamometer was discontinued.

\section{THE METHOD OF TEST USED UNDER SHALLOW CUTS}

\section{EQUIPMENT}

The method of test adopted is illustrated in Figure 2. It makes use of two tools set at equal depths in one tool holder and depends upon the fact that the "trailer" or following tool will not cut so long as the "leader" or cutting tool shows no wear.

A micrometer adjustment is provided in the groove into which the trailer tool is placed in the tool holder, as is shown in Figure 3. The leader, or test tool, is first clamped securely in the tool holder, which is then moved in the direction of the depth of cut until a piece of thin (cigarette) paper can just be drawn between the work and the nose of the test tool. The micrometer adjustment is then used to bring the trailer tool into a similar position, and the trailer is securely clamped in the holder by means of the set-screws shown in Figure 3. After adjustment to equal depths the desired depth of cut is secured by setting the carriage on the lathe in the usual manner.

One of the advantages of this method of test is its simplicity, as the only special equipment required is the tool holder. Another advantage is that there is nothing to interfere with the rigidity of the test tool.

One of the disadvantages of the method is shown in Figure 4 and relates to a correction which should be applied to the observed duration of cut. If the true length of cut of the test tool $L$ is represented by $A$

o T. E. Stanton and J. H. Hyde, Forces Exerted on the Surface of Cutting Tools. Proc. Inst. Mech Eng., pt. 1, p. 175; 1925 . 
in Figure 4, then $B$ represents the observed length of cut which differs from the true value by the amount $C$, representing approximately the distance between the two tools. This distance is small in relation to

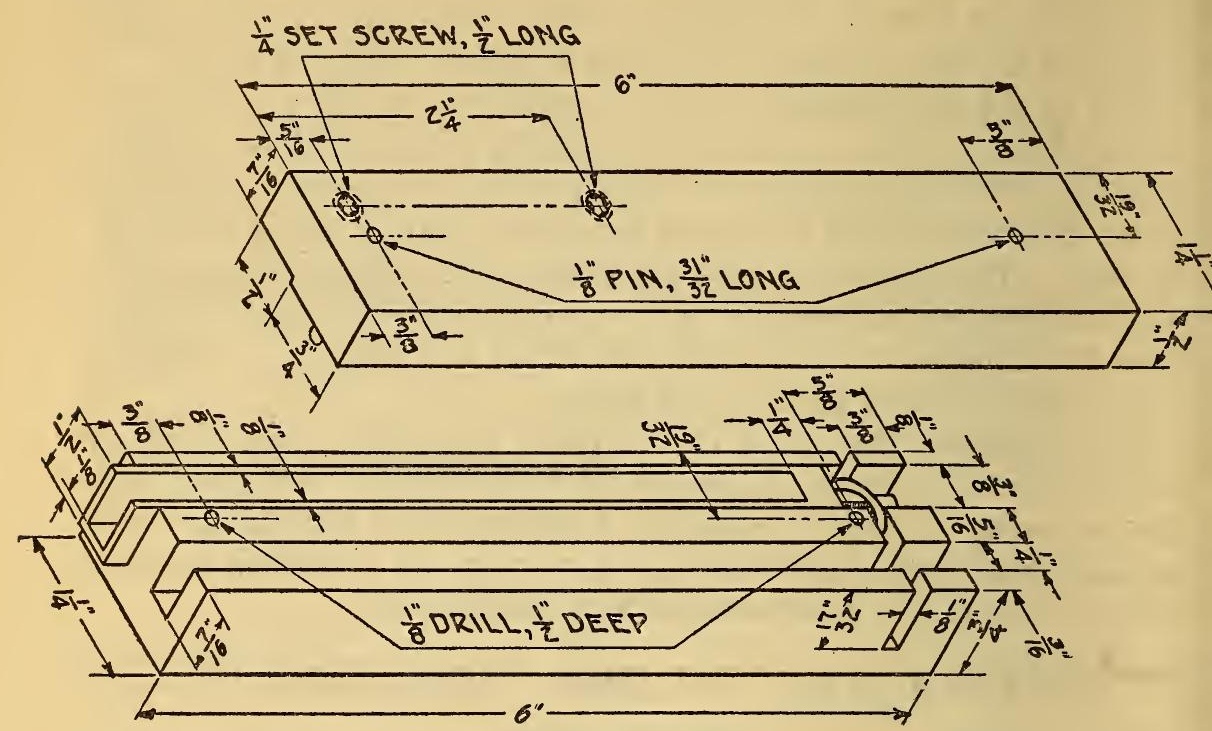

FIGURE 3.-Details of the construction of the special tool holder illustrated in Figure 2

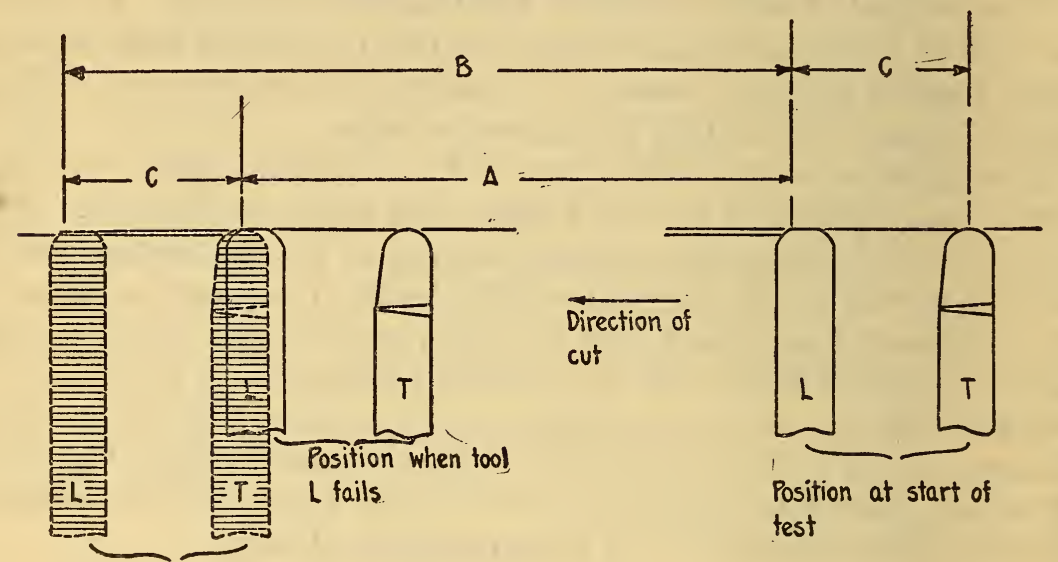

Position when failure is observed

FIgURE 4.-Corrections to be applied to the observed lengths of cut in the tests made under shallow cuts and fine feeds

See text for discussion.

the total length of cut only when the cutting conditions permit long life. Under such conditions the correction to be applied may be neglected, since it will ordinarily be within the limits of reproduci- 
B. S. Journal of Research, RP120

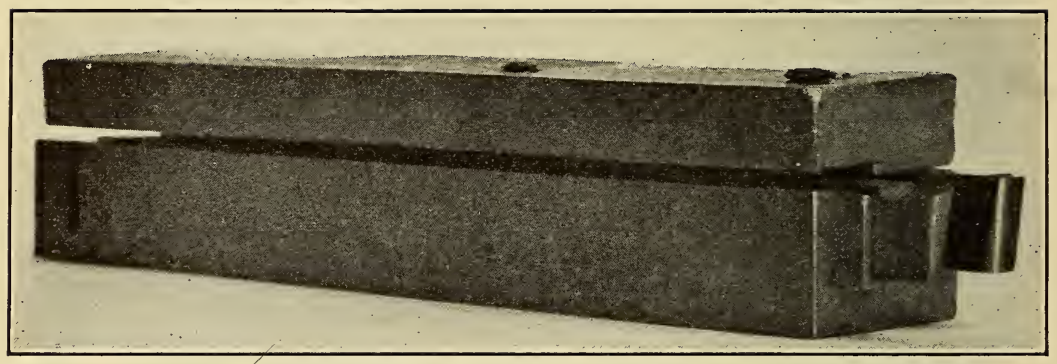

FIgUre 2.-Special tool holder used in the tests under shallow cuts and fine feeds 
bility attained in the experiments, but the reported durations of cut have all been corrected and represent $A$, not $B$, in Figure 4 . The necessary corrections of the observed lengths of cut ( $B$, fig. 4 ) can readily be applied, since the rate of advance of the tools is readily determined from the speed of rotation of the test forging and the feed, both of which are ordinarily recorded in any turning tests.

Except when otherwise indicated, the test tool used under shallow cuts and fine feeds had a broad nose and was of the form and dimensions shown in Figure 5, B. A round nose tool, of the form and dimensions used in rough turning (fig. $5 A$ ), was ordinarily used for the trailer.

A

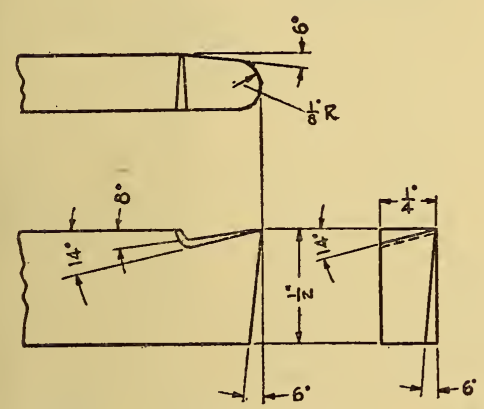

8

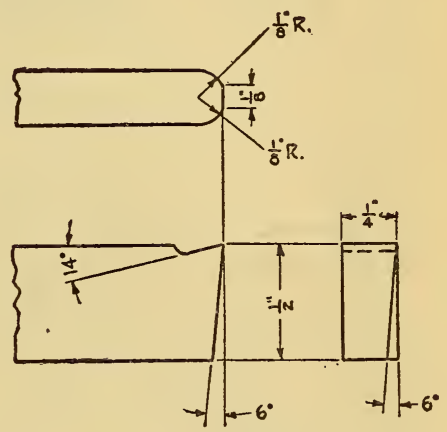

FIGURE 5.-Forms and dimensions of the tools used in a majority of the tests

$A-$ Tool for rough turning. $B-$ Tool for shallow cuts and fine feeds.

\section{PROCEDURE}

From three to six tools were tested after each of two grindings for each condition investigated, and the tests were all made in sequence. For example, in the study of the effect of cutting speed on tool performance one tool was tested at each of the selected speeds in the series, then a second tool was tested at each of the different speeds, and this procedure repeated until the desired number of tools had been tested for each condition. Only average values are used in the comparisons made throughout this report.

Testing tools in sequence has long been practiced and tends to minimize variations in results arising from inhomogeneities in the metal being cut which is seldom entirely uniform with respect to its machining properties. While this is important in rough turning, it appears to be of even greater importance with shallow cuts. Some very large differences were encountered in the tool performance at 
different parts of steel forgings which showed very uniform tensile properties at different depths and from end to end.

The chemical compositions and the heat treatments of the tools used in all of the experiments except those in which a study was made of the effects of different hardening and tempering temperatures are summarized in Table 2. The compositions, treatments, and properties of the test forgings are given in Table 3. 


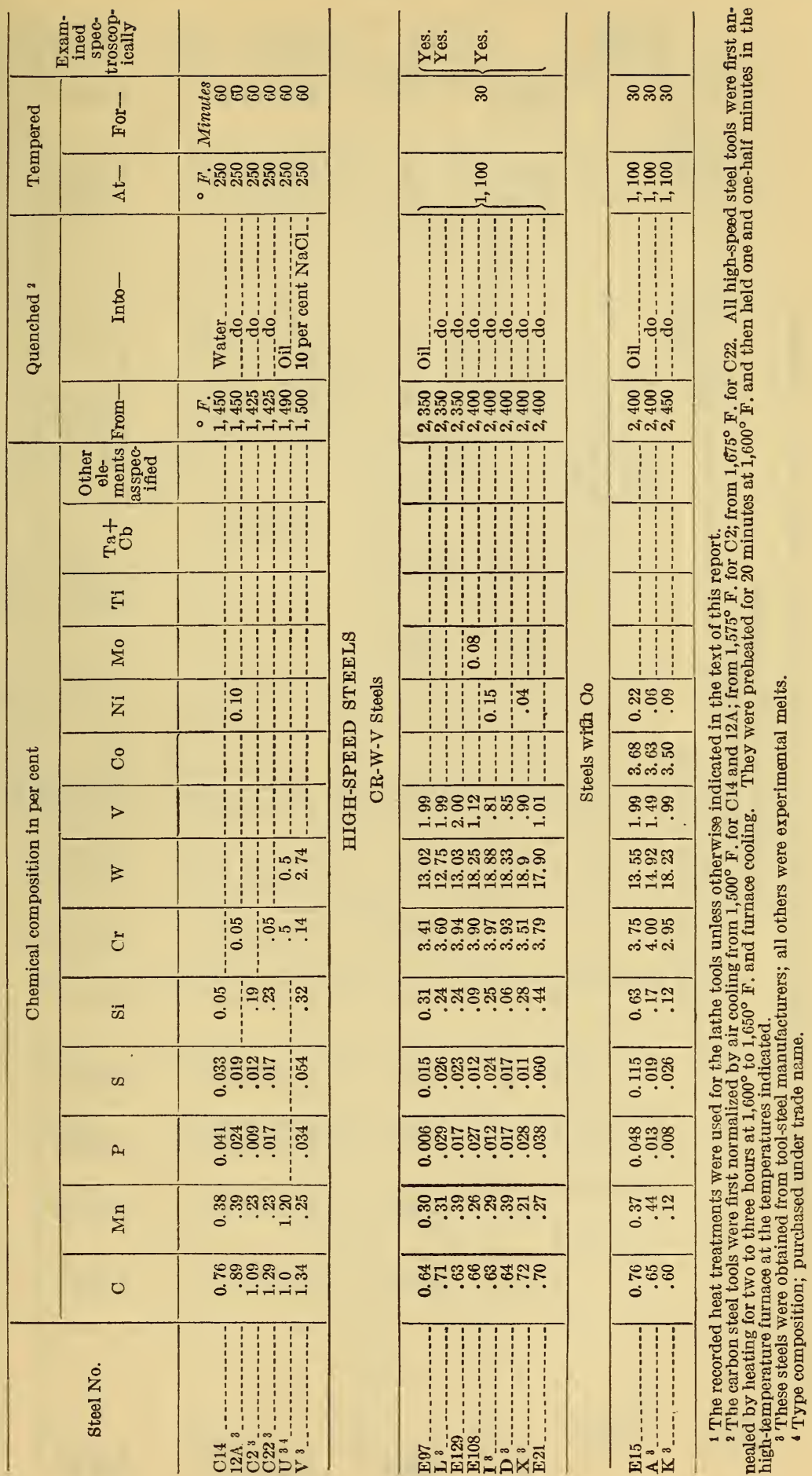




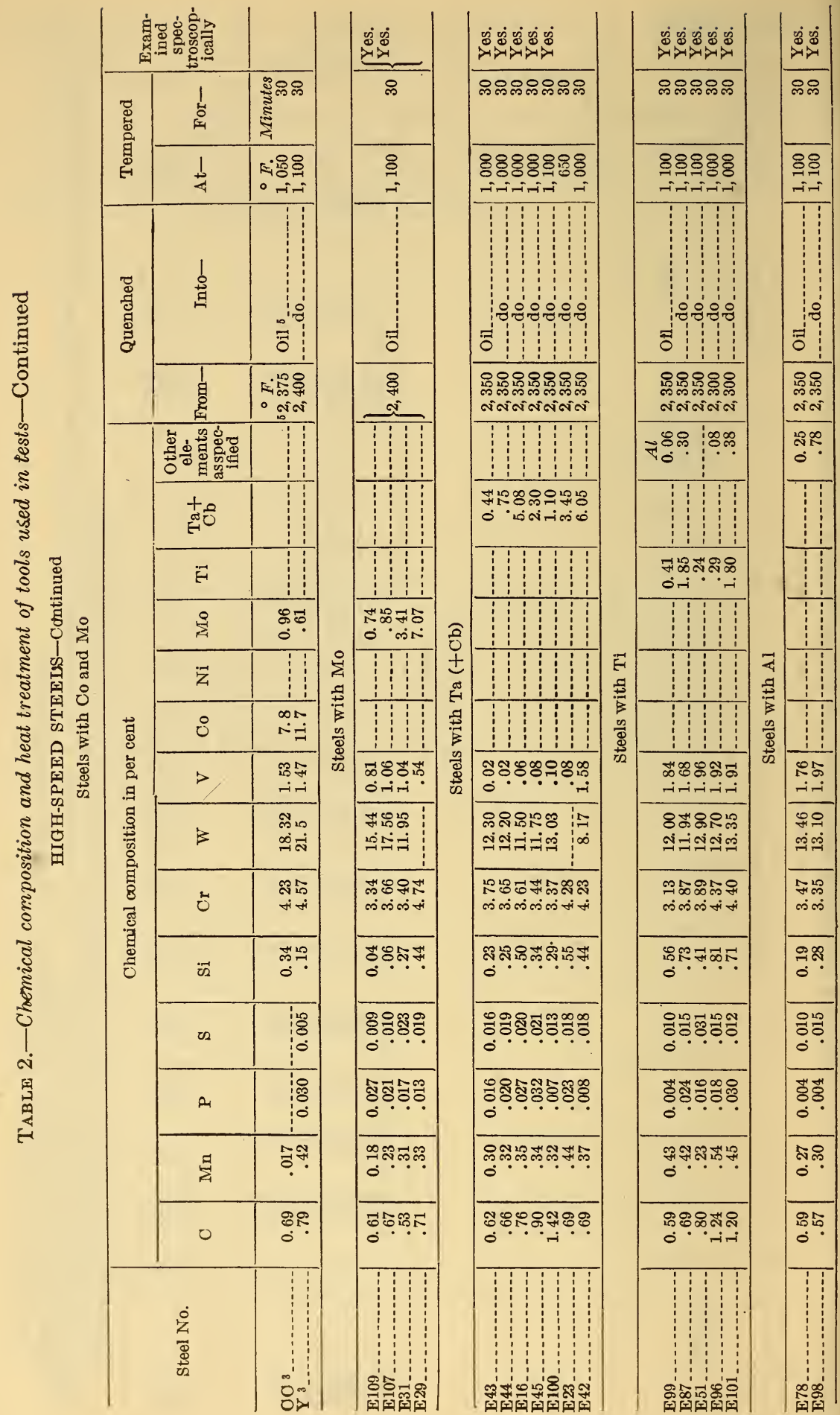




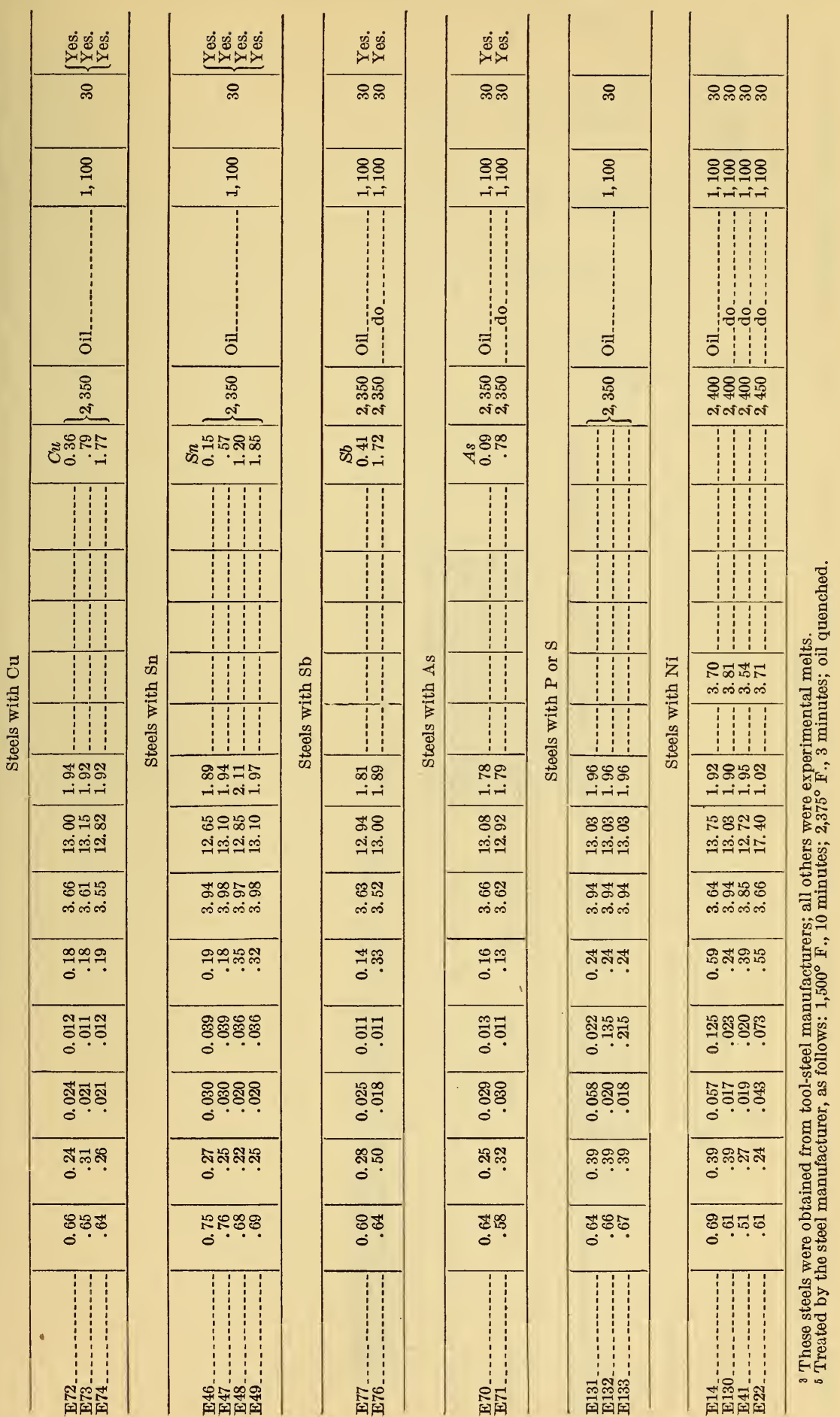




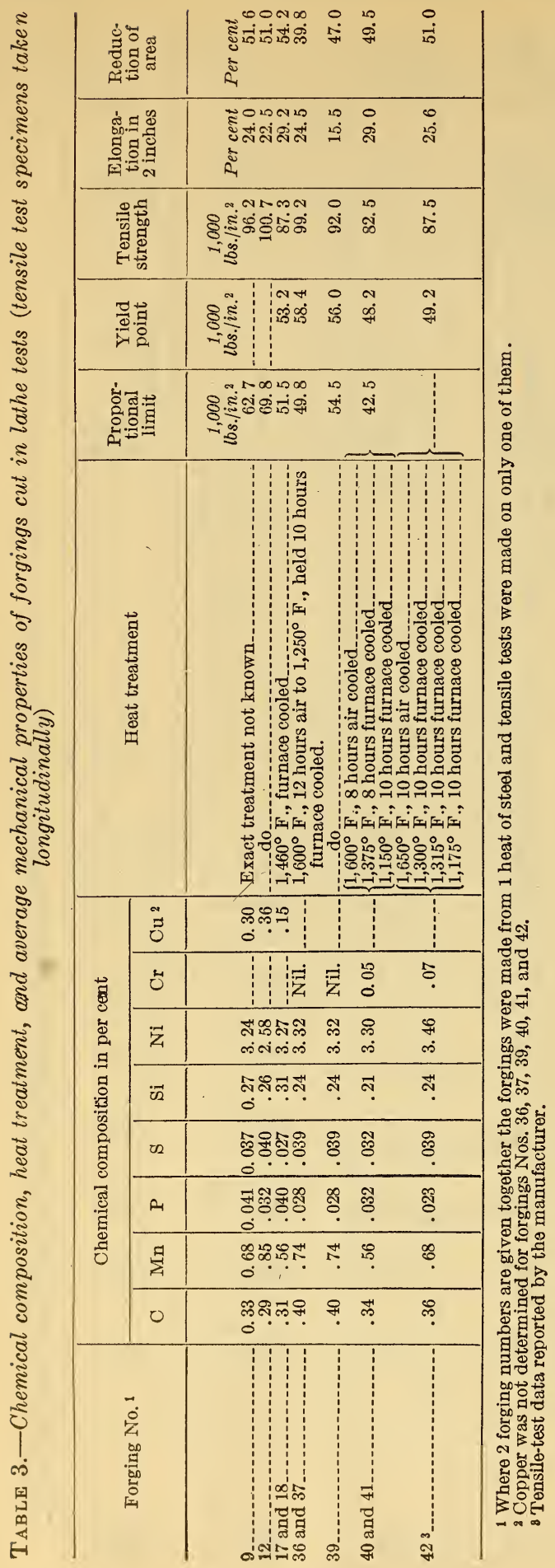


B. S. Journal of Research, RPI20

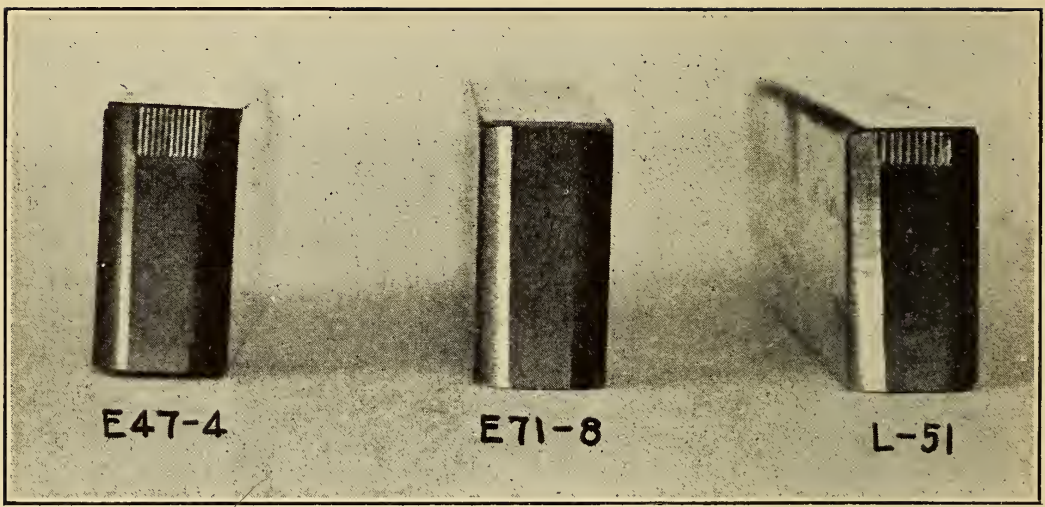

FigURE 6.-New tool and tools which failed in the tests under shallow cuts and fine feeds

E71-8 is a new tool; E47-4 used at $400 \mathrm{ft} . / \mathrm{min}$. with 0.010 inch depth and $0.0115 \mathrm{in} . / \mathrm{rev}$. feed on test forging No. 40; L51 used with 0.005 inch depth and 0.0154 in./rev. feed at $400 \mathrm{ft}$./min. on forging No. 40. 


\section{HOW CARBON AND HIGH-SPEED STEEL TOOLS FAILED}

With the broad-nose tools used in the experiments, the leading edge first showed wear and the crumbling or wearing away of the nose then progressed from the leading edge to the trailing edge. This shift in the working portions of the tool from the leading to trailing edges took place slowly and could be followed quite readily in the case of most of the high-speed steel tools. It occurred more rapidly in the carbon steel tools, which generally were ruined very soon after the leading edge showed evidence of crumbling or spalling.

In the tests with high-speed steel tools a groove was formed on the top surface of the tool near the leading edge, and vertical grooves were also formed on the face, as is shown in Figure 6. The spacing of the grooves on the face corresponded to the feeds employed in the tests, and the length of the grooves was dependent upon the depth of cut. A depression or groove was also formed on the top surface of the carbon steel tools, but there was often no evidence of the feed grooves on the face after failure. When visible, the feed grooves in the carbon steel tools were not so marked as in the high-speed steel tools.

With the method of test employed, the trailer tool indicated when the leader or test tool had worn enough to produce a measurable change in the depth of cut. Experience showed that the trailer began to cut when the wear of the leader was between about 0.001 and $0.002 \mathrm{inch}$, and this was considered as the point of failure of the test tools. These values apply to tests in which the two tools are originally set at equal depths, but it should be recognized that the wear representing failure may be increased by using originally a shallower setting for the trailer than for the leader. The test is therefore applicable to a wider range of conditions than those used in the experiments.

When the tools failed in a short time, it was found that wear of 0.001 or 0.002 inch was concomitant with a complete breakdown of the tool comparable to that found with deep cuts in rough turning. In other words, the nose was rubbed off to a sufficient depth to decrease the depth of cut appreciably. (See Tables 4 and 5.)

This manner of failure was characteristic of both carbon and highspeed steel tools but, as already pointed out, this end point was reached at different rates in the two steels. The carbon steel tools failed almost immediately after the leading edge of the tools showed wear, whereas the high-speed steel tools frequently continued for some time thereafter to take a full cut.

When the tools failed completely by rubbing off of the nose, a glaze was produced on the test forging just as in the rough turning tests and gave an additional indication of failure. 
TABLE 4.-Effect of cutting conditions on the amount of wear of the high-speed steel tools at the time at which they were considered to have failed ${ }^{1}$

\begin{tabular}{|c|c|c|c|c|c|c|c|}
\hline $\begin{array}{l}\text { Cutting speed } \\
\text { (ft./min.) }\end{array}$ & Feed & $\begin{array}{l}\text { Depth of } \\
\text { cut }\end{array}$ & Area of cut & Tool steel ${ }^{2}$ & $\begin{array}{l}\text { Number of } \\
\text { tools tested }\end{array}$ & $\begin{array}{l}\text { Average } \\
\text { tool life }\end{array}$ & $\begin{array}{c}\text { A verage } \\
\text { decrease in } \\
\text { depth of cut } \\
\text { at failure }\end{array}$ \\
\hline $400_{-}$ & $\left\{\begin{array}{r}\text { In./rev. } \\
0.0115 \\
.0132 \\
.0142 \\
.0154 \\
.0204\end{array}\right.$ & $\begin{array}{l}\text { Inch } \\
\qquad .005\end{array}$ & $\left\{\begin{array}{l}\text { Sq. in. } \\
0.000058 \\
.000066 \\
.000071 \\
.000077 \\
.000102\end{array}\right.$ & E97 & $\begin{array}{l}5 \\
5 \\
5 \\
5 \\
5\end{array}$ & $\begin{array}{r}\text { Minutes } \\
25.0 \\
21.7 \\
24.6 \\
23.3 \\
19.9\end{array}$ & $\begin{array}{r}\text { Inch } \\
0.0010 \\
.0025 \\
.0025 \\
.0015 \\
.0010\end{array}$ \\
\hline 350 & $\left\{\begin{array}{l}.0115 \\
.0132 \\
.0142 \\
.0154 \\
.0204\end{array}\right.$ & .010 & $\begin{array}{l}.000115 \\
.000132 \\
.000142 \\
.000154 \\
.000204\end{array}$ & E97 & $\begin{array}{l}5 \\
5 \\
5 \\
4 \\
5\end{array}$ & $\begin{array}{l}56.8 \\
58.5 \\
42.5 \\
44.6 \\
25.1\end{array}$ & $\begin{array}{l}.0035 \\
.0060 \\
.0070 \\
.0035 \\
.0070\end{array}$ \\
\hline 380 & $\left\{\begin{array}{l}.0115 \\
.0132 \\
.0142 \\
.0154 \\
.0204\end{array}\right.$ & .015 & $\left\{\begin{array}{l}.000162 \\
.000198 \\
.000213 \\
.000231 \\
.000306\end{array}\right.$ & E97 & $\begin{array}{l}4 \\
4 \\
5 \\
5 \\
5\end{array}$ & $\begin{array}{r}19.5 \\
11.6 \\
5.4 \\
5.4 \\
2.6\end{array}$ & $\begin{array}{l}.0135 \\
.0125 \\
.0125 \\
.0135 \\
.0150\end{array}$ \\
\hline $400 \ldots$ & .0115 & $\begin{array}{l}.020 \\
.015 \\
.010 \\
.005\end{array}$ & $\begin{array}{l}.000230 \\
.000162 \\
.000115 \\
.000058\end{array}$ & E97 & $\begin{array}{l}5 \\
4 \\
4 \\
5\end{array}$ & $\begin{array}{r}4.1 \\
12.3 \\
27.6 \\
36.3\end{array}$ & $\begin{array}{l}.0175 \\
.0130 \\
.0060 \\
.0015\end{array}$ \\
\hline $350 \ldots$ & .0204 & $\begin{array}{l}.020 \\
.015 \\
.010 \\
.005\end{array}$ & $\begin{array}{l}.000408 \\
.000306 \\
.000204 \\
.000102\end{array}$ & E97 & $\begin{array}{l}5 \\
5 \\
4 \\
4\end{array}$ & $\begin{array}{r}2.4 \\
5.7 \\
21.4 \\
38.9\end{array}$ & $\begin{array}{l}.0195 \\
.0135 \\
.0065 \\
.0015\end{array}$ \\
\hline $\begin{array}{l}300 \\
350 \\
400 \\
450\end{array}$ & .0115 & .020 & .000230 & E97 & $\begin{array}{l}5 \\
5 \\
5 \\
5\end{array}$ & $\begin{array}{r}125.5 \\
28.2 \\
7.5 \\
1.6\end{array}$ & $\begin{array}{l}.0120 \\
.0175 \\
.0165 \\
.0170\end{array}$ \\
\hline
\end{tabular}

1 Tests were made on forging No. 40 (Table 3) with tools of the form and dimension shown in Figure $5, B$. 2 Composition and heat treatment given in Table 2.

TABLE 5.-Effect of cutting conditions on the amount of wear of 1.3 per cent $C$ steel tools at the time at which they were considered to have failed 1

\begin{tabular}{|c|c|c|c|c|c|c|c|}
\hline$\underset{\text { (ft./min.) }}{\text { Cutting speed }}$ & Feed & $\begin{array}{l}\text { Depth of } \\
\text { cut }\end{array}$ & Area of cut & Tool steel 2 & $\begin{array}{l}\text { Number } \\
\text { of tools } \\
\text { tested }\end{array}$ & $\begin{array}{l}\text { A verage } \\
\text { tool life }\end{array}$ & $\begin{array}{l}\text { A verage } \\
\text { decrease } \\
\text { in depth } \\
\text { of cut at } \\
\text { failure }\end{array}$ \\
\hline 110 & $\begin{array}{r}\text { In./rev. } \\
0.0115 \\
.0142 \\
.0154 \\
.0204 \\
.0204\end{array}$ & $\begin{array}{l}\text { Inch } \\
\quad 0.010\end{array}$ & $\left\{\begin{array}{l}\text { Sq.in. } \\
0.000115 \\
.000142 \\
.000154 \\
.000204 \\
.000204\end{array}\right.$ & $\mathrm{C} 22$ & $\begin{array}{l}1 \\
1 \\
1 \\
1 \\
1\end{array}$ & $\begin{array}{r}\text { Minutes } \\
9.4 \\
10.8 \\
7.5 \\
35.9 \\
55.2\end{array}$ & $\begin{array}{r}\text { Inch } \\
0.0045 \\
.0030 \\
.0055 \\
.0055 \\
.0040\end{array}$ \\
\hline $\begin{array}{l}160 \\
103 \\
95 \\
65 \\
85\end{array}$ & $\begin{array}{l}.0115 \\
.0115 \\
.0115 \\
.0154 \\
.0204 \\
.0204 \\
.0204\end{array}$ & $\begin{array}{l}.005 \\
.015 \\
.020 \\
.020 \\
.020 \\
.010 \\
.020\end{array}$ & $\begin{array}{r}.000058 \\
.000162 \\
.000230 \\
.000308 \\
.000408 \\
000204 \\
.000408\end{array}$ & $\begin{array}{l}\mathrm{C} 22 \\
\mathrm{C} 22 \\
\mathrm{C} 22 \\
\mathrm{C} 22 \\
\mathrm{C} 22 \\
\mathrm{C} 22 \\
\mathrm{C} 22\end{array}$ & $\begin{array}{l}1 \\
1 \\
1 \\
1 \\
1 \\
1 \\
1\end{array}$ & $\begin{array}{l}11.4 \\
10.3 \\
10.0 \\
13.9 \\
11.6 \\
88.2 \\
74.4\end{array}$ & $\begin{array}{l}.0030 \\
.0120 \\
.0095 \\
.0210 \\
.0165 \\
.0070 \\
.0035\end{array}$ \\
\hline 160 & .0115 & .005 & .000058 & $\mathrm{C} 22$ & $\begin{array}{l}2 \\
1 \\
1\end{array}$ & $\begin{array}{r}37.5 \\
1.9 \\
3.2\end{array}$ & $\begin{array}{l}.0030 \\
.0050 \\
.0025\end{array}$ \\
\hline $\begin{array}{l}165 \\
160 \\
165 \\
\end{array}$ & $\begin{array}{l}.0115 \\
.0115\end{array}$ & $\begin{array}{l}.005 \\
.005\end{array}$ & $\begin{array}{l}.000058 \\
.000058\end{array}$ & $\begin{array}{l}12 \mathrm{~A} \\
\mathrm{C} 14\end{array}$ & $\begin{array}{l}1 \\
1 \\
1\end{array}$ & $\begin{array}{r}12.9 \\
1.0 \\
24.1\end{array}$ & $\begin{array}{l}.0025 \\
.0055 \\
.0025\end{array}$ \\
\hline $163 \ldots$ & .0115 & .005 & .000058 & $\mathrm{C} 2$ & $\begin{array}{l}1 \\
1\end{array}$ & $\begin{array}{l}2.5 \\
0.5\end{array}$ & $\begin{array}{l}.0025 \\
.0030\end{array}$ \\
\hline
\end{tabular}

1 Tests were made on forging No. 41 with tools of the form and dimensions shown in Figure $5, B$. 2 Composition and heat treatment given in Table 2. 
When the cutting conditions permitted the tools to cut for only a short time, the selected method of test gave an end point which was concomitant with complete failure of the tool, and the trailer tool became unnecessary. Under more nearly practical conditions, when the tools continued to cut for long periods, the wear on the nose of 0.001 or 0.002 inch was seldom concomitant with complete failure. Under such conditions it became impracticable to determine the time of failure without an indicator, such as the trailer tool. Tests of very short duration, which might be made in the ordinary manner, even with shallow cuts and fine feeds, are of doubtful value unless it is practicable to develop at least approximate relations between such short-time tests and the long-time cutting required in practical service. Therefore, a study was made of the effects of speed, feed, and depth of cut on the durations of cut.

\section{EFFECT OF CUTTING SPEED ON TOOL LIFE}

\section{FOR HIGH-SPEED STEEL TOOLS}

The results of tests at different cutting speeds with a feed of 0.0115 inch per revolution and depths of 0.010 or 0.020 inch are summarized in Figure 7 and show that there was a continuous increase in the life of high-speed steel tools as the cutting speed was decreased. Within a life range of from 2 to 125 minutes, the experimental results may be represented by the equation

$$
V T^{n}=c
$$

in which $V$ is the cutting speed in feet per minute, $T$ the tool life in minutes, and $n$ and $c$ are constants.

In one of the two sets of tests summarized in Figure 7, the experimental results were most closely represented by equation (1) when $n$ was 1110 , while the best representation in the second set was obtained when $n$ was $1 / 12$.

When taking shallow cuts with high-speed steel tools, Ripper and Burley ${ }^{10}$ found that the relation between the cutting speed and tool life could be represented by equation (1) with $n$ equal to $1 / 12$. They did not report the actual values of tool life, but a study of the points plotted in their charts showed that only in some cases were the relations between cutting speed and tool life best represented by equation (1) with $n=1 / 12$; in others, as good or better representation was obtained with $n=1 / 10$.

The value of the exponent $n$ in equation (1) can not be definitely established at this time. The value $1 / 10$ was selected for use in this investigation since it is closer than $1 / 12$ to the exponent in a similar equation, which Taylor demonstrated was applicable to conditions of

10 See footnote 3, p. 831.

$77886^{\circ}-29-2$ 
rough turning. However, either of the quoted values should give results sufficiently accurate for practical purposes except when extrapolating to very long-time cutting from tests of relatively short duration.

\section{FOR CARBON STEEL TOOLS}

The change from very short life to very long life in carbon tool steels was most often produced by decreases of less than 5 feet per minute in the cutting speed. In the majority of the cases investigated if the tools did not fail in less than 5 minutes they continued to cut for 90 minutes without sign of failure.

In general, the tests were stopped after 90 minutes, but in a few cases tools which did not fail in this time were allowed to continue to

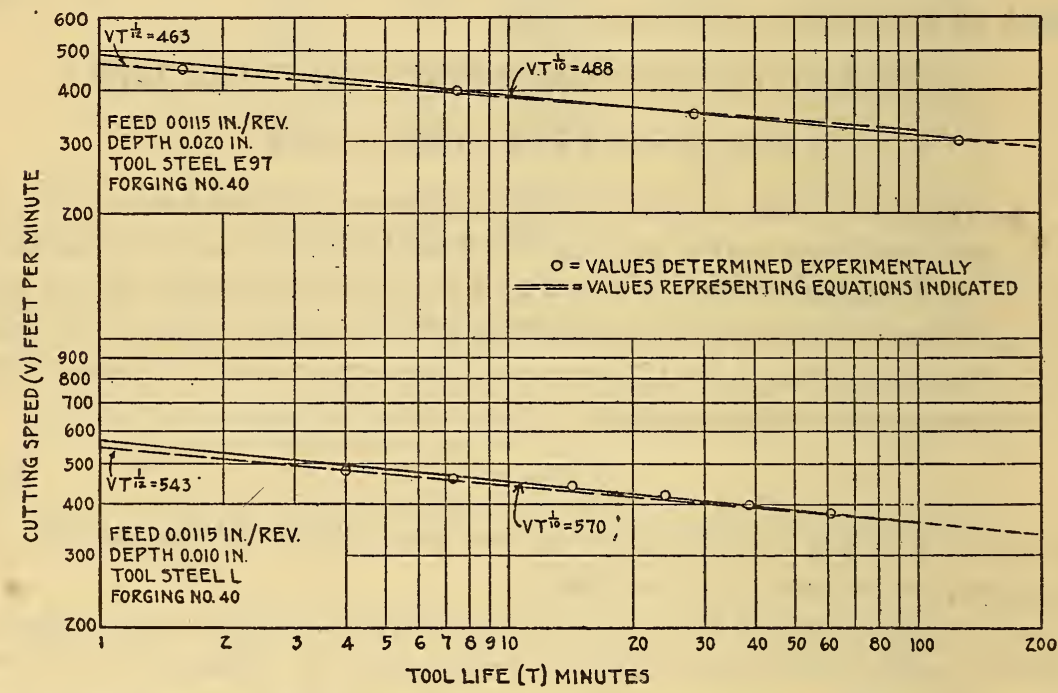

Figure 7.-Relation between the cutting speed and the tool life under shallow cuts and fine feeds

Tests made dry

cut for another 90 minutes (total time of cutting, 3 hours) without indication of failure. This, together with the general character of the cutting speed-tool life curves indicated that carbon-steel tools which cut for 90 minutes would, in general, cut for much longer periods, such as are desired in practice.

The highest speed at which the tools would cut for 90 minutes without failure was considered to represent a "critical cutting speed." It was determined by testing individual tools at successively lower cutting speeds, which differed by 2 to 5 feet per minute, until a 90 -minute cut was obtained without failure. 
The critical cutting speeds discussed in this report are not equal to the speeds permitting exactly 90 minutes' tool life, but, due to the sharp increases in life with decrease in cutting speed, they are so close to the latter that the two may be considered to be the same for practical purposes.

The sharp decrease in life with increase in cutting speed in the case of carbon-steel tools is probably associated with the temperatures generated at the working portions of the tools. Increase in cutting speed means increase in working temperatures, and carbon steels are known to lose hardness more rapidly with temperature rise than high-speed tool steels. The gradual change in tool life in high-speed steels is probably associated with a gradual loss in hardness, with rise in temperature resulting from increase in either cutting speed, feed, or depth of cut.

\section{EFFECT OF FEED AND DEPTH OF CUT ON CUTTING SPEED}

\section{FOR HIGH-SPEED STEEL TOOLS}

A summary of the experiments with high-speed steel tools cutting under different feeds and depths is given in Figure 8. The relations between the cutting speed for a given tool life, the feed and depth of cut, may be represented approximately by the equation

$$
V=K_{1}-K_{2}(D F)=K_{1}-K_{2} A
$$

when $V$ is the cutting speed, $D$ is the depth of cut, $F$ is the feed, $A$ is the area of cut ( $=D F$ ), and $K_{1}$ and $K_{2}$ are constants.

With the tools and test forgings used in the experiments, as recorded in Tables 2 and 3, and a selected tool life of 90 minutes, equation (2) becomes

$$
V=370-32 D F \times 10^{4}
$$

For a selected tool life of 20 minutes and otherwise comparable conditions equation (2) becomes

$$
V=430-38 D F \times 10^{4}
$$

In equations (3) and (4), $V$ is expressed in feet per minute, $D$ in inches and $F$ in inches per revolution.

Some of the plotted points are at some distance from the lines representing equation (2) in Figure 8, but Table 6 shows that the variations between the plotted points and the values given by equation (2) were within about \pm 6 per cent. This is within the limits of reproducibility of the experiments and is as close concordance as may be expected. As already indicated, appreciable variations were encountered in the cutting properties from point to point in the 
large test forgings. Likewise, only minor variations from the intended depths of cut in setting the tools in the lathe represent a

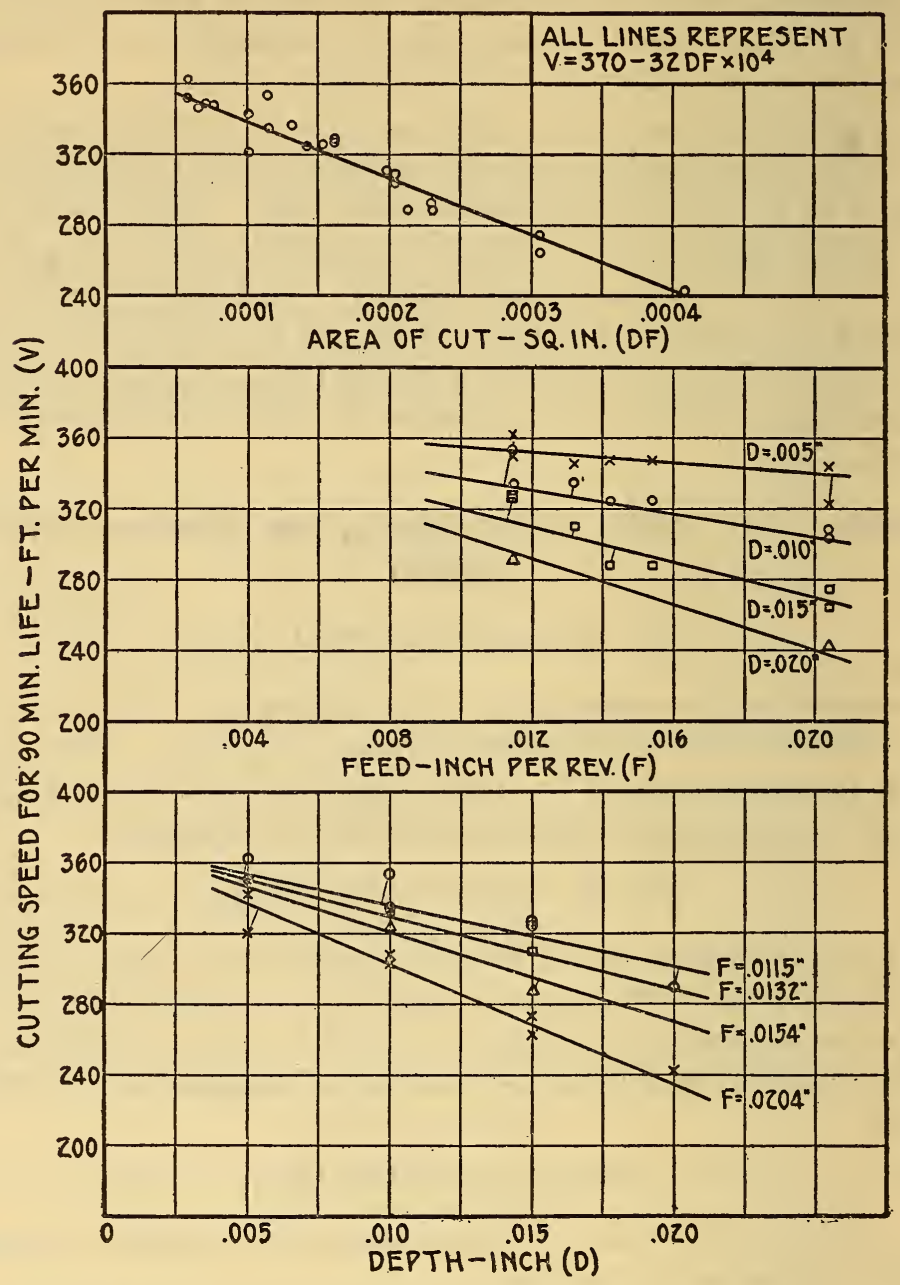

Figure 8.-Effect of feed and depth of cut and the area of cut on the cutting speed of high-speed steel tools when taking shallow cuts at fine feeds

All tests were made dry with tool steel E97 (Table 2) on forging No. 40 (Table 3).

large percentage variation with the shallow cuts under investigation, and, hence, have a relatively marked effect upon the observed tool life so that reproduction of results becomes difficult. 
TABLE 6.-Effect of feed and depth on performance of high-speed tool steel 1

\begin{tabular}{|c|c|c|c|c|c|c|c|c|c|c|c|c|c|}
\hline \multirow[b]{2}{*}{$\begin{array}{c}\text { Speed } \\
\text { (ft./min.) }\end{array}$} & \multirow[b]{2}{*}{ Feed } & \multirow[b]{2}{*}{ Depth } & \multirow[b]{2}{*}{$\begin{array}{l}\text { Area } \\
\text { of cut }\end{array}$} & \multicolumn{6}{|c|}{ Tool life (minutes) } & \multirow{2}{*}{$\begin{array}{l}20 \text {-min- } \\
\text { ute cut- } \\
\text { ting } \\
\text { speed } \\
\text { (calcu- } \\
\text { lated } \\
\text { from } \\
V T^{1 / 10} \\
=c \text { ) }\end{array}$} & \multirow{2}{*}{$\begin{array}{l}90 \text {-min- } \\
\text { ute cut- } \\
\text { ting } \\
\text { speed } \\
\text { (calcu- } \\
\text { lated } \\
\text { from } \\
V T^{1 / 10} \\
=c \text { ) }\end{array}$} & \multirow{2}{*}{$\begin{array}{l}\text { 90-minute } \\
\text { cutting } \\
\text { speed (cal- } \\
\text { culated } \\
\text { from } \\
V=370- \\
320,000 D F \text { ) }\end{array}$} & \multirow{2}{*}{$\begin{array}{c}\text { Dif- } \\
\text { ference } \\
\text { be- } \\
\text { tween } \\
\text { last } \\
\text { and } \\
\text { next to } \\
\text { last } \\
\text { col- } \\
\text { umns } \\
\text { in ft./ } \\
\text { min. }\end{array}$} \\
\hline & & & & 1 & 2 & 3 & 4 & 5 & $\begin{array}{c}\text { Aver- } \\
\text { age }\end{array}$ & & & & \\
\hline 400 & $\left.\begin{array}{l}\text { In./rev. } \\
0.0115 \\
.0132 \\
.0142 \\
.0154 \\
.0204\end{array}\right\}$ & $\left\{\begin{array}{l}\text { Inch } \\
0.005\end{array}\right.$ & $\begin{array}{l}\text { Sq. in. } \\
\left\{\begin{array}{l}0.000058 \\
.000066 \\
.000071 \\
.000077 \\
.000102\end{array}\right.\end{array}$ & $\begin{array}{l}30.5 \\
18.3 \\
21.1 \\
25.4 \\
25.5\end{array}$ & $\begin{array}{l}26.6 \\
25.7 \\
26.9 \\
22.3 \\
16.1\end{array}$ & $\begin{array}{l}22.2 \\
19.1 \\
23.0 \\
28.4 \\
17.3\end{array}$ & \begin{tabular}{l|}
24.9 \\
19.7 \\
24.2 \\
22.1 \\
20.8
\end{tabular} & $\begin{array}{l}20.7 \\
25.9 \\
28.0 \\
18.4 \\
19.8\end{array}$ & \begin{tabular}{l|}
25.0 \\
21.7 \\
24.6 \\
23.3 \\
19.9
\end{tabular} & $\begin{array}{r}\text { Ft./min. } \\
410 \\
405 \\
407 \\
406 \\
400\end{array}$ & $\begin{array}{r}\text { Ft./min. } \\
351 \\
346 \\
348 \\
347 \\
342\end{array}$ & \begin{tabular}{|r|} 
Ft./min. \\
351 \\
349 \\
347 \\
345 \\
337
\end{tabular} & $\begin{array}{r}0 \\
+3 \\
-1 \\
-2 \\
-5\end{array}$ \\
\hline 350 & $\left\{\begin{array}{l}.0115 \\
.0132 \\
.0142 \\
.0154 \\
.0204\end{array}\right\}$ & .010 & $\left\{\begin{array}{l}.000115 \\
.000132 \\
.000142 \\
.000154 \\
.000204\end{array}\right.$ & $\begin{array}{l}54.1 \\
49.0 \\
56.5 \\
42.6 \\
21.9\end{array}$ & $\begin{array}{l}59.5 \\
62.4 \\
43.6 \\
45.2 \\
31.2\end{array}$ & $\begin{array}{r}58.6 \\
60.1 \\
37.6 \\
34.8\end{array}$ & $\begin{array}{l}51.3 \\
66.8 \\
38.2 \\
49.5 \\
15.0\end{array}$ & $\begin{array}{l}60.4 \\
54.0 \\
36.5 \\
41.2 \\
22.6\end{array}$ & $\begin{array}{l}56.8 \\
58.5 \\
42.5 \\
44.6 \\
25.1\end{array}$ & $\begin{array}{l}385 \\
390 \\
375 \\
378 \\
360\end{array}$ & $\begin{array}{l}334 \\
335 \\
324 \\
325 \\
308\end{array}$ & $\begin{array}{l}333 \\
328 \\
325 \\
321 \\
305\end{array}$ & $\begin{array}{l}-1 \\
-7 \\
+1 \\
-4 \\
-3\end{array}$ \\
\hline $380 \ldots$ & $\left\{\begin{array}{l}.0115 \\
.0132 \\
.0142 \\
.0154 \\
.0204\end{array}\right.$ & .015 & $\left\{\begin{array}{l}.000162 \\
.000198 \\
.000213 \\
.000231 \\
.000306\end{array}\right.$ & \begin{tabular}{r|}
19.1 \\
16.9 \\
4.9 \\
5.9 \\
2.9
\end{tabular} & \begin{tabular}{l|}
$\cdots$ \\
\hdashline 5. \\
5.2 \\
2.8
\end{tabular} & $\begin{array}{r}12.1 \\
9.5 \\
5.4 \\
7.1 \\
2.6\end{array}$ & $\begin{array}{r}30.7 \\
9.4 \\
6.6 \\
3.6 \\
2.6\end{array}$ & $\begin{array}{r}16.2 \\
10.7 \\
4.7 \\
5.0 \\
2.3\end{array}$ & $\begin{array}{r}19.5 \\
11.6 \\
5.4 \\
5.4 \\
2.6\end{array}$ & $\begin{array}{l}379 \\
360 \\
335 \\
335 \\
310\end{array}$ & $\begin{array}{l}326 \\
310 \\
288 \\
288 \\
274\end{array}$ & $\begin{array}{l}318 \\
307 \\
302 \\
296 \\
272\end{array}$ & $\begin{array}{r}-8 \\
-3 \\
+14 \\
+8 \\
-2\end{array}$ \\
\hline $350 \ldots$ & .0204 & $\begin{array}{l}.020 \\
.015 \\
.010 \\
.005\end{array}$ & $\begin{array}{r}.000408 \\
.000306 \\
.000204 \\
.000102\end{array}$ & $\begin{array}{r}2.4 \\
4.7 \\
23.2 \\
40.1\end{array}$ & \begin{tabular}{r}
2.6 \\
5.0 \\
\hdashline- \\
\end{tabular} & $\begin{array}{r}3.0 \\
4.8 \\
20.9 \\
47.6\end{array}$ & $\begin{array}{r}1.6 \\
7.4 \\
22.2 \\
38.9\end{array}$ & $\begin{array}{r}2.4 \\
6.6 \\
19.5 \\
29.0\end{array}$ & $\begin{array}{r}2.4 \\
5.7 \\
21.4 \\
38.9\end{array}$ & $\begin{array}{l}281 \\
308 \\
351 \\
373\end{array}$ & $\begin{array}{l}242 \\
264 \\
303 \\
321\end{array}$ & $\begin{array}{l}239 \\
272 \\
305 \\
337\end{array}$ & $\begin{array}{r}-3 \\
+8 \\
+2 \\
+16\end{array}$ \\
\hline \multirow[t]{2}{*}{$400 \ldots$} & . 0115 & $\left\{\begin{array}{l}.020 \\
.015 \\
.010 \\
.005\end{array}\right.$ & $\begin{array}{l}.000230 \\
.000162 \\
.000115 \\
.000058\end{array}$ & $\begin{array}{r}3.5 \\
17.7 \\
29.3 \\
39.2\end{array}$ & \begin{tabular}{r}
3.5 \\
\hdashline-4 \\
40.9
\end{tabular} & $\begin{array}{r}4.4 \\
13.1 \\
26.9 \\
33.5\end{array}$ & $\begin{array}{r}4.9 \\
10.0 \\
24.9 \\
31.0\end{array}$ & \begin{tabular}{r|}
4.1 \\
8.4 \\
29.2 \\
36.7
\end{tabular} & $\begin{array}{r}4.1 \\
12.3 \\
27.6 \\
36.3\end{array}$ & $\begin{array}{l}341 \\
380 \\
413 \\
424\end{array}$ & $\begin{array}{l}292 \\
327 \\
354 \\
362\end{array}$ & $\begin{array}{l}296 \\
318 \\
333 \\
351\end{array}$ & $\begin{array}{r}+4 \\
-9 \\
-20 \\
-11\end{array}$ \\
\hline & & & & & & & & & & & & \multicolumn{2}{|c|}{$\begin{array}{l}\text { Average within } \\
\pm 6 \text { per cent. }\end{array}$} \\
\hline
\end{tabular}

1 Tests made with steel E97 on test forging No. 40. Composition and treatment of the tools given in Table 2. Tool form shown in Figure 5, B; composition and properties of test forging given in Table 3.

Equation (2) indicates that the cutting speed is a function of the area of cut and affected equally by changes in the depth and feed. This is at variance with the results of Ripper and Burley ${ }^{11}$ for shallow cuts and those of Taylor and his associates ${ }^{12}$ for rough turning. Ripper and Burley found that "if the area of cut is kept constant a higher associated ${ }^{13}$ cutting speed is obtainable when the cut is deep and the feed fine than when the cut is shallow and the feed coarse." They expressed the relations between cutting speed, feed, and depth of cut by the following equation

$$
V=\frac{K_{1}}{F^{2 / 3}}-\left(K_{2}-K_{3} F\right) D
$$

in which, $K_{1} K_{2}$, and $K_{3}$ are constants.

11 See footnote 3, p. 831.

12 See footnote 2, p. 830 .

${ }^{13}$ Cutting speed giving a definite tool life, 
It is probable that the cutting speed is not affected equally by changes in the feed and depth of cut, but it is also probable that the differences between the true laws of cutting, and the results obtained on the assumption that the cutting speed is a function of the area of

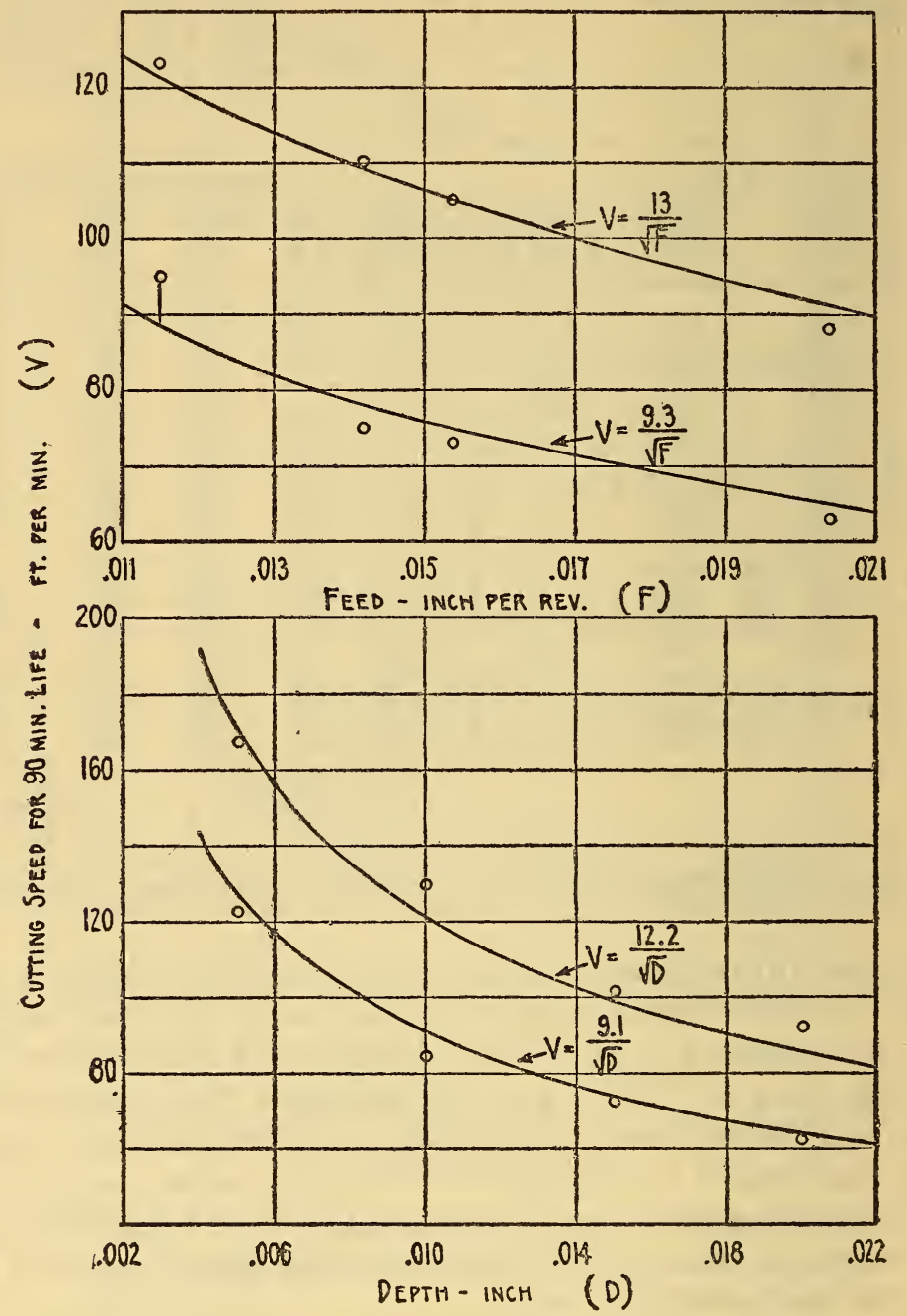

FIGURE 9.-Effect of feed and depth of cut on the cutting speed of 1.3 per cent $C$ steel tools when taking shallow cuts at fine feeds All tests were made dry with steel C 22 (Table 2) on forging No. 41 (Table 3).

cut, will be small in the case of the shallow cuts and fine feeds here investigated.

The experiments made in this investigation using different feeds and depths of cut were not carried out with a view to establishing the laws of cutting. They were made solely to permit a more general 
interpretation of the results of tests designed to throw light upon metallurgical variables, such as the composition and heat treatment of the tools. From this standpoint it is immaterial whether one or another form of equation is employed so long as a reasonably close concordance is obtained between the experimental results and the calculated values. In this respect equation (2) seems adequate for present purposes and was used in the extrapolation of experimental data as required in this investigation.

\section{FOR CARBON STEEL TOOLS}

The effect of feed and depth of cut on the cutting speeds of carbon steel tools is shown in Figures 9 and 10. In this case the relations

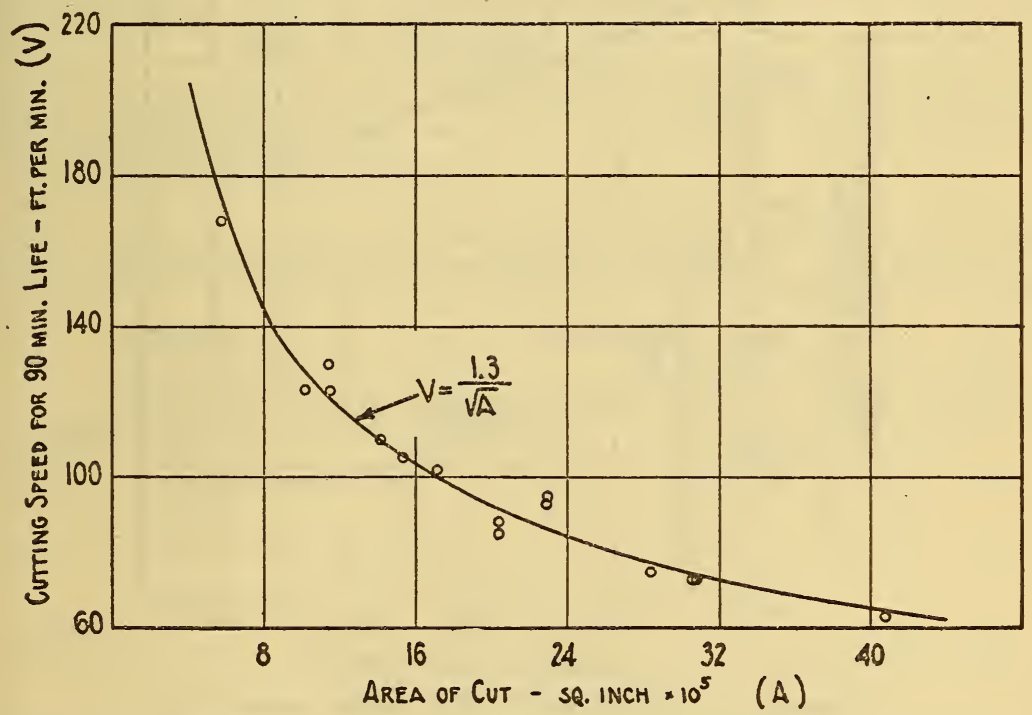

Frgure 10.-Effect of area of cut on the cutting speed of 1.3 per cent $C$ steel tools when taking shallow cuts at fine feeds

All tests were made dry with steel C 22 (Table 2) on forging No. 41 (Table 3).

may be represented approximately by the equation

$$
V=\frac{K}{D F}=\frac{K}{A}
$$

With the tools and the test forgings used in the experiments and the selected tool life of 90 minutes, equation (6) becomes

$$
V=\frac{1.3}{A}
$$

where $V$ is expressed in feet per minute and $A$ in square inches. 
Under the range of cutting conditions investigated, the cutting speeds for high-speed steel tools were much higher than those for carbon steel tools, but the differences tended to diminish as the areas of cut were decreased. With sufficiently shallow cuts and fine feeds or with adequate cooling it may be possible for carbon steel tools to have higher cutting speeds than high-speed steel tools, as has been reported by some investigators. ${ }^{14}$ This is shown graphically in Figure 11, where the cutting speed-area of cut curve for high-speed steel tools is a straight line and that for carbon steel tools rises very rapidly for cuts less than about 0.0001 square inch. The two curves

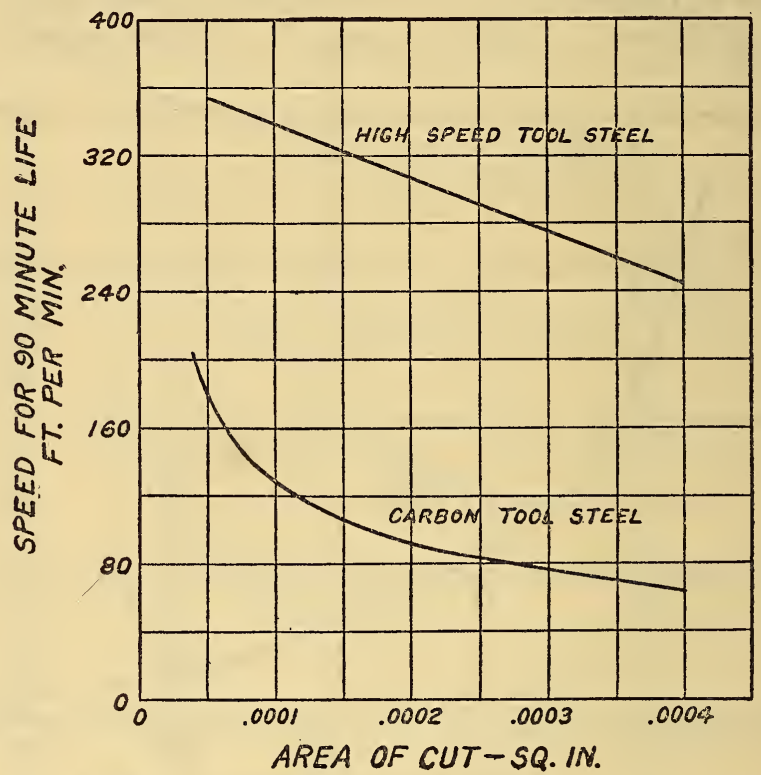

FIGURE 11.-Comparison of the cutting speeds of 1.3 per cent $C$ and the high-speed steel tools with different areas of cut

Based on data given in Figures 8, 9, and 10 .

may cross with sufficiently small areas of cut or if the tools are working at low temperatures through the use of cutting liquids.

\section{VARIATIONS IN TOOL FORM}

\section{SHAPE OF THE NOSE OF THE TOOL}

Tests were made with tools of different forms and angles with the principal object of determining whether successful application of the described method of test was dependent upon having a broad-nose tool. 
Comparisons were first made of the performance of the broad-nose tools, illustrated in Figure $5, B$, with tools of the forms and dimensions shown in Figures 12, $A$ and $B$. Both of the tools illustrated in Figure 12 were similar to tools studied by the Lathe Tools Research Committee ${ }^{15}$ except for size, a slight increase in the front and side clearance angles, and in the plan angle of the tool in Figure 12, $A$.

TABLE 7.-Performance of tools of different forms when taking shallow cuts and fine feeds ${ }^{1}$

\begin{tabular}{|c|c|c|c|c|c|c|c|c|c|c|c|}
\hline \multirow{2}{*}{ Tool form } & \multicolumn{10}{|c|}{ Tool life (minutes) } & \multirow{2}{*}{$\begin{array}{l}\text { Cutting } \\
\text { speed for } \\
90 \text {-minute } \\
\text { life }^{2}\end{array}$} \\
\hline & 1 & 2 & 3 & 4 & 5 & 6 & 7 & 8 & 9 & Average & \\
\hline $\begin{array}{l}\text { Broad nose (fig. } 5, B) \\
65^{\circ} \text { plan angle (fig. 12, } A \text { ) } \\
\text { Pointed tool (fig. 12, } B \text { ) }\end{array}$ & $\begin{array}{c}17.2 \\
43.0 \\
0\end{array}$ & $\begin{array}{c}28.7 \\
0\end{array}$ & $\begin{array}{c}27.6 \\
40.0 \\
0\end{array}$ & $\begin{array}{l}21.8 \\
22.4 \\
36.7\end{array}$ & $\begin{array}{r}16.2 \\
44.0 \\
-\end{array}$ & $\begin{array}{l}11.8 \\
20.7\end{array}$ & $\begin{array}{l}20.0 \\
37.5\end{array}$ & $\begin{array}{l}21.9 \\
28.4\end{array}$ & $\begin{array}{c}24.7 \\
-\end{array}$ & $\begin{array}{l}20.1 \\
33.1\end{array}$ & $\begin{array}{r}\text { Ft./min. } \\
327 \\
344\end{array}$ \\
\hline
\end{tabular}

1 Composition and treatment of tool steel E97 given in Table 2. Composition and properties of test forging No. 41 given in Table 3 . All tests made at $380 \mathrm{ft}$./min. cutting speed, $0.0115 \mathrm{in} . / \mathrm{rev}$. feed, and 0.010 inch depth except as otherwise noted.

2 Computed by equation (1) of the text.

3 This test made at $250 \mathrm{ft}$./min. cutting speed.

The results of the tests are summarized in Table 7 and show that the tool with a plan angle of $65^{\circ} \mathrm{had}$ a longer life (and higher cutting

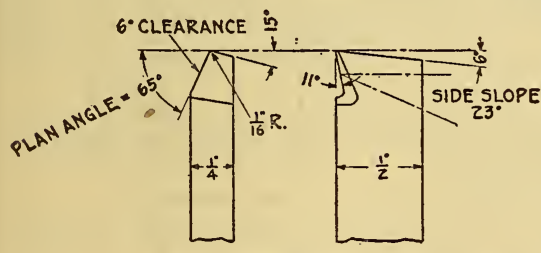

A

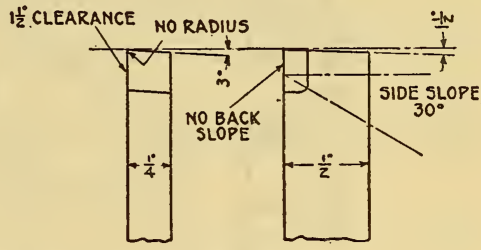

B

FIgURE 12.-Tools of special form used in some of the lathe tests under shallow cuts and fine feeds

speed) than the broad-nose tool illustrated in Figure 5, $B$. The sharp pointed tool (fig. 12, $B$ ) failed immediately under the conditions of test which permitted the other two tools to cut for 20 to 35 minutes, but with a reduction in the cutting speed from 380 to 250 feet per minute the sharp pointed tools gave evidence of a measurable length of life.

The finish produced on the work appeared to be somewhat smoother and more highly polished with the broad-nose tools (fig. $5, B$ ) than with the tools having a $65^{\circ}$ plan angle (fig. 12, $A$ ). The latter tools failed abruptly, whereas with the broad-nose tools failure was progressive from leading to trailing edges as has already been described.

15 Department of Scientific and Industrial Research, Manchester Association of Engineers. Report of the Lathe Tools Research Committee, 1922, His Majesty's Stationery Office, London. 
Spiral chips were characteristic of the broad-nose tools, whereas straight chips and chips which were not as deeply colored were produced by the tools having the $65^{\circ}$ plan angle.

\section{BACK SLOPE AND SIDE SLOPE IN BROAD-NOSE TOOLS}

Further evidence that the trailer tool method of test is applicable to a wide range of conditions is found in the results of tests made with broad-nose tools (fig. $5, B$ ) having back slopes varying from $5^{\circ}$ to $40^{\circ}$ and side slopes of $0^{\circ}$ and $8^{\circ}$.

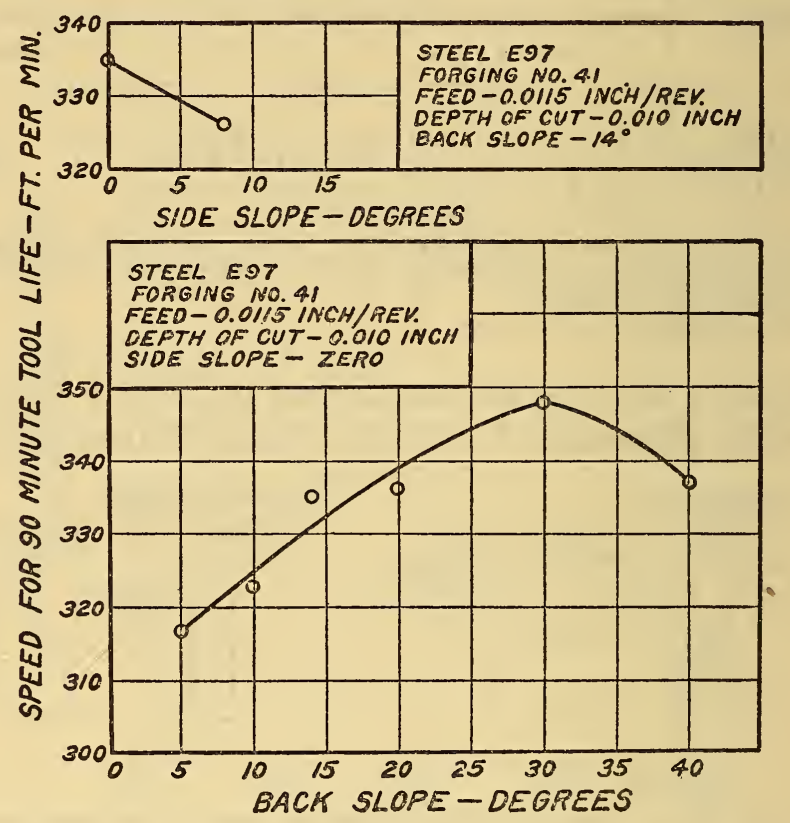

Figure 13.-Effect of change in back slope and in side slope on the cutting speed of the broad-nose tools of Figure $5(B)$ when made of high-speed steel

As is shown in Figure 13, the cutting speed of tools with $8^{\circ}$ side slope was less than that of tools with $0^{\circ}$ side slope, and the best performance of the latter was obtained with about $30^{\circ}$ back slope. With increase to $40^{\circ}$ or decrease to $5^{\circ}$ back slope the cutting speed decreased.

In addition to showing that the broad-nose tools (fig. $5, B$ ) had a shorter life but left a more desirable finish on the work than the tools with $65^{\circ}$ plan angle and that tool angles affected the performance of the former to an appreciable degree, these tests demonstrate that the successful application of the trailer tool method of test is not dependent upon having tools of a particular form. 


\section{EFFECT OF LARD OIL AND WATER ON CUTTING SPEED OF HIGH-SPEED STEEL TOOLS}

Since most industrial machining is done wet, the dry tests, already described, were supplemented by a few tests with water ${ }^{16}$ or lard oil ${ }^{17}$ as cutting liquids, but instead of making comparisons under one speed, feed, and depth of cut, tests were carried out at different speeds to give durations of cut from about 2 to 50 minutes.

A stream of the chosen liquid was thrown on the top surface of the tool through a $1 / 4$-inch nozzle at the rate of approximately 0.35 gallons per minute. Alternate wet and dry tests were made to eliminate, as far as practicable, from the results, variations arising from differences in the machining properties from point to point in the test forgings.

The results of the tests are summarized in Figure 14, and show that there was a gain in the cutting speed (or tool life) from the use of

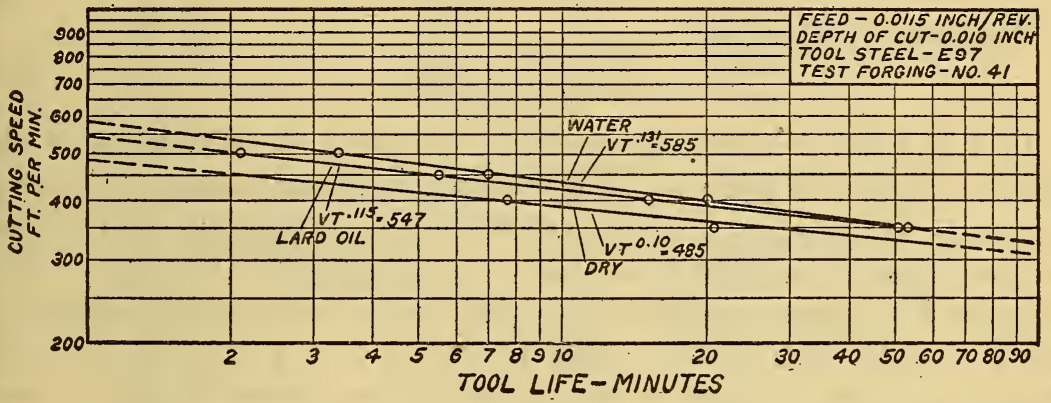

FIGURE 14.-Relations between the tool life and the cutting speed of highspeed steel tools when cutting wet and dry

See text for discussion.

either water or the lard oil. The increase was slightly greater with water than with the lard oil in tests of short duration (made with the highest cutting speeds) but equal in the tests in which tool failure occurred in about 50 minutes.

In other words, the slopes of the straight lines representing the relations between cutting speed and tool life in the logarithmic plotting used in Figure 14 were not the same for the wet and dry tests. This may be significant although it should be noted that the differences are not much greater than the scatter of points which can ordinarily be expected with the methods of test employed.

In the tests of short duration the operating temperatures of the tools are known to have been higher than in the tests of long dura-

16 One and one-half per cent by weight of washing soda was added to the water to minimize corrosion of the machine tool equipment.

17 The lard oil used was purchased under United States Government master specification No. $2 \mathrm{~d}$ for Lubricants and Liquid Fuels. Bur. Mines Tech. Paper 323B, United States Department of Commerce, 1927. 
tion, and the gains from water, which is a more effective coolant than oils, would be expected to be greater than the gains from the lard oil. With decrease in the cutting speed, the frictional temperatures decreased. There was less need for cooling, and it is not unreasonable to find equal gains from the two liquids.

If it is assumed that the temperatures of the working portions of the tools at given speeds, feeds, and depths of cut decreased in order from the dry tests to tests with the lard oil and water, then it may be said that the slopes of the lines representing the experimental results in Figure 14 increase with decrease in the operating temperatures. The three conditions may then be represented in terms of equation (1), as follows:

For dry tests

For tests with lard oil

$$
V T^{0.100}=485
$$

$$
V T^{0.115}=547
$$

For tests with water

$$
V T^{0.131}=585
$$

If it is further assumed that the variations in the slopes of the lines in Figure 14 were not due entirely to experimental errors, but represent the true trend of effects and that it is justifiable to extrapolate to longer cutting periods than were obtained in the experiments, then the line representing the tests with lard oil crosses that representing the tests with water. This means that a greater gain would result from lard oil than water under the long-time cutting of commercial practice.

These features are of interest, but before they can be accepted without reservations further work should be done, and, as pointed out in a recent report of the American Society of Mechanical Engineers Special Research Committee on Cutting of Metals, ${ }^{18}$ much more must be known of the true action of cutting liquids.

Possibly the greatest benefit obtained with the liquids was the better finish produced and not the increase in tool life. In general, dry turning gave a highly polished and smooth finish at the start of the cut, but there was a tendency for the surface to become less smooth as the test progressed, resulting in a very poor finish on the work piece just before tool failure. At this time there was also a tendency toward chattering, and very often small, shiny particles became embedded in the work piece. The finish produced when operating with the liquids was not so highly polished at the start of the cut as when dry. However, it appeared to be as smooth, and this smoothness was maintained throughout the whole cutting time.

\footnotetext{
18 Progress Report No. 1 on Cooling and Lubrication of Cutting Tools. Subcommittee on Cutting
} Fluids. Presented at the December, 1928, meeting of the American Society of Mechanical Engineers. 


\section{EFFECT OF HEAT TREATMENT OF TOOLS ON CUTTING SPEED}

\section{HIGH-SPEED STEEL TOOLS}

The performance of high-speed steel tools is quite largely dependent upon the heat treatment to which they have been subjected, and the best results are obtained in rough turning when the customary steels containing about 0.7 per cent carbon, 18 per cent tungșten, 4 per

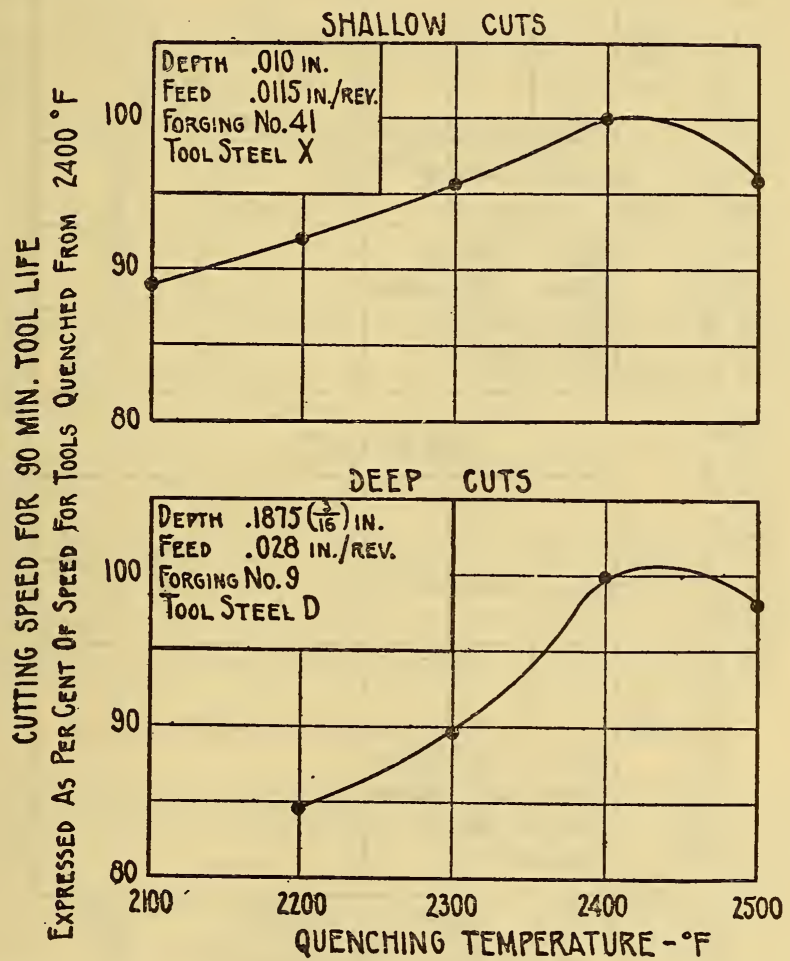

FIgURE 15.-Effect of quenching temperature on the cutting speed of high-speed steel tools under shallow cuts and under heavy duty

All tools were tempered at $1,100^{\circ} \mathrm{F}$. subsequent to hardening. Compositions of the tools are given in Table 2; properties of the forgings are given in Table 3. All tests were made dry.

cent chromium, and 1.1 per cent vanadium are quenched from 2,400 to $2,450^{\circ} \mathrm{F}$. and subsequently tempered at about $1,100^{\circ} \mathrm{F} .{ }^{19}$ This treatment gives close to the maximum tool life, but the tools must be well supported, as they are more brittle than when hardened from lower temperatures.

${ }^{19}$ H. J. French, J. Strauss, and T. G. Digges, Effect of Heat Treatment on Lathe Tool Performance and Some Other Properties of High-Speed Steels, Trans. Am. Soc. Steel Treating, 4, p. 353; 1923. 
Tempering at $1,050^{\circ}$ to $1,100^{\circ} \mathrm{F}$., subsequent to hardening from $2,400^{\circ} \mathrm{F}$., may improve the tool life slightly, but a more important effect is improved toughness.

The effect of variations in the hardening temperature upon the life of roughing tools is shown in the lower half of Figure 15, in which the cutting speeds giving 90 minutes tool life are expressed as the

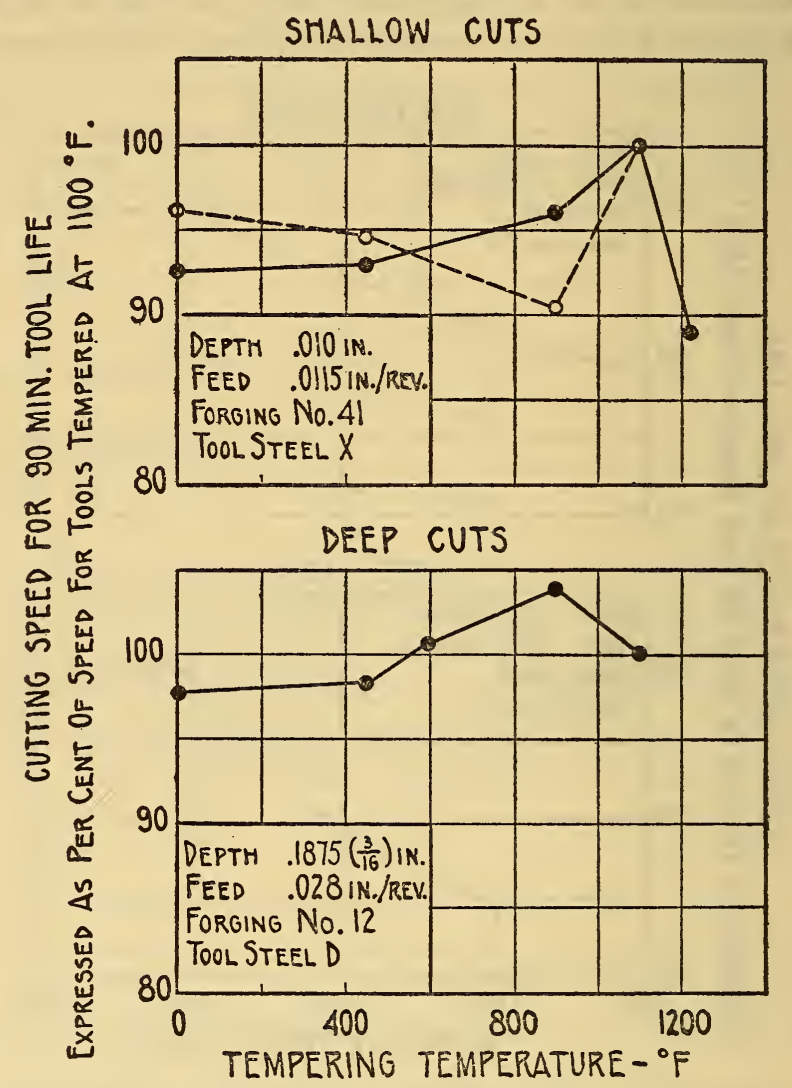

FIgURE 16.-Effect of tempering temperature on the cutting speed of high-speed steel tools under shallow cuts and under heavy duty

All tools were first oil quenched from $2,4 C 0^{\circ} \mathrm{F}$. Compositions of the tools are given iu Table 2; properties of the forgings are given in Table 3. All tests were made dry.

percentage of the cutting speed of tools quenched from $2,400^{\circ} \mathrm{F}$. Figure 15 shows that the hardening treatments which gave the best results for heavy duty also gave the best results with shallow cuts and fine feeds. However, the percentage differences in the tool performance were somewhat smaller in the case of the shallow cuts than for heavy duty. 
The effects of variation in tempering temperature on tool life for both deep and shallow cuts are illustrated in Figure 16 and show that tempering at $1,100^{\circ} \mathrm{F}$. tended to improve the tool performance, particularly for shallow cuts and fine feeds. This can probably be explained by the conversion to martensite of the greater part of the austenite retained upon quenching. Under shallow cuts and fine feeds the operating temperatures are closer to atmospheric than under conditions of rough turning where the temperatures are often close to "red heat." With shallow cuts the differences in hardness between the fully martensitic steels and those containing appreciable proportions of austenite are probably maintained throughout the life of the tools and may affect their performance. Differences in hardness probably disappear under the high temperatures reached in rough turning, due to a natural "softening" of all steels with large increases in temperature or to the automatic conversion of the austenite to martensite by the heat generated in the test, or both.

In the foregoing experiments relative to the effects of heat treatment upon the performance of the customary high tungsten-low vanadium high-speed tool steel, the trailer tool method of test for shallow cuts and fine feeds gave results similar to those obtained in the breakdown, or Taylor, tests for rough turning. With some compositions of high-speed steel, notably in the case of that containing nickel, the rough turning experiments and those with shallow cuts did not necessarily place the steels in the same order of performance as will be shown in subsequent sections of this report.

\section{1.3 PER CENT CARBON STEEL TOOLS}

Tests were made of carbon steel tools, containing 1.3 per cent carbon, when quenched and tempered at different temperatures, and the results are summarized in Table 8. The cutting speed was not affected to any measurable degree by variation in the hardening temperature from $1,425^{\circ}$ to $1,650^{\circ} \mathrm{F}$., nor did subsequent tempering at temperatures up to $375^{\circ} \mathrm{F}$. change the performance of the untempered tools. The toughness of the tools probably varied considerably under these different heat treatments, but this is not so important with the shallow cuts and fine feeds used in the experiments as with the deep cuts and coarse feeds encountered in rough turning with high-speed steels.

\section{PERFORMANCE COMPARISONS OF DIFFERENT CARBON AND LOW-ALLOY TOOL STEELS UNDER SHALIOW CUTS}

Tests were made under shallow cuts and fine feeds of carbon. steel tools containing from about 0.75 to 1.3 per cent carbon and of a low tungsten "finishing tool steel" and a so-called nondeforming tool steel containing about $1 \frac{1}{4}$ per cent manganese and small proportions 
of chromium and tungsten. The object of these tests was to compare the performance of the different compositions when subjected to heat treatments substantially the same as those recommended by the respective manufacturers for general purposes.

TABLE 8.-Effect of heat treatment on the performance of 1.3 per cent $C$ steel tools 1

\begin{tabular}{|c|c|c|c|c|}
\hline Hardening temperature $\left({ }^{\circ} \mathrm{F} .\right)^{2}$ & $\begin{array}{c}\text { Tempering } \\
\text { tempera- } \\
\text { ture }^{3}\end{array}$ & $\begin{array}{l}\text { Cutting } \\
\text { speed }\end{array}$ & $\begin{array}{l}\text { Average } \\
\text { tool life }\end{array}$ & $\begin{array}{l}\text { Cutting } \\
\text { speed giv- } \\
\text { ing 90- } \\
\text { minute } \\
\text { tool life }\end{array}$ \\
\hline $1,425 \ldots$ & ${ }^{\circ} F$ & $\begin{array}{r}\text { Ft./min } \\
163 \\
161 \\
160\end{array}$ & $\begin{array}{r}\text { Minutes } \\
20.4 \\
3.2 \\
(90)\end{array}$ & 160 \\
\hline $1,425 \ldots$ & 250 & $\begin{array}{r}163 \\
160 \\
160 \\
160\end{array}$ & $\begin{array}{r}1.9 \\
1.4 \\
73.7 \\
(90)\end{array}$ & 160 \\
\hline $1,425 \ldots \ldots$ & 375 & $\begin{array}{l}163 \\
160\end{array}$ & $\begin{array}{l}47.8 \\
(90)\end{array}$ & $-\ldots+\ldots$ \\
\hline 1,425 & 250 & $\begin{array}{l}165 \\
163 \\
160\end{array}$ & $\begin{array}{l}38.0 \\
(90) \\
(90)\end{array}$ & 163 \\
\hline 1,525 & 250 & $\begin{array}{l}168 \\
165 \\
163\end{array}$ & $\begin{array}{l}0.8 \\
1.1 \\
(90)\end{array}$ & 163 \\
\hline $1,650 \ldots$ & 250 & $\begin{array}{l}170 \\
165 \\
163\end{array}$ & $\begin{array}{r}3.6 \\
1.8 \\
(90)\end{array}$ & 163 \\
\hline
\end{tabular}

1 Tests made with steel C22 (Table 2) at 0.0115 in./rev. feed and 0.005 inch depth of cut on forging No. 41 (Table 3).

2 All tools normalized by heating 45 minutes at $1,675^{\circ} \mathrm{F}$. and cooling in still air; held 10 minutes at specified hardening temperature and quenched in water.

3 Tempered for one hour at specified temperatures.

4 Bracketed values indicate that the tools did not fail in the designated time.

The results of the tests are summarized in Table 9 and show that the cutting speeds were nearly the same for all of the steels. The tungsten tool steel $(\mathrm{V}$, Table 9) gave somewhat better performance than the manganese steel (U, Table 9), but the differences between the latter and the carbon tool steels were probably within the limits of reproducibility of the results.

The reason why the six steels tested showed comparable performance is probably to be found in the nature of the test. So long as the cutting conditions are such that the operating temperatures do not exceed certain values, which are not known at present, the tools continue to cut for long periods. With small increases in the cutting speed, or other variables, such as feed or depth of cut, this limiting temperature of operation is exceeded and the tools quickly fail. In other words, the test as carried out indicates the relative limits in the temperatures of operation under which the tools will stand up. Tungsten is one of the metals known to improve the resistance to "softening" of steels at high temperatures and has probably been responsible for the slight superiority in the cutting speed of steel V, 
Table 9. On the other hand, the ability of steels to resist "softening" with temperature increase is probably not affected appreciably by carbon variations between 0.75 and 1.3 per cent, and the different carbon steels all showed comparable cutting speeds.

TABLE 9.-Summary of tests with carbon and low alloy tool steels ${ }^{1}$

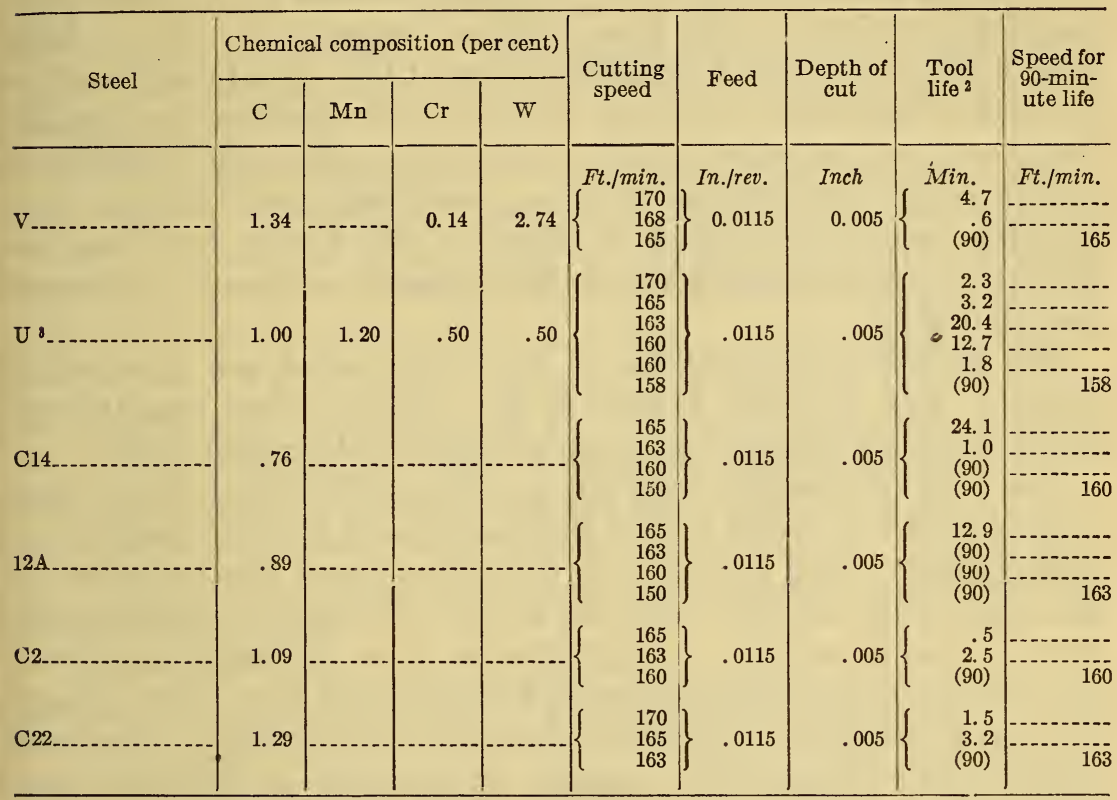

1 For compositions and heat treatments in detail see Table 2; tests made on forging No. 41, with composition and properties given in Table 3 , tool form shown in Figure $5 \mathrm{~B}$.

${ }^{2}$ Bracketed values indicate that the tools did not fail in the designated time.

Type composition, purchased under trade name.

There were no detectable differences in the surfaces produced on the work piece by the different carbon and low-alloy steel tools.

\section{HIGH SPEED STEEL TOOLS OF DIFFERENT COMPOSI- TIONS USED UNDER SHALLOW AND DEEP CUTS}

\section{PREPARATION OF THE STEELS AND TOOLS}

The chemical composition of high-speed steel tools for rough turning was studied by Taylor and his associates ${ }^{20}$ and has since been made the subject of many other experiments. ${ }^{21}$ In fact, it is probably safe

\footnotetext{
${ }^{20}$ See footnote 2, p. 830
}

${ }_{21}$ Many papers on this subject will be found in the bibliography of High-Speed Tool Steels, Trans. Am. Soc. Steel Treat., 3, p. 47; 1922. Only a few of the more recent references are included here. H. J. French, J. Strauss, Lathe Breakdown Tests of Some Modern High-Speed Steels, Trans. Am. Soc. Steel Treat., 2, p. 1125; 1923 B. S. Tech. Paper No. 228. W. Oertel and F. Polzguter; Beitrag zur Kenntnis des Einilusses von Kobalt und Vanadin auf die Eigenshaften von Schnellarbeitsstahl. Berichte d. Fach. des Vereins deut. Eisenhuttenleute, 47, p. 1 ; July 17, 1924. L. Guillet, Les aciers à outils a coupe rapide renfermant du cobalt, Rev. de Met., 22, p. 88; 1925. R. Hohage and A. Grutzner Schneidversuche mit Schnellarbeitsstahlen. Stahl u. Eisen, p. 1126; July 9, 1925. H. J. French and T. G. Digges Experiments With Nickel, Tantalum, Cobalt, and Molybdenum in High-Speed Steels, Trans. Am. Soc. Steel Treat. 8, p. 681; 1925 , F. C. A. H. Lantsberry High-Speed Steels, Trans. Am. Soc. Steel Treat. 11, p. 711; 1927.

$$
77886^{\circ}-29-3
$$


to say that continuous efforts have been made during the past 20 years to improve the performance of high-speed tool steels intended for heavy duty. Comparable studies have not been made for the shallow cuts and fine feeds which generally characterize finish turning operations, and, accordingly, high-speed steels of different compositions were tested by the "trailer-tool" method described in this report and the results compared with those obtained under heavy duty. Tests were made of important industrial types of high-speed steel, such as the high tungsten-low vanadium steels, the low tungsten-high vanadium steels, and the cobalt steels. A study was also made of additions of appreciable proportions of nickel, molybedenum, titanium, and tantalum and of the effects of elements which may be classed as impurities, such as phosphorus, sulphur, arsenic, antimony, tin, copper and aluminum.

The chemical compositions of the steels tested are recorded in Table 2, and, as there indicated, the majority were experimental melts, but a few commercial steels were included for comparison.

The high-speed steels were not free from all elements other than those reported in Table 2, but, in general, only small proportions of other elements were present. In one or two cases small amounts of aluminum were added to quiet the metal in the ladle. Small proportions of nickel, cobalt, or molybdenum were probably introduced through the scrap high-speed steel which formed part of the charge in some of the heats, and other elements were probably introduced inadvertently through their presence as impurities in the ferro-alloys employed.

Spectroscopic examination ${ }^{22}$ was made of samples from many of the experimental steels and, with the exception of phosphorus, sulphur, and arsenic, which are not very sensitive in arc spectra, the results confirmed those obtained by chemical analysis, as reported in Table 2. In addition to these elements, small proportions of impurities were found, as follows: Copper, aluminum, and molybdenum were found in all the steels examined, but with the exception of the steels to which these metals were intentionally added the proportions were small and considered to be below 0.03 per cent. Small proportions of tin, introduced from the ferrotantalum, were found in the tantalum steels, E44, E45, E16, and E100. Nickel was found in samples E70, E71, E77, E51, and E87. Cobalt was found in steel E51. Nickel, cobalt, and molybdenum were present in steel E51 and, if 100 per cent recovery of these elements from the high-speed steel scrap is assumed, steel E51 contained about 0.35 per cent cobalt, 0.25 per cent nickel, and 0.10 per cent or less of molybdenum.

Steels L and E97 (Table 2), used as the basis of comparisons in the study of impurities, contained traces, estimated at 0.01 to 0.03 per

${ }^{22}$ Examinations made by Dr. W. F. Meggers, chief of the spectroscopy section. 
cent, of copper and aluminum, but there was no evidence of antimony or arsenic. The most sensitive tin lines are close to iron lines, and therefore it was difficult to get a positive indication of tin which may likewise be present in traces in these two steels.

In general, only small proportions of impurities were found by spectroscopic analysis, and these should not affect the comparisons to be made, particularly as steels containing different proportions of the added elements are available in most cases to show the trends in the effects produced.

In the study of impurities, the proportions of arsenic, tin, copper, etc., were much higher, in most cases, than the proportions which would ordinarily be encountered in commercial high-speed steels, but it is frequently advantageous to deal with extremes so as to emphasize the effects of important variables. It should also be kept in mind that the phosphorus, sulphur, arsenic, antimony, copper, or tin were not residual but were added to the steels in the ladle and that the effects produced may differ from those observed when the corresponding elements are carried through all stages of manufacture from the ores or introduced into the steels in other ways. Nevertheless, the ladle additions made constitute a logical step in the study of the subject of impurities.

The steels produced experimentally were melted in an indirec $t$ arc furnace. The molten steel was generally tapped hot enough to permit its being held in the ladle for a few moments before casting into 55 -pound ingots having a top section about 3 by 3 inches and a length of 22 inches. A split iron mold was used in which the ratio of mold weight to ingot weight was about 1.9 ; in practically all cases hot tops were used and a top discard made of about 25 per cent.

The required amounts of metallic antimony, arsenic, copper, tin, or aluminum were placed in the ladle and the molten steel poured on top. Phosphorus and sulphur were introduced into the steels by ladle additions of ferrophosphorus containing about 25 per cent phosphorus and pyrite ( $\mathrm{FeS})$. The titanium and tantalum were added to the metal in the furnace by placing the required amounts of their respective ferro-alloys in sheet-steel containers and pushing these below the surface of the bath about five minutes before tapping: The recovery varied but did not exceed about 50 per cent of the titanium added as carbon-free ferrotitanium of the composition shown in Table 10.

With the exception of steel E51, the steels containing titanium also contained aluminum which was introduced by the ferro-alloys used. It was largely on this account that two steels, E78 and E98, (Table 2) were made with aluminum additions. Any marked effects produced by titanium could then be determined by comparison of the steels 
containing both titanium and aluminum with those containing only aluminum.

TABLE 10.-Ferro-alloys used in making some of the special high-speed tool sieels

\begin{tabular}{l|c|c|c|c|c|c|c|c|c|c}
\hline \multirow{2}{*}{ Ferro-alloy } & \multicolumn{7}{|c}{ Chemical composition ${ }^{1}$ (per cent) } \\
\cline { 2 - 6 } & $\mathrm{C}$ & $\mathrm{Mn}$ & $\mathrm{Si}$ & $\mathrm{Al}$ & $\mathrm{Ti}$ & $\mathrm{Ta}$ & $\mathrm{Cb}$ & $\mathrm{Mo}$ & $\mathrm{W}$ & $\mathrm{Sn}$ \\
\hline Carbon-free ferrotitanium & & & & & & & & & \\
\hline $\begin{array}{l}\text { Ferrotantalum } \\
\text { Ferromolybdenum }\end{array}$ \\
Ferrotungsten containing molybdenum
\end{tabular}

1 As reported by the manufacturer.

$2 \mathrm{P}=0.057$ per cent; $\mathrm{S}=0.19$ per cent.

3 Made from California Scheelite ore.

In one case about 97 per cent of the tantalum was recovered when using low-carbon ferrotantalum, but, in general, the recovery was appreciably less varying from about 60 to 80 per cent. As will be noted from Table 10, the ferrotantalum used contained roughly 1 part of columbium for every 8 parts of tantalum. While the steels made will be referred to as tantalum steels, it is to be understood that they also contain columbium. This element, if recovered in the same proportions as tantalum, is present in the steels in amounts equal to about one-ninth of the total percentages given in Table 2.

Molybdenum additions were made in the furnace with the original charge by means of ferromolybdenum of the compositions given in Table 10. However, in two cases-those of heats E107 and E109 (Table 2)-the molybdenum was introduced as an impurity in the ferrotungsten (Table 10). Cobalt was added in shot or cube form in the furnace with the original charge, while nickel was added as shot or electrolytic nickel in the furnace or in the ladle.

After casting the ingots were allowed to become cold and were then annealed. Surface imperfections were removed on a shaper or surface grinder. Steels with heat numbers between $\mathrm{E} 14$ and E51, inclusive, (Table 2) were forged with a steam drop hammer to $3 / 4$ by $1 \frac{1 / 4}{4}$ inch bars; all other steels were forged to 2 by 2 inch bars under a press and then rolled into $1 \frac{1}{2}$ by $1 \frac{1}{2}$ inch bars. Forging and rolling temperatures were kept between about $2,150^{\circ}$ and $1,800^{\circ} \mathrm{F}$. Subsequent to forging or rolling the bars were again annealed by heating two to three hours at $1,600^{\circ}$ to $1,650^{\circ} \mathrm{F}$. and slowly cooling in the furmace.

Test tools about 5 inches long, with a cross section of $1 / 2$ by $1 / 4$ inch, were machined from the rolled or forged bars, and care was taken in grinding the nose to have the top surface of the finished tool comprised of metal adjacent to the surfaces of the hot finished bars.

The tools were preheated for 20 minutes at around $1,600^{\circ} \mathrm{F}$., introduced into the high-temperature furnace and kept there one and one-half minutes, and then quenched in a thin oil. They were subsequently tempered 30 to 45 minutes at temperatures given in 
Table 2. The results described in Section IX, 1 of this report and earlier work ${ }^{23}$ form the basis of selection of the hardening temperatures used which are recorded in Table 2. In most cases these are known to produce close to the best performance of which the several steels are capable. This does not apply to the steels containing tantalum nor to the commercial steels containing the highest proportions of cobalt, which in individual cases were treated by or according to the recommendations of the manufacturer.

\section{HOT WORKING AND MACHINING PROPERTIES}

An adequate idea of the working and machining characteristics of the steels listed in Table 2 can probably be obtained only under conditions approaching those of commercial production, but certain definite effects were observed in the working and machining of the experimental melts which deserve mention at this time.

Difficulties were encountered in forging two of the molybdenum steels, E31 and E29. (Table 2.) In both heats the ingots cracked badly, and only small proportions were secured in final bar form. The tungsten-molybdenum steel (E31) was, perhaps, the worst in this respect, as the ingot split under the first few light blows of the hammer. Possibly, modifications in the forging practice employed would have been productive of better results, but it appeared that these molybdenum steels were more sensitive to working conditions than the ordinary types of high-speed steel.

So-called "sweating out" of the molybdenum visible by the thick, bluish smoke arising from the steel was observed only during forging: (not in heat treatment), but examination of the forged bars of steel E29 indicated negligible losses of molybdenum. Quite probably the smoke observed in forging was the volatilization of the molybdenum oxide already forming part of the scale.

One of the forged and annealed bars was first pickled in an ammoniacal citrate solution to loosen the scale which was then carefully brushed or chipped from the underlying metal. Six successive cuts, each 0.003 inch deep, were then taken beneath the cleaned surface and each of the six samples analyzed for molybdenum. Table 11 indicates negligible losses of molybdenum in the unoxidized metal unless the losses were concentrated in very shallow outer layers. However, this seems improbable since, as pointed out by Bain, ${ }^{24}$ molybdenum volatilizes very slowly, even in vacuuo, and diffuses slowly in iron alloys, whereas the oxide of molybdenum is quite volatile. Rapid diffusion and rapid volatilization would both be

\footnotetext{
${ }^{23}$ See footnote 19 , p. 855.

${ }^{24}$ E. C. Bain, Discussion of Paper, referred to in footnote 21, p. 865, by H. J. French and T. G. Digges on Experiments with Nickel Tantalum, Cobalt, and Molybdenum in High-Speed Steels, Trans. Am. Soc. Steel Treating, 8, p. 6; 1925.
} 
necessary for appreciable losses of metallic molybdenum at the unoxidized surfaces of the steel.

The steel containing 0.78 per cent aluminum did not have as good hot-working properties as steels without appreciable proportions of this element, as was shown by bad corner cracks produced in rolling. (Fig. 17.)

One of the steels containing titanium (E96) showed a high degree of hot shortness in rolling although it seemed to forge in a satisfactory manner. This was probably not due either to the aluminum (0.08 per cent) or to high carbon (1.24 per cent), since a steel with equal carbon (E101) and steels with higher proportions of aluminum (0.38 per cent aluminum in steel E101 and 0.30 per cent aluminum in steel E87) had more satisfactory working properties. The splitting of the forged bar in rolling as is shown in Figure 17 may have been due to segregation. In this connection it should be noted that in this steel the recovery of titanium was only about 15 per cent of that added to the molten metal.

TABLE 11.-Molybdenum found in successive layers beneath the surface of forged bars of steel E29 1

\begin{tabular}{|c|c|}
\hline Location of sample with respect to pickled and brushed surface & $\begin{array}{l}\text { Molybde- } \\
\text { num }\end{array}$ \\
\hline $\begin{array}{l}\text { Entire cross section of bar } \\
0 \text { to } 0.003 \text { inch below surface } \\
0.003 \text { to } 0.006 \text { inch below surface } \\
0.006 \text { to } 0.009 \text { inch below surface } \\
0.009 \text { to } 0.012 \text { inch below surface } \\
0.012 \text { to } 0.015 \text { inch below surface } \\
0.015 \text { to } 0.018 \text { inch below surface }\end{array}$ & $\begin{array}{r}\text { Per cent } \\
7.18 \\
7.06 \\
7.14 \\
7.19 \\
7.15 \\
7.16 \\
7.16\end{array}$ \\
\hline
\end{tabular}

1 Chemical composition given in Table 2.

In general, the difficulties in hot-working the different steels were more pronounced in rolling than in forging or pressing. The steels containing 1.7 per cent antimony or 1.8 per cent tin showed a high degree of hot-shortness and could not be forged or rolled. (See Fig. 18.) The ingot of steel E48 containing 1.2 per cent tin "smoked" in forging like the high molybdenum steels.

None of the other steels gave appreciable difficulties in forging, but several showed surface cracks, mostly at the corners, on rolling. Among these were the steels containing 0.4 per cent antimony, the steels with around 0.8 per cent or more of copper, the steel containing 0.8 per cent arsenic, and the steel containing 1.4 per cent carbon and 1.10 per cent tantalum.

All of the high-speed steels referred to in Table 2 could themselves be readily machined when in the annealed condition except the steel containing 1.8 per cent copper and the three steels containing about $3 \frac{3}{4}$ per cent nickel and 0.6 to 0.7 per cent carbon. The steel with 


\section{$\mathrm{Cr}-\mathrm{W}-\mathrm{V}$ STEELS}

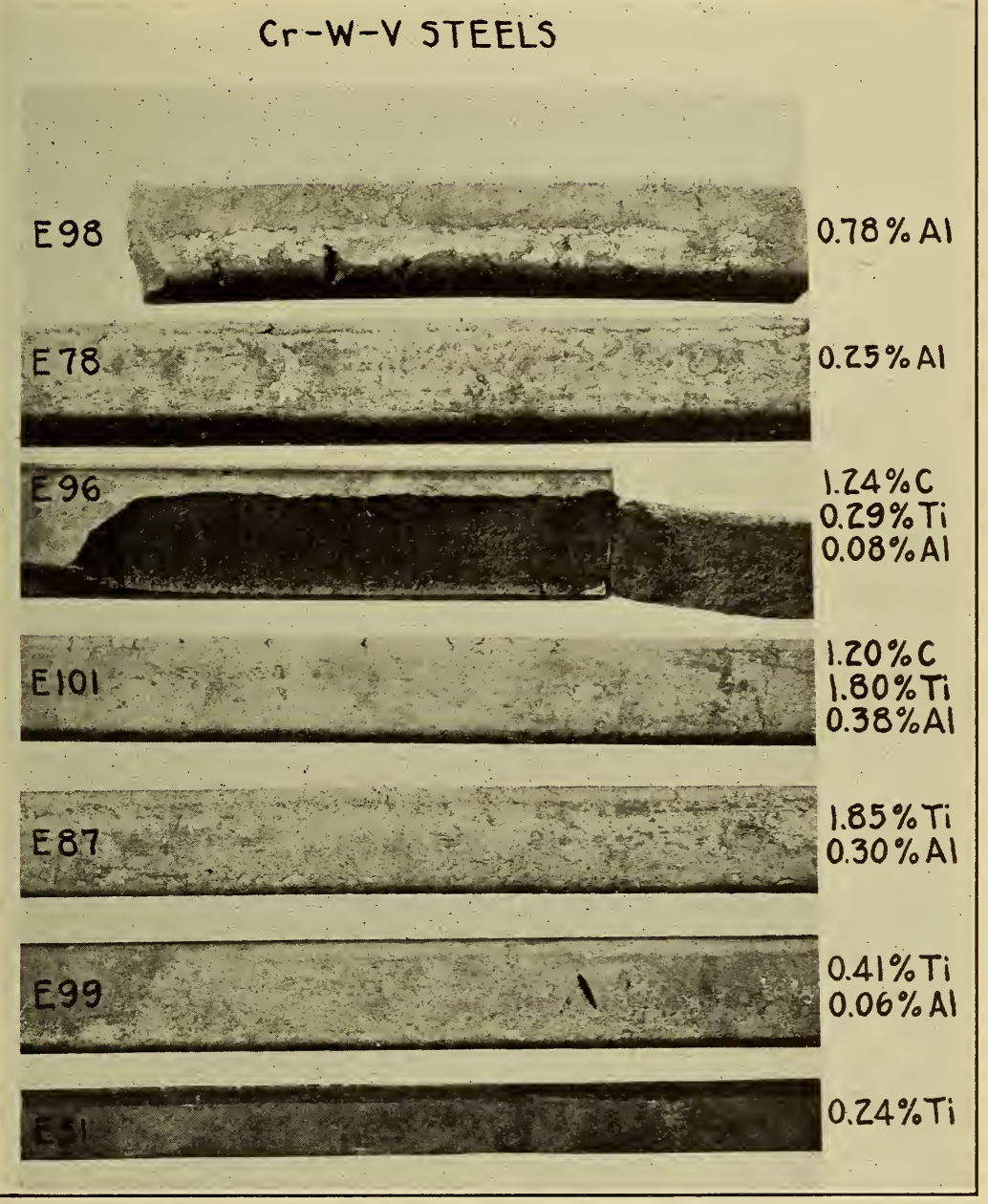

FIGURE 17.-Appearance of some of the rolled or forged high-speed steel bars containing titanium and aluminum

See Table 2 for detailed chemical composition. 
B. S. Journal of Research, RP120

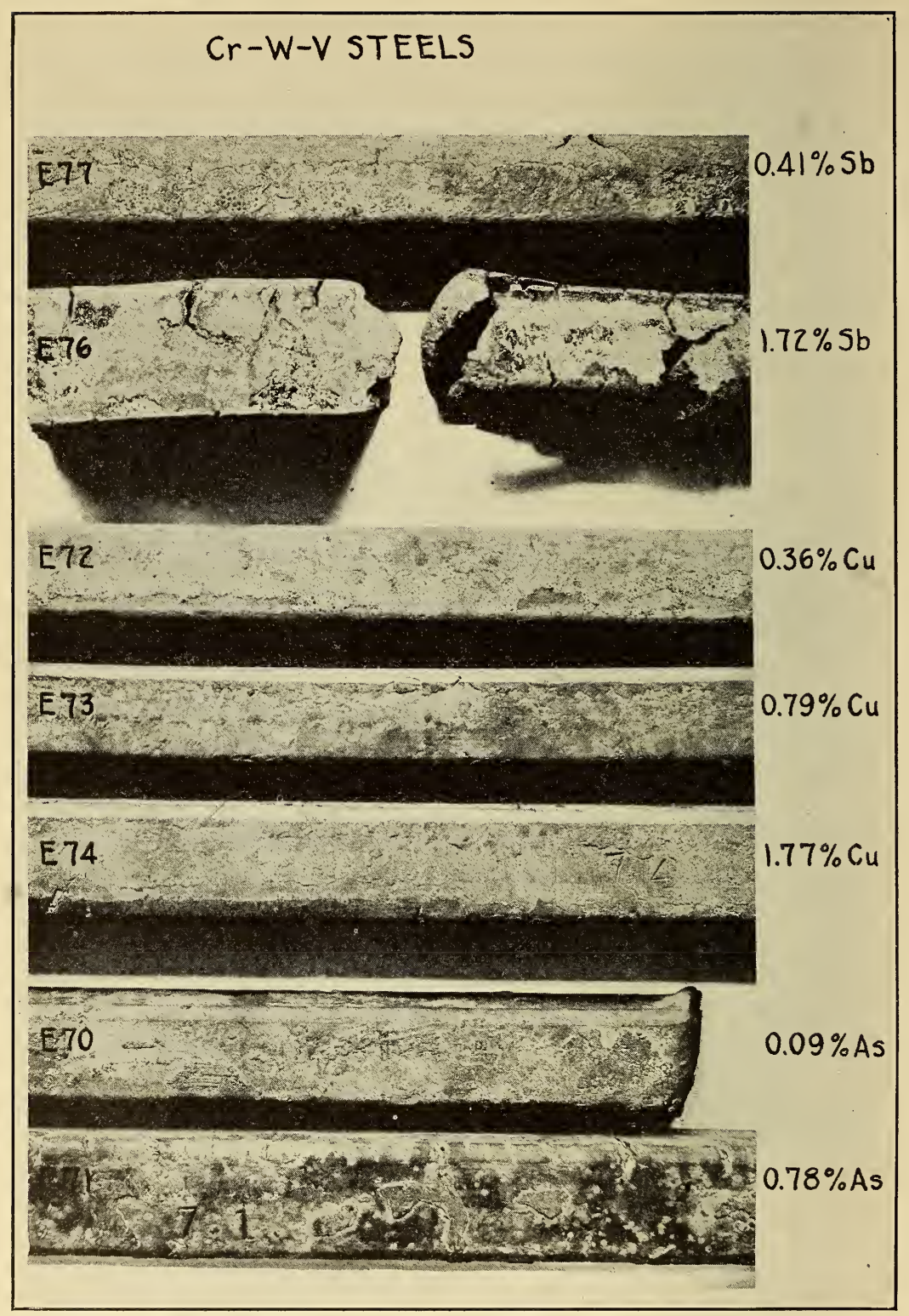

FIGURE 18.-Appearance of the rolled high-speed steel bars containing arsenic, antimony, or copper See Table 2 for detailed chemical composition. 
copper (E74) was machined with difficulty, but it was impossible to machine two of the nickel steels, E22 and E14, either in the cast or forged conditions even after prolonged annealing. Steel E130 was machined with difficulty, but with comparable proportions of nickel and lowered carbon content the machining properties were greatly improved. Steel E41 containing about 0.5 per cent carbon and 31/2 per cent nickel, while not "soft," could be machined without great difficulty after annealing.

\section{GENERAL COMMENTS ON LATHE TESTS}

The steels referred to in Table 2 and the lathe-tool tests to be discussed were made at intervals over a long period of time on different test forgings, so that a direct comparison of all the tools is not practicable. This does not prevent determination of the effects of the added metals considered, since each set of tests was considered to be complete in itself and included one or more of the plain chromiumtungsten-vanadium high-speed steels as the basis for comparisons.

All tests were made at selected speeds, feeds, and depths of cut and the tool life determined. From 6 to 12 tools of each steel were tested for each of the selected cutting conditions. However, instead of reporting the average tool life comparisons are made of the cutting speed permitting a tool life of 90 minutes. This was obtained from the average tool life by means of equation (1) with $n=\frac{1}{10}$ for tests made under shallow cuts and fine feeds ("trailer-tool" tests) and with $n=\frac{1}{7}$ for tests made with heavy cuts and coarse feeds (rough turning). ${ }^{25}$

The chromium-tungsten-vanadium steels used as the basis of comparisons in a majority of cases were experimental melts made in the same manner as the steels containing additions of the special elements. However, in some cases commercial high-speed steels were substituted for the experimental steels, so that the performance of the different lathe tools might be viewed in the light of commercial products. The results recorded in Table 12 show that the experimental steels gave comparable performance to the commercial steels of like composition which were selected for comparisons under either shallow cuts and fine feeds or deep cuts and coarse feeds.

\section{STEELS WITH MOLYBDENUM}

Many of the cobalt high-speed steels contain from 0.5 to 1 per cent of molybdenum, but ferrotungsten containing appreciable proportions of molybdenum has not always been considered to be desirable by American steel manufacturers. ${ }^{26}$

${ }_{25}$ The basis of the selected values for the exponent $n$ in equation (1) is discussed in Section $V$ of this report and in the reference of footnote 1, p. 830 ,

${ }_{36}^{36}$ Private communications. 
TABLE 12.-Comparisons of commercial and experimental high-speed tool steels in lathe tests

SHALLOW CUTS AND FINE FEEDS

\begin{tabular}{|c|c|c|c|c|c|c|c|c|}
\hline \multirow{2}{*}{$\begin{array}{l}\text { Steel } \\
\text { No. } 1\end{array}$} & \multirow{2}{*}{ Type of steel } & \multicolumn{4}{|c|}{ Cutting conditions } & \multirow{2}{*}{$\begin{array}{l}\text { Num- } \\
\text { ber of } \\
\text { tools } \\
\text { tested }\end{array}$} & \multirow{2}{*}{$\begin{array}{l}\text { Aver- } \\
\text { age tool } \\
\text { life }\end{array}$} & \multirow{2}{*}{ Remarks } \\
\hline & & Speed & Feed & Depth & $\begin{array}{c}\text { Forging } \\
\text { No. }{ }^{3}\end{array}$ & & & \\
\hline $\begin{array}{l}\mathrm{L}=- \\
\mathrm{E} 97- \\
\mathrm{A} 15 .\end{array}$ & $\begin{array}{l}\text { Low W-high V... } \\
\text { Low W-cobalt }\end{array}$ & $\left\{\begin{array}{r}\text { Ft./min. } \\
400 \\
400 \\
380 \\
380\end{array}\right.$ & $\begin{array}{r}\text { In./rev. } \\
0.0154 \\
.0154 \\
.0115 \\
.0115\end{array}$ & $\begin{array}{r}\text { Inch } \\
0.005 \\
.005 \\
.010 \\
.010\end{array}$ & $\begin{array}{l}40 \\
40 \\
41 \\
41\end{array}$ & $\begin{array}{r}10 \\
10 \\
6 \\
6\end{array}$ & $\begin{array}{c}\text { Minutes } \\
47.1 \\
48.8 \\
20.7 \\
19.3\end{array}$ & $\begin{array}{l}\text { Commercial steel. } \\
\text { Experimental melt. } \\
\text { Commercial steel. } \\
\text { Experimental melt. }\end{array}$ \\
\hline
\end{tabular}

DEEP CUTS AND COARSE FEEDS

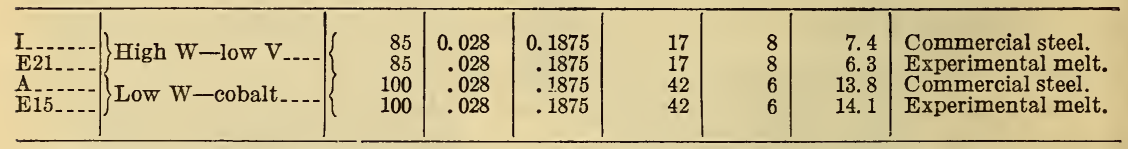

1 See Table 2 for chemical compositions of the tools and their heat treatment; tool form given in Figure $5, B$.

${ }_{2}$ See Table 3 for chemical compositions and properties of the forgings cut.

The four steels containing molybdenum (Table 2) may be said to fall into two classes, the one in which molybdenum was introduced as an impurity in the ferrotungsten, made from California Scheelite ores, and the second in which molybdenum was used intentionally as a replacement of part or all of the tungsten.

Steels E109 and E107 were made with the idea of determining whether small amounts of molybdenum produced any appreciable effects upon the tool performance of the customary chromiumtungsten-vanadium high-speed steels. In steels E31 and E29 part or all of the tungsten was replaced by molybdenum in the approximate ratio of 1 part molybdenum for each $2 \frac{1}{2}$ parts of tungsten. This ratio represents approximately equivalent effects as determined in lathe-tool tests by Arnold and Ibbotson. ${ }^{27}$

While not strictly accurate, all four of the steels with molybdenum may be considered to be modifications of the customary high tungsten-low vanadium high-speed steel in which 1 part of molybdenum has replaced approximately $2 \frac{1}{2}$ parts of tungsten, and it is on this basis that the results of the lathe tests are summarized in Figure 19.

It would appear from Figure 19 that molybdenum may be substituted for part or all of the tungsten without radically changing the lathe-tool performance under shallow cuts and fine feeds or under heavy duty. If the results in Figure 19 show any definite trends, they are that molybdenum is somewhat disadvantageous from the standpoint of shallow cuts, but may improve the steels for heavy duty.

${ }_{27}$ J. O. Arnold and F. Ibbotson, The Molecular Constituents of High-Speed Tool Steels and Their Correlations with Lathe Efficiencies, J. Iron and Steel Inst., 99, No. 1, p. 407; 1919. 
More definite conclusions can not be drawn, since steels E31 and E29 are, respectively, low in carbon and in vanadium, and the importance of these variations when taking shallow cuts is not known at this time.

The performance of the molybdenum steel, E29 (without tungsten), was somewhat irregular under shallow cuts, as is shown in Table 13. The cutting speed in one set of tests was almost identical with that of the tungsten steel E97 but in another set of tests made with a deeper cut was somewhat lower.

The rough turning tests did not establish superiority or inferiority of the high-speed steel tools containing molybdenum, and in this respect the results in Figure 19 are consistent with those obtained by earlier invescigators who, in some cases, found that the steels with molybdenum gave better performance than the tungsten steels,

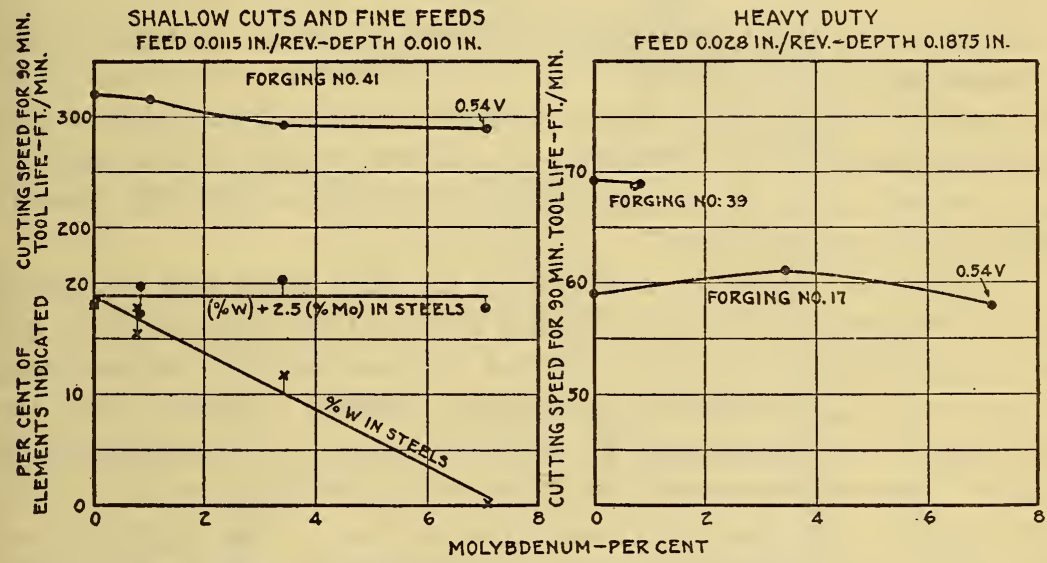

FIgURE 19.-Effect of molybdenum on the cutting speed of chromiumtungsten-vanadium steel tools when taking shallow cuts and when tested under heavy duty

The molybdenum in these steels replaced a part or all of the tungsten as indicated graphically on the left side of the chart and as explained in the text. Compositions of the tools and their heat treatment are given in Table 2; properties of the forgings are given in Table 3. All tests were made dry.

while in other cases this order was reversed. Detailed comparisons of the results of some previous investigations are given in Table 14. $\mathrm{T}_{\mathrm{ABLE}}$ 13.-Performance comparisons under shallow cuts of $\mathrm{Cr}-\mathrm{Mo}-\mathrm{V}$ and $\mathrm{Cr}-\mathrm{W}-\mathrm{V}$ high-speed steel tools

\begin{tabular}{|c|c|c|c|c|c|c|c|c|c|c|c|}
\hline \multirow{2}{*}{ Steel No.1 } & \multicolumn{5}{|c|}{ Chemical composition (per cent) } & \multicolumn{4}{|c|}{ Cutting conditions } & \multirow{2}{*}{$\begin{array}{l}\text { Average } \\
\text { tool } \\
\text { life }\end{array}$} & \multirow{2}{*}{$\begin{array}{l}\text { Cutting } \\
\text { speed } \\
\text { for } 90- \\
\text { minute } \\
\text { tool life }\end{array}$} \\
\hline & $\mathrm{C}$ & $\mathrm{Cr}$ & $\mathrm{W}$ & $\mathrm{V}$ & Mo & Speed & Feed & $\begin{array}{l}\text { Depth } \\
\text { of cut }\end{array}$ & $\begin{array}{c}\text { Forging } \\
\text { No. }\end{array}$ & & \\
\hline $\begin{array}{l}\text { E97 } \\
\text { E29-. } \\
\text { E97-. } \\
\text { E29... }\end{array}$ & $\begin{array}{r}0.64 \\
.71 \\
.64 \\
.71\end{array}$ & $\begin{array}{l}3.41 \\
4.74 \\
3.41 \\
4.74\end{array}$ & \begin{tabular}{c}
13.02 \\
\hdashline 13.02 \\
\hdashline.. \\
\end{tabular} & $\begin{array}{r}1.99 \\
.54 \\
1.99 \\
.54\end{array}$ & 7.07 & $\begin{array}{r}\text { Ft. } \min . \\
380 \\
380 \\
400 \\
400\end{array}$ & $\begin{array}{l}\text { In./rev. } \\
0.0115 \\
.0115 \\
.0115 \\
.0115\end{array}$ & $\begin{array}{l}\text { Inch } \\
0.010 \\
.010 \\
.005 \\
.005\end{array}$ & $\begin{array}{l}41 \\
41 \\
41 \\
41\end{array}$ & $\begin{array}{r}\text { Minutes } \\
16.4 \\
6.0 \\
14.6 \\
13.8\end{array}$ & $\begin{array}{r}\text { Ft./min. } \\
320 \\
290 \\
333 \\
332\end{array}$ \\
\hline
\end{tabular}

${ }^{1}$ See Tables 2 and 3, respectively, for details of tool steel treatments and properties of forging No. 41 ;

tool form shown in Figure $5, B$.
2 Computed by means of equation (1) of the text with $n=\frac{1}{10}$. 
TABLE 14.-Roughing lathe-tool performance of high-speed steels with and without molybdenum reported by some earlier investigators

\begin{tabular}{|c|c|c|c|c|c|c|c|c|}
\hline \multicolumn{5}{|c|}{ Chemical composition (per cent) } & \multirow[b]{2}{*}{$W+\underset{M 0}{216} \times$} & \multirow{2}{*}{$\begin{array}{l}\text { Rela- } \\
\text { tive } \\
\text { tool } \\
\text { per- } \\
\text { form- } \\
\text { ance }\end{array}$} & \multirow{2}{*}{$\begin{array}{c}\text { Metal } \\
\text { re- } \\
\text { moved } \\
\text { in } \\
\text { speed } \\
\text { incre- } \\
\text { ment } \\
\text { tests }\end{array}$} & \multirow[b]{2}{*}{ Source of data } \\
\hline $\mathrm{C}$ & $\mathrm{Cr}$ & W & V & Mo & & & & \\
\hline $\begin{array}{r}0.79 \\
.79 \\
.63\end{array}$ & $\begin{array}{l}\text { 4. } 27 \\
\text { 3. } 18 \\
\text { 3. } 14\end{array}$ & $\begin{array}{l}23.90 \\
12.40 \\
18.70\end{array}$ & $\begin{array}{r}0.69 \\
.52 \\
.49\end{array}$ & 3.98 & $\begin{array}{r}\text { Per cent } \\
23.90 \\
22.35 \\
18.70\end{array}$ & $\begin{array}{l}1.35 \\
1.00 \\
1.02\end{array}$ & $\begin{array}{l}\text { Pounds } \\
\end{array}$ & $\begin{array}{l}\text { Hohage and Grutzner; Stahl u. Eisen, } \\
\text { July, p. 1126; } 1925 \text {. }\end{array}$ \\
\hline $\begin{array}{l}.55 \\
.76 \\
.75\end{array}$ & $\begin{array}{l}2.62 \\
2.82 \\
2.79\end{array}$ & $\begin{array}{l}15.93 \\
12.12\end{array}$ & $\begin{array}{l}1.16 \\
1.28 \\
1.29\end{array}$ & $\begin{array}{l}2.06 \\
5.79\end{array}$ & $\begin{array}{l}15.93 \\
17.27 \\
14.47\end{array}$ & (n) & $\begin{array}{r}110 \\
96 \\
112\end{array}$ & $\begin{array}{l}\text { Arnold and Ibbotson; J. Iron and Steel } \\
\text { Inst., 99, p. 407; 1919. }\end{array}$ \\
\hline
\end{tabular}

As far as can be judged from the described tests, the replacement of tungsten by molybdenum is not a substitution which should be advocated for lathe tools, but in case of a depleted tungsten supply molybdenum would be very useful in producing steels with at least the same general order of performance as is obtained with the present tungsten high-speed steels.

The high molybdenum steels, such as E29, have one advantage over the tungsten steels for roughing tools in that their hardness and performance is not so largely affected by variations in the hardening temperatures as is shown in Figure 20. When hardened from low temperatures around $2,200^{\circ} \mathrm{F}$. the high molybdenum steel actually showed better performance than the customary tungsten steels similarly treated. On the other hand, the hardness of the tungsten steels containing 1 per cent or less of molybdenum was the same as that of corresponding steels without molybdenum when subjected to the same heat treatments.

Up to the present time it has not been practicable to expect uniformly good performance from high-molybdenum high-speed steel tools, but more extended experience with such steels would probably result in the development of a technique in manufacture and handling which would result in a more satisfactorily uniform performance.

\section{STEELS WITH COBALT}

Cobalt has been an important element in the so-called tungstenless alloys for high-speed cutting tools, but the steels considered here are the customary chromium-tungsten-vanadium steels modified only by additions of cobalt. In the commercial steels of this type from 2.5 to 5 per cent of cobalt has usually been added, but more recently steels with much higher proportions of cobalt have been placed on the American market. Some of these also contain molybdenum in proportions up to about 1 per cent, but since the results already described showed that 1 per cent or less of molybdenum had no appreciable 

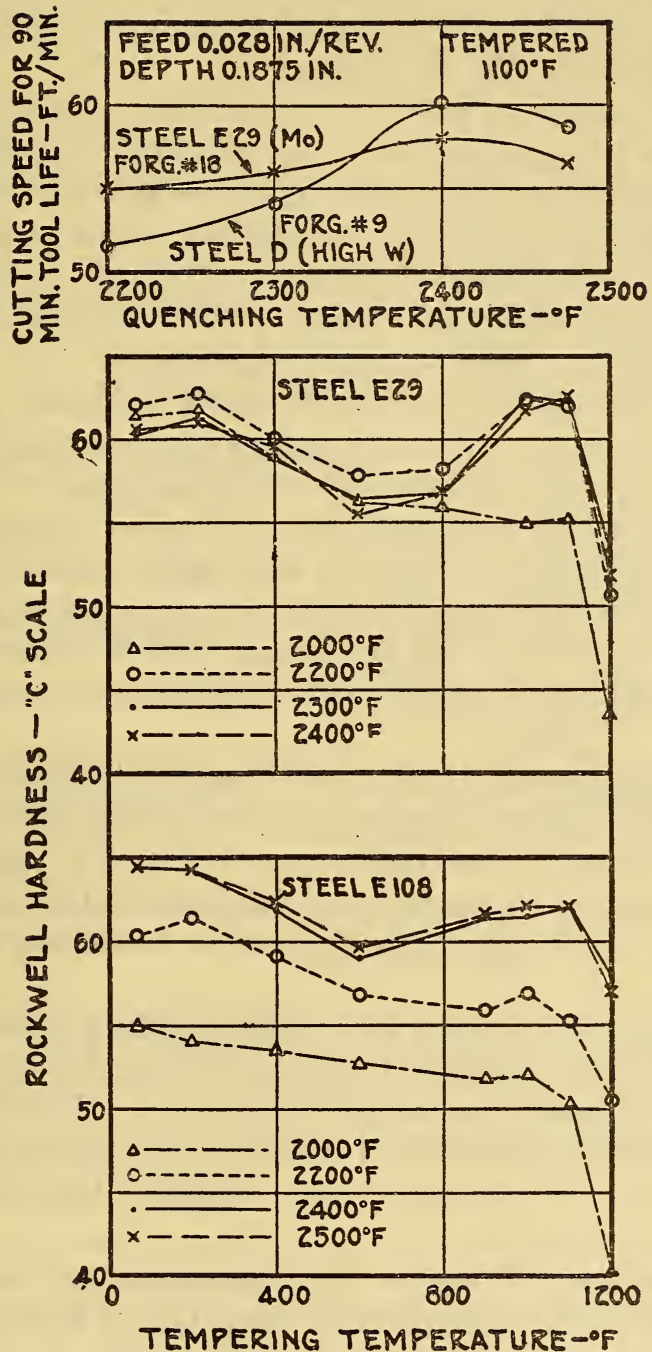

Frgure 20.-Effect of heat treatment on the cutting speed and hardness of some of the high-speed steels containing molybdenum

Composition of the tools and their heat treatments are given in Table 2; properties of the forgings are given in Table 3. All lathe tests were made dry. Quenching temperature shown in the body of the chart. The cutting speed of steel D containing no molybdenum is given for comparison with the molybdenum steel E29. 
influence on the cutting speeds of the customary chromium-tungstenvanadium steels, either with shallow cuts or under heavy duty, the presence of 0.6 and 0.9 per cent molybdenum, in steels $\mathrm{CC}$ and $\mathrm{Y}$, repesctively, Table 2, may be disregarded.

Several advantages are known to result from the addition of cobalt to the customary high-speed steel compositions. Steels with around 5 per cent cobalt can be hardened from somewhat higher temperatures than would be safe for the corresponding steels without cobalt, ${ }^{28}$ and under such conditions of treatment will, on the average, give better performance under very heavy duty where the deep cuts and coarse feeds produce high frictional temperatures.

Another advantage of the cobalt steels reported by European investigators ${ }^{29}$ is that their performance is not so largely dependent upon the hardening temperatures as is the case in corresponding steels without cobalt, and with low hardening temperatures, say, around $2,300^{\circ} \mathrm{F}$., higher hardness and better performance can be expected. However, the cobalt steels are reported to acquire a soft skin on hardening, ${ }^{30}$ with the result that they have not been widely used in form cutters or other tools which must be heat treated in finished form.

The high-cobalt steels, similar to CC and Y (Table 2), have been reported to give excellent performance in cutting hard metals; it is claimed ${ }^{31}$ they have also made practicable the commercial machining of 14 per cent manganese steels, but the best performance is obtained only when the highest possible hardening temperatures are used.

Under shallow cuts and fine feeds higher cutting speeds were shown by the steels with cobalt than by those without, but 8 to 12 per cent of cobalt was no more effective than 5 per cent. (Fig. 21.) Furthermore, the benefits derived from the cobalt were not large, amounting to 10 to 25 feet per minute for cutting speeds of the order of 325 feet per minute.

Similar effects were found in the heavy-duty tests as is shown in Figure 21. With the exception of steel, CC (Table 2) the cutting speed increased with the proportion of cobalt, but the increase between 3.5 and 12 per cent was not nearly as large as that between 0 and 3.5 per cent. With 3.5 per cent cobalt, there was a somewhat larger percentage gain in the heavy-duty tests than in the tests under shallow cuts and fine feeds.

Superior performance of the steel with 3.5 per cent cobalt was probably due to the fact that it was hardened from a temperature

${ }^{28}$ See footnote 19, p. 855 . Also F. Repatz, Die Leistung von Schnellstahlmessern und ihre Prüfung. Stahl u. Eisen, 49, p. 1109; 1926.

${ }^{28} \mathrm{~L}$. Guillet, Les aciers à outils a coupe rapide refermant du cobalt. Rev. de Met., 22, p. 88; 1928.

${ }^{30}$ F. C. A. F. Lantsberry, High-Speed Steels, Trans. Am. Soc. Steel Treating, 11, p. 711; 1927.

${ }^{31}$ A. S. Martin, Machining Manganese Steel on a Commercial Basis, Iron Trade Rev., 82, p. 564; 1928. 
50 to $75^{\circ} \mathrm{F}$. higher than that used in hardening the 8 and 12 per cent cobalt steels and the steel without cobalt. Results reported by Oertel and Polzguter, ${ }^{32}$ which have been included in Figure 21, indicate that cobalt additions around 3 per cent do not result in greatly increased cutting speeds when the steels are all hardened from the same temperatures.

There is little doubt that cobalt by itself tends to increase the cutting speed, but the maximum benefits are derived only with modified heat treatments. The results given in Figure 21 show further that cobalt additions are of somewhat greater benefit for heavy duty than for tools used with shallow cuts and fine feeds. But in rough turning nickel steels, such as were used in the described

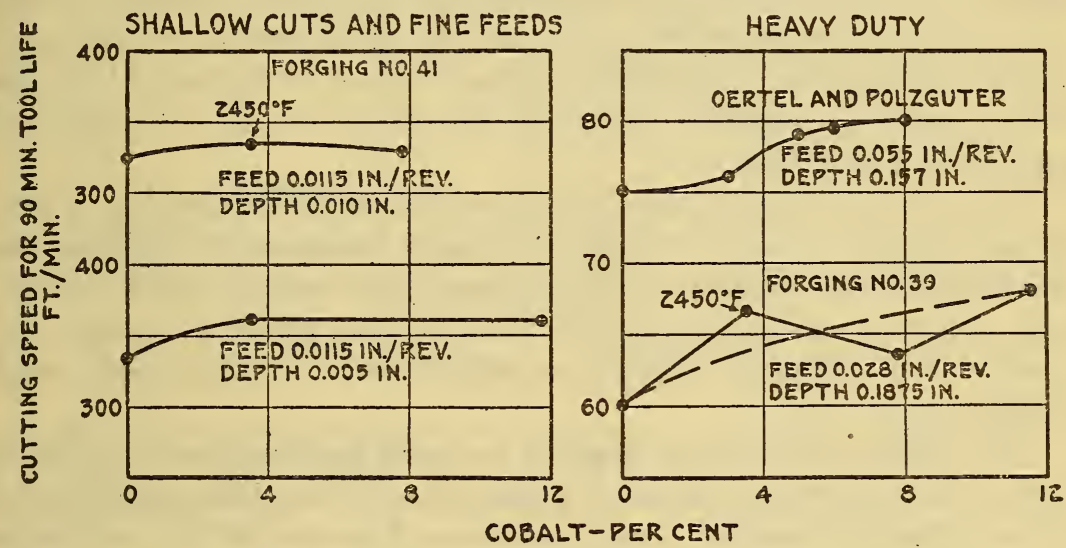

FIgUre 21.-Effect of cobalt on the cutting speed of high-speed steel tools when taking shallow cuts and under heavy duty

Compositions of the tools are given in Table 2; properties of the forgings are given in Table 3 . Unless otherwise indicated, the tools were oil quenched from $2,375^{\circ}$ to $2,400^{\circ} \mathrm{F}$. and tempered at $1,050^{\circ}$ to $1,100^{\circ} \mathrm{F}$. All tests were made dry. The source of the data credited to Oertel and Polzguter is given in footnote $21, \mathrm{p} .859$ of the text.

experiments, increase in cobalt above about 5 per cent did not produce improvements commensurate with those resulting from additions of 3.5 to 5 per cent cobalt and high hardening temperatures.

\section{STEELS WITH ARSENIC, ANTIMONY, COPPER, OR TIN}

As a general rule, little attention is paid by consumers to the presence of copper, tin, arsenic, or antimony in commercial high-speed tool steels, although it is known that all of these elements will be found occasionally, and some of them frequently, in the American products. Some may be introduced from scrap which forms part of the original charge, or, as is sometimes the case with tin and arsenic, small proportions may be present as impurities in the ferro-alloys used in manufac-

${ }^{32}$ See footnote 21, p. 859. 
ture. In any case, arsenic, antimony, copper, and tin are generally believed to exert harmful effects upon high-speed tool steels.

According to Sandberg, ${ }^{33}$ copper, tin, arsenic, bismuth, and antimony are ordinarily present in small amounts in high-speed steels but have no ill effects unless they are present, individually, in excess of 0.02 per cent. McKenna ${ }^{34}$ states that the detrimental effects of tin, copper, and arsenic are not generally realized by the trade, and that small quantities of these impurities are exceedingly harmful. The character of the data upon which these statements are based is not known, and technical literature does not contain information on the magnitude of the effects produced by different proportions of the metals in question or whether they are equally deleterious for all classes of serivce. The need for further information is shown by inquiries which have been received by the bureau from time to time from consumers and producers and by the fact that the American Society for Testing Materials has a committee appointed to study the effects of tin and arsenic in high-speed tool steels.

A large part of the results here described were discussed in a preliminary report, ${ }^{35}$ but since a much broader background is now available for the interpretation of the tool tests under shallow cuts and fine feeds reference will again be made briefly to the effects of copper, tin, arsenic, and antimony upon the performance of high-speed steel turning tools.

The results of tests under shallow cuts and fine feeds and also those under heavy duty are grouped in Figure 22 and show that the influence of the different elements considered was a function of the conditions to which the tools were subjected.

With shallow cuts, each of the four elements-copper, tin, arsenic, and antimony-adversely affected the tool performance and in each case the magnitude of the decrease in tool life or the cutting speed became greater as the proportion of the impurity was increased. Copper was the least harmful; next in order came tin, while arsenic and antimony were the most objectionable.

The effects of the several elements upon the performance of roughing tools did not necessarily correspond to those observed with shallow cuts. The arsenic addition lowered the cutting speed, but the addition of 0.4 per cent antimony or 0.5 per cent or less of tin had no measurable effect. Higher proportions of tin lowered the cutting speeds, but the high-speed steels containing copper showed slightly better performance than the corresponding steels without copper.

\footnotetext{
${ }^{33}$ R. M. Sandberg, Progress in Hardening High-speed Steel, Fuels and Furnaces (F. C. Andresen and Associates, Pittsburgh, Pa.), 6, No. 1, p. 53; January, 1928.

${ }^{34}$ R. C. McKenna, Practical Information Concerning High-Speed Steel, Am. Machinist, 51, p. $989 ; 1919$.

${ }^{3 s}$ H. J. French and T. G. Digges, Effects of Antimony, Arsenic, Copper, and Tin in High-Speed Tool Steel, Trans, Am. Soc. Steel Treat., 13, p. 919; 1928.
} 
This effect was confirmed in two independent sets of tests as is shown in Figure 22.

The described results seem to justify the conclusions that copper has the least harmful effects of the four metals here considered upon the cutting speeds of high-speed steel turning tools; that small proportions of tin, below about 0.1 per cent, do not seriously affect the cutting speeds; but that arsenic and antimony should be kept out of high-speed tool steels to be used under varied conditions of service.

In general, the presence of small proportions of these different elements is much less important for tools to be used only in rough turning than when shallow cuts are considered. This is, perhaps, to

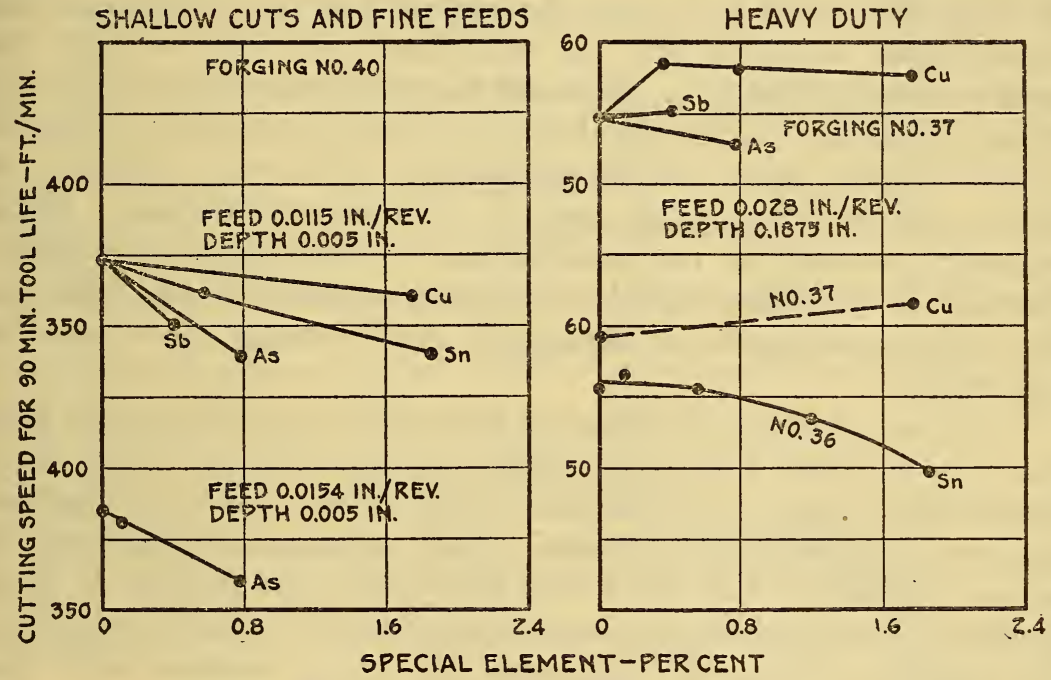

FIGURE 22.-Effects of arsenic, antimony, copper, and tin on the cutting speed of high-speed steel tools under shallow cuts and under heavy duty

Compositions of the tools and their heat treatment are given in Table 2; properties of the forgings are given in Table 3. All tests were made dry.

be expected, since any tendency to promote crumbling of the cutting edge, which would be observed with shallow cuts when the frictional temperatures are low, would probably be masked by the softening of the steel at the high operating temperatures encountered in rough turning.

In addition to lathe tool tests, Rockwell hardness tests were made on samples quenched and tempered in various ways, and with few exceptions the hardness of the steels containing the different impurities was practically the same as that of the steels without these impurities similarly treated. The addition of 0.15 per cent tin increased the hardness of the steel as oil-quenched from $2,000^{\circ} \mathrm{F}$.; when the proportion of tin was raised to 0.57 per cent, there was an additional 
increase in the hardness, but with further increase in tin the hardness decreased slightly.

The additions of antimony, arsenic, copper, or tin produced no outstanding changes in the structures of the high-speed steel tools, although there was a tendency for increase in grain size with increase in copper content and a decrease in grain size as the proportions of antimony, arsenic, or tin were increased. Typical structures are shown in a preliminary report referred to in footnote 35 (p. 872) of the text.

\section{STEELS WITH ALUMINUM}

The principal reason for considering the effects of aluminum upon the high-speed steel tools was the presence of this element in the ferrotitanium available and its consequent introduction into the steels containing titanium. Without knowing something of the magnitude of the effects of the aluminum, the trend of the effects produced by the titanium could not be established. However, aluminum is widely used as a corrective agent in steel-making practice. While ordinarily avoided in the manufacture of high-speed tool steels, aluminum is sometimes added in the ladles or molds, and its influence upon the performance of high-speed steel cutting tools becomes important.

As far as is known, the effect of aluminum upon high-speed steel tools has not been made the subject of investigations which have reached the stage of publication, but generally useful information has been gathered in other fields. Small additions of aluminum to molten iron alloys will react with any iron oxide present to form alumina, a part of which may be eliminated under suitable conditions. With larger additions of aluminum, the same reactions can take place, but the larger part of the aluminum is dissolved in the steel as aluminum.

According to Guillet, ${ }^{36}$ the presence of aluminum in iron-carbon alloys-

has the effect of preventing the pearlite from assuming its ordinary forms; it is, in a manner, contorted, and forms little nodules which are the more easily colored by picric acid and the more closely resemble troostite in proportion as the percentage of aluminum increases. With a very high percentage of aluminum it is even possible to have free cementite formed in a hypoeutectoid steel. ***

Quenching transforms only the nodules of the preexisting pearlite, giving place to martensite, generally encircled around its edges by troostite. The result is always the same, no matter what the temperature of quenching. It must, therefore, be recognized that the iron-aluminum solution is incapable of dissolving carbon.

From the mechanical point of view quenching has no effect except when the pearlite exhibits its ordinary structure; that is to say, so long as the aluminum is below 3 per cent.

${ }^{36}$ L. Guillet, Quarternary Steels, J., Iron and Steel Inst., No. 2, p. 1; 1906. 
Aluminum was found to increase the tensile strength and decrease the elongation and reduction of area, slowly at first but rapidly when the aluminum was raised above 3 or 4 per cent; the brittleness also increased rapidly.

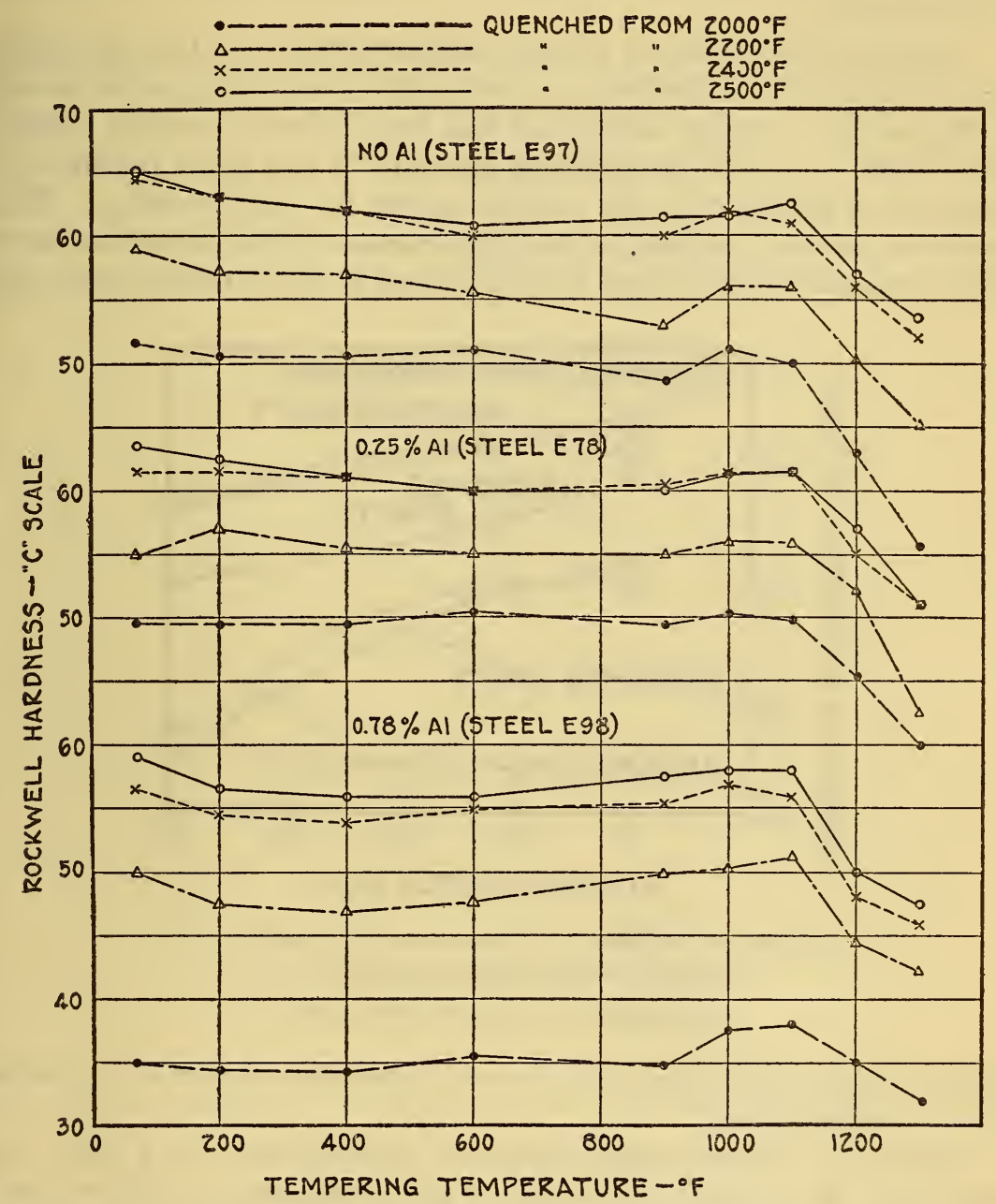

FIGURE 23.-Hardness of high-speed steels containing different proportions of aluminum when subjected to different heat treatments

Compositions of the steels are given in Table 2 .

The effects produced in the high-speed steels by aluminum were similar in some respects to those described by Guillet for carbon steels but were observed with smaller additions of aluminum. As is shown in Figures 23 and 24, the hardness of the steels containing aluminum decreased, after either quenching or quenching followed by tempering, as the proportion of aluminum was raised from prac$77886^{\circ}-29-4$ 
tically 0 to 0.8 per cent. However, the numerical values of the hardness obtained were quite largely dependent upon the quenching temperature. In effect, the entire set of hardness curves (fig. 23) was shifted to lower values of hardness as the proportion of aluminum was increased.

Aluminum also adversely affected the performance of the high-speed steel tools both with shallow cuts and under heavy duty, as is shown in Figure 25. In fact, aluminum was one of the few metals considered which, in small proportions around 0.3 per cent, produced a measurable decrease in the cutting speeds in rough turning. This decrease became greater as the proportions of the aluminum were increased, and with 0.8 per cent the drop in the cutting speed was

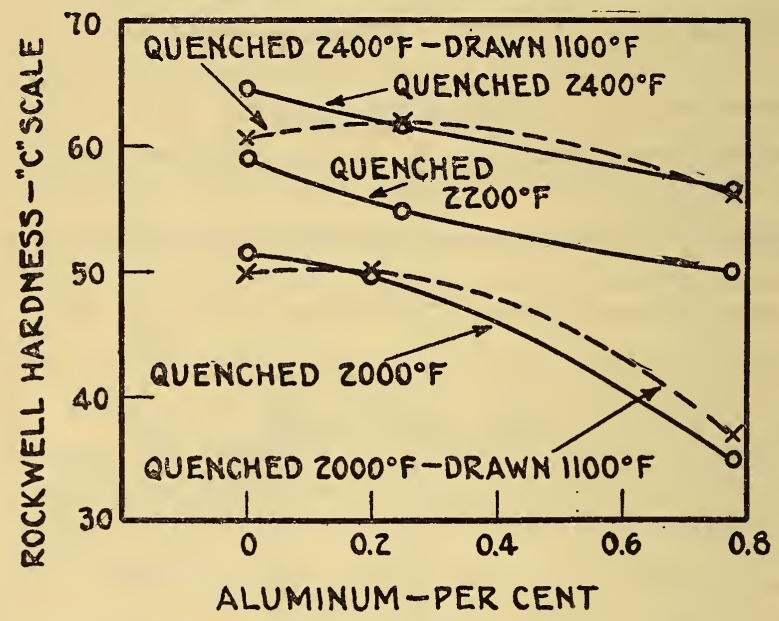

FIgURE 24.- Effect of aluminum on the hardness of quenched and tempered high-speed steel

Compositions of the steels are given in Table 2.

greater than that produced by equal proportions of any of the other elements considered.

Deleterious effects were observed with shallow cuts and fine feeds, but in this case the effects of the aluminum were about on a par with those of arsenic and antimony and more marked than those of either tin or copper.

The reasons for decrease in the hardness and the tool performance with increase in the aluminum have not been established, but the structures of the steels throw some light on this subject.

The structure of one of the quenched and untempered high-speed steel tools containing about 0.8 per cent aluminum was, perhaps, the most illuminating since it showed characteristics somewhat similar to those described by Guillet for carbon steels. As is shown in Figure 26, $c$, a large number of undissolved particles were found at the aus- 


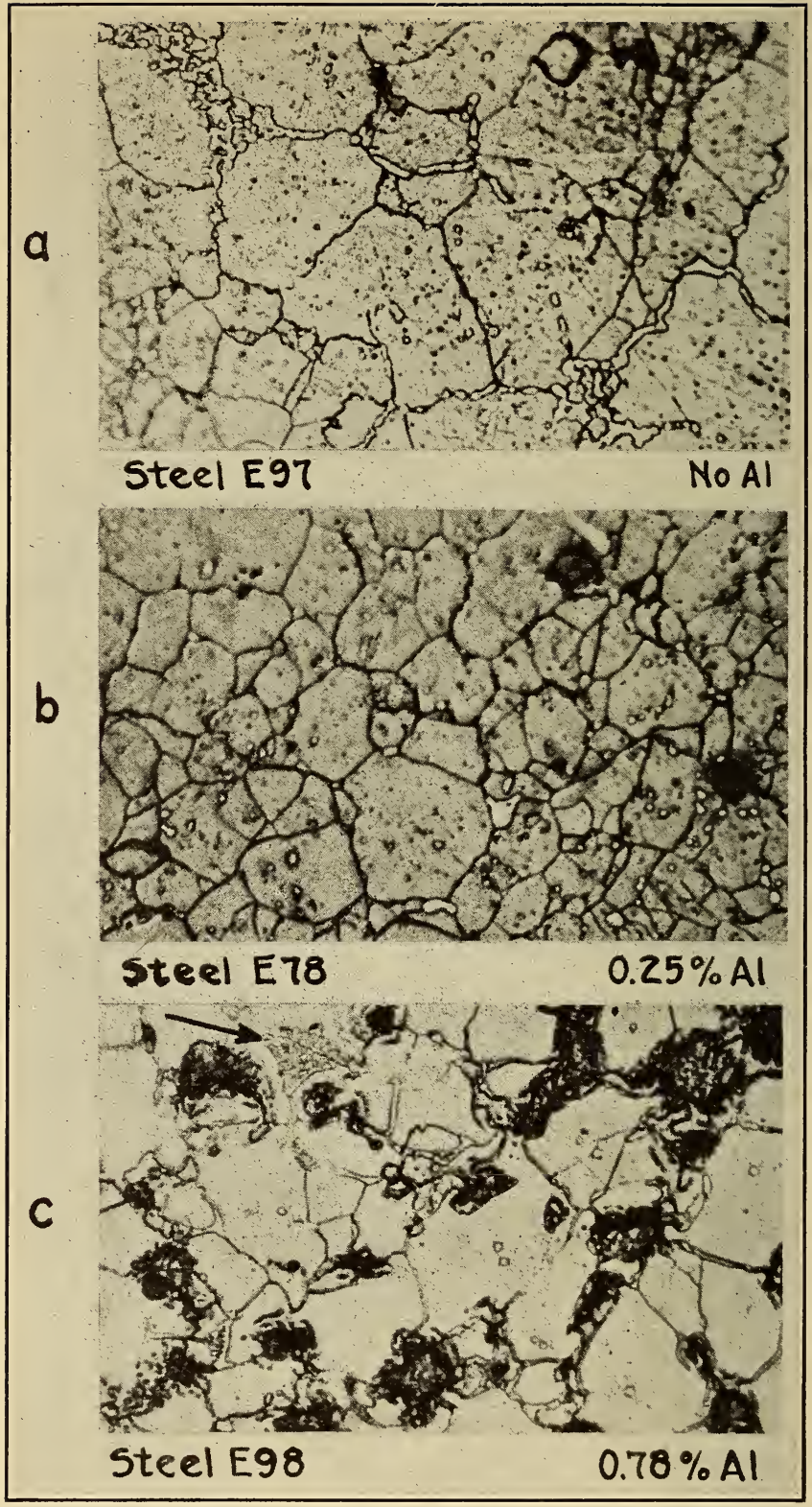

FIGURE 26.-Structures of hardened high-speed steels containing different proportions of aluminum. $\times 750$

Samples oil quenched from $2,350^{\circ} \mathrm{F}$. not tempered; etched with 2 per cent $\mathrm{HNO}_{3}$ in alcohol. 
tenite grain boundaries, and the outer areas of the zones of concentration of these undissolved constituents were encircled by more darkly etched areas, perhaps representing a structure comparable to troostite.

Such a large number of undissolved aggregates are not ordinarily found in the customary high-speed steels quenched from comparable temperatures (fig. 26, $a$ ) and must represent a decreased dissolving power of the austenite (matrix) for one or more of the elements, carbon, chromium, tungsten, and vanadium which constitute the key elements in the steels under consideration.

In other words, the 0.8 per cent aluminum has decreased the solubility in the austenite of one or more of the elements mentioned and through the resultant precipitation has lowered the hardness and other useful properties of the steel. Along with this precipitation is evidence

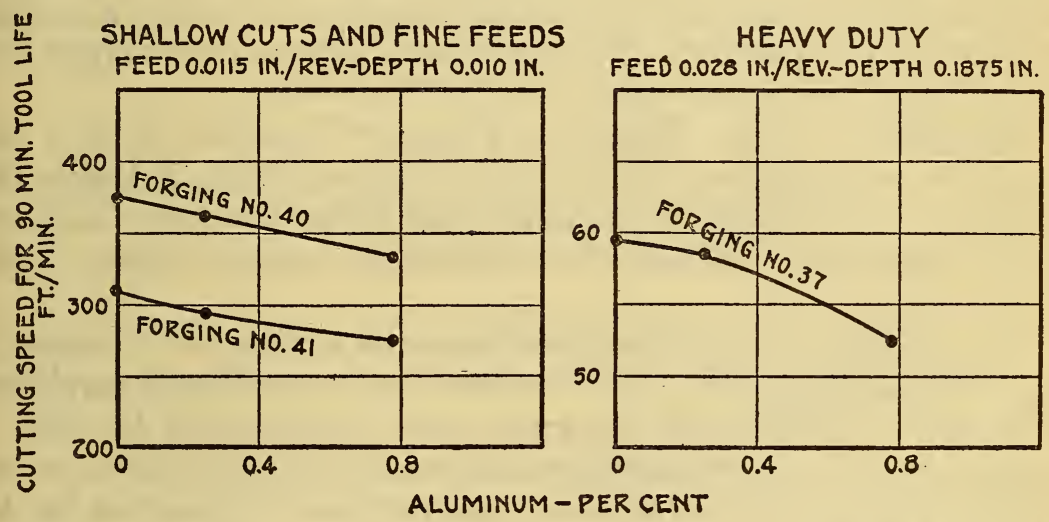

FIGURE 25.-Effect of aluminum on the cutting speed of high-speed steel tools under shallow cuts and under heavy duty

Compositions of the tools and their heat treatment are given in Table 2; properties of the forgings are given in Table 3 . All tests were made dry.

of the formation of low melting point eutectics (see arrow, fig. 26, c) which are only evident in the customary high-speed steels as cast or when overheated. Such partial melting is an added source of danger in high-speed steel tools and probably contributed in a measurable degree to the poor performance described.

The exact nature of the compounds and the low melting eutectics has not been determined, but the observed structures, hardness, tool performance, and poor hot working properties previously described clearly show the importance of guarding against the introduction of more than very small proportions of aluminum in high-speed tool steels.

\section{STEELS WITH TITANIUM}

So far titanium has not shown much promise as an alloying element in steels and is now mainly used as one of a number of corrective agents (scavengers) in steel making, and in this latter field it seems 
to combine most readily with oxygen and nitrogen. The present situation regarding the applications and effects of titanium in steels is about as described by Gillett and Mack, ${ }^{37}$ as follows:

The alloying effect of titanium seems to be negligible, its only use being as a scavenger to remove oxygen and, perhaps, nitrogen. It seems to reduce segregation of carbon and of impurities. Some of the data cited by the advocates of titanium ${ }^{38}$ to show its value as a scavenger lie well within the range of results obtained without it, and the proof of its usefulness is seldom clear-cut. A thorough study ${ }^{30}$ of the deoxidation of rail steel by titanium and by silicon has been made by the Bureau of Standards. This shows that the action of titanium in restraining segregation is definitely shown only in the top of the ingot; that the average mechnaical properties of the steel are not noticeably altered by titanium; and that the claim that the oxidation products of titanium do not remain in the steel is not in accord with the facts.

Stoughton ${ }^{40}$ believes that titanium causes occluded oxidized materials which would cause inclusions to be more readily separated from the melt, and Giolitti ${ }^{41}$ mentions the use of titanium and vanadium as having specific action in developing fine grain on heat treatment. Titanium probably serves a useful purpose as a scavenger, but it has no place in a list of true alloying elements.

According to recent studies by Tamaru, ${ }^{42}$ titanium up to 4 per cent is in solid solution in the ferrite of carbon steels; it lowers the solubility of carbon in the austenite and accelerates graphitization. As the titanium in the steel was increased the carbon content of the eutectic decreased.

True alloying of any appreciable amounts of titanium in steels is not readily accomplished. Ferrocarbon titanium ordinarily employed in titanium treated steels does not serve satisfactorily for such a purpose under ordinary manufacturing conditions, since the titanium carbides present in the ferro-alloy are not readily dissolved in the steel. Even with so-called carbon-free ferrotitanium favorable conditions were found to be necessary for a reasonably good recovery of the added titanium.

In the five high-speed steels containing titanium, which are listed in Table 2, the titanium was added to and did not replace any portion of the elements ordinarily present. Three of these steels contained about the customary proportions of carbon, while two others were much higher in carbon content.

With 0.6 to 0.8 per cent carbon and 0.4 per cent or less of titanium the hardness of the steels increased generally with increase in the quenching temperature in much the same manner as corresponding

${ }^{37}$ H. W. Gillett and E. L. Mack, Molybdenum, Cerium, and Related Alloy Steels, Chemical Catalog Co. (Inc.), New York; 1925.

as Titanium Alloy Manufacturing Co., Titanium, Its Effects on Steel. Booklet; 1919. Ferro-Carbon Titanium in Steel Making. Booklet; 1916.

${ }^{39}$ G. K. Burgess and G. W. Quick, A Comparison of the Deoxidation Effects of Titanium and Silicon on the Properties of Rail Steel, B. S. Tech. Paper No. 241; 1923.

40 B. Stoughton, The Metallurgy of Iron and Steel, McGraw-Hill Book Co. (Inc.), p. 206; 1923.

11 F. Giolitti, Steel Castings of High Strength and Toughness, Chem. Met. Eng., 24, p. 161; 1921.

$22 \mathrm{~K}$. Tamaru, On the Equilibrium Diagram of the System Iron-Carbon-Titanium, Sci. Repts. Tohoku Imp. Univ., Series I, 15, No. 1, p. 25; March, 1925. 


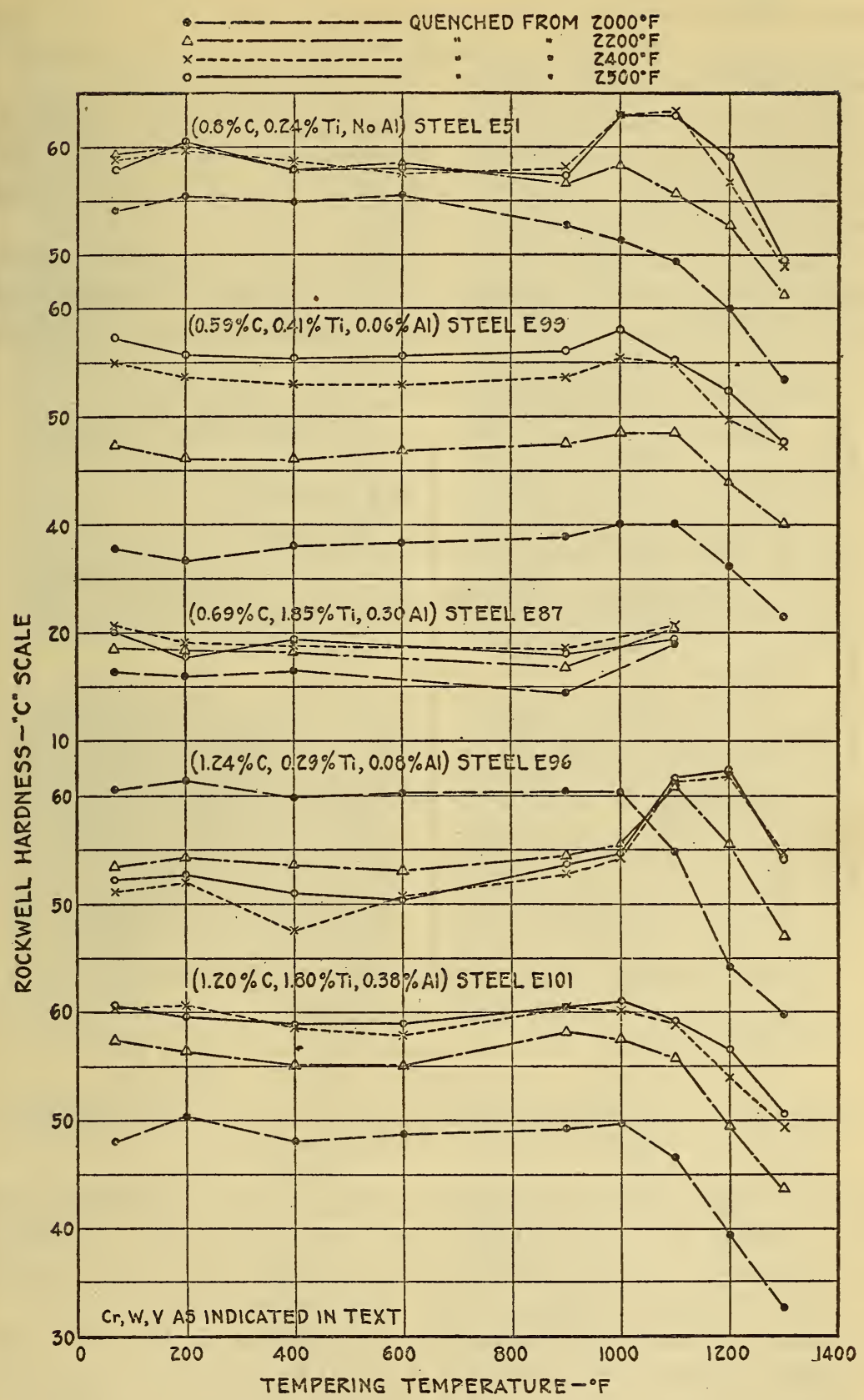

FIGURE 27.-Hardness of high-speed steels containing different proportions of titanium (and aluminum) when subjected to different heat treaiments

Complete chemical compositions are reported in Table 2. 
steels without titanium, but the effect of quenching temperature was more marked in the steel containing 0.4 per cent titanium than in that with 0.24 per cent. (Fig. 27.)

With any one quenching temperature the hardness of the untempered samples decreased as the titanium was increased, and with 1.85 per cent titanium the steel would not harden when quenched from any temperature between 2,000 and $2,500^{\circ} \mathrm{F}$.

When the carbon was raised from around 0.7 to 1.2 per cent and the titanium kept at around 1.8 per cent, the steel again hardened upon quenching, the hardness being dependent upon the quenching tem-

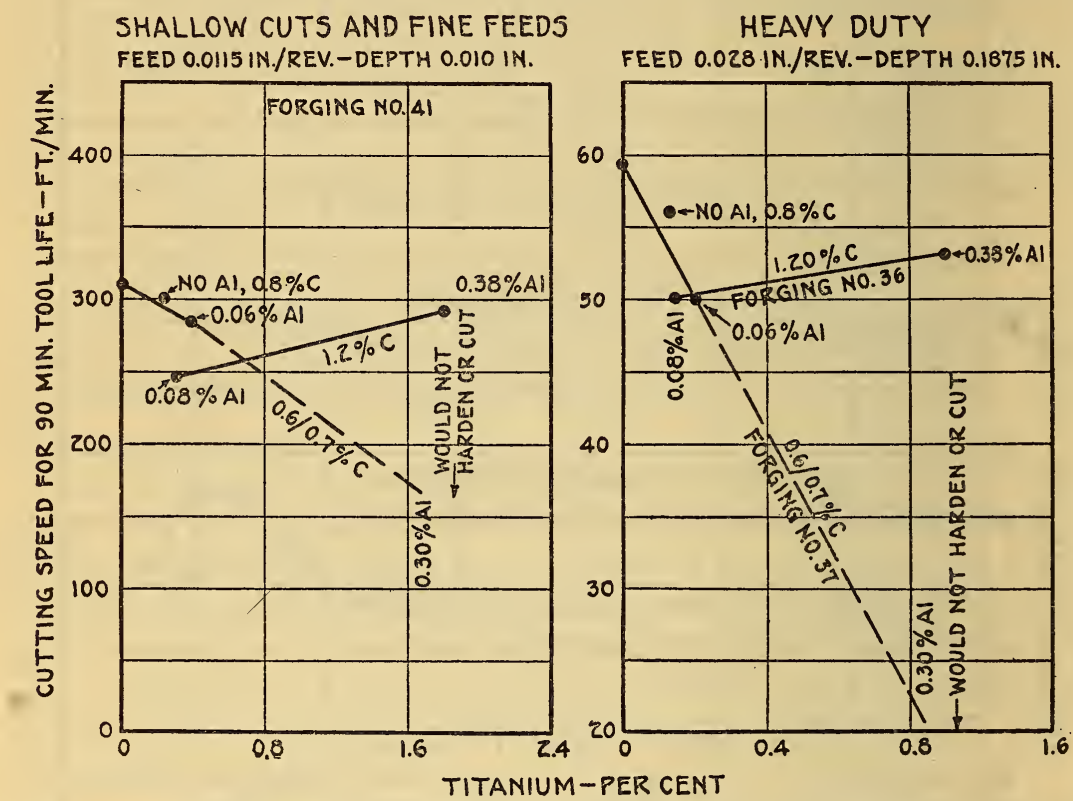

FigURE 28.-Effect of titanium (plus aluminum) on the cutting speed of highspeed steel tools under shallow cuts and under heavy duty

Compositions of the tools and their heat treatment are given in Table 2; properties of the forgings are given in Table 3 . All tests were made dry.

perature used. However, with comparable carbon (1.2 per cent) and less titanium ( 0.29 per cent) the hardness on quenching decreased with increase in the quenching temperature, probably indicating the retention of more austenite. When first quenched from $2,000^{\circ} \mathrm{F}$., samples of this latter steel showed no rehardening on tempering (fig. 27) as did the samples quenched from 2,300 to $2,500^{\circ} \mathrm{F}$.

These results are all shown graphically in Figure 27 and indicate that the hardness of the quenched steels was not solely a function of the proportion of titanium but depended upon the relative amounts of titanium and carbon present. 


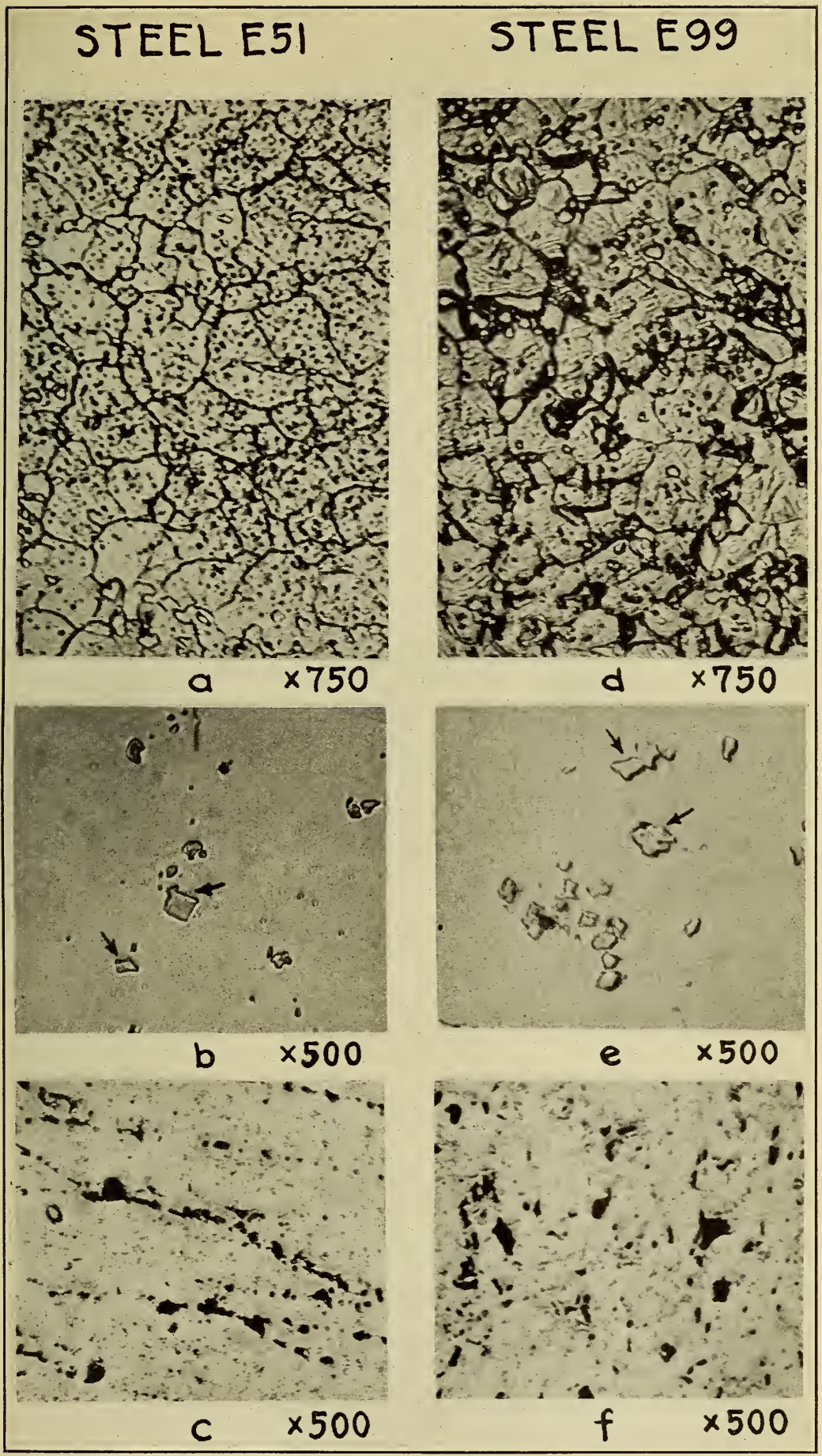

FIGURE 29.-Structures of hardened high-speed steels containing different proportions of titanium (and aluminum)

Compositions of the steels are given in Table 2; $(a)$ and $(d)$, etched with 5 per cent $\mathrm{HNO}_{3}$ in alcohol; $(b)$ and $(e)$, unetched; $(c)$ and $(f)$, etched in boiling solution of $\mathrm{KMnO}_{4}(4 \mathrm{~g}), \mathrm{NaOH}(4 \mathrm{~g})$ in $100 \mathrm{ml}$ $\mathrm{H}_{2} \mathrm{O}$. Samples first oil quenched from $2,350^{\circ} \mathrm{F}$. 


\section{STEEL E 87}
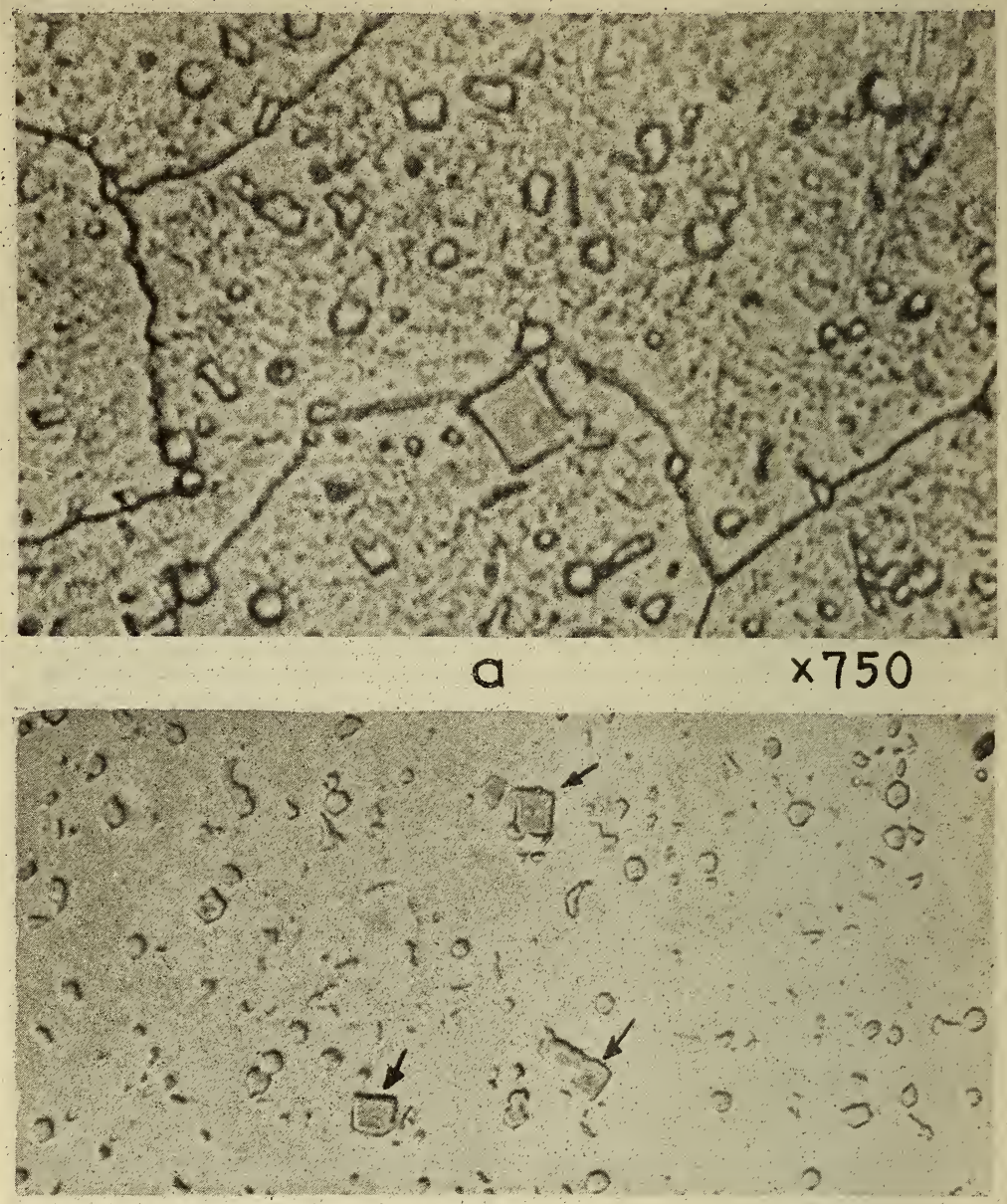

b $\quad \times 500$

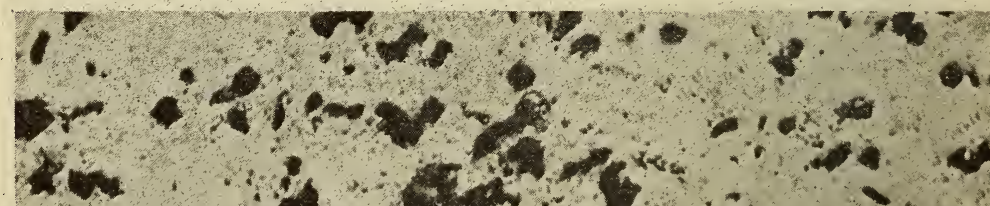

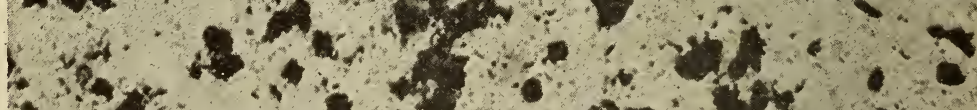

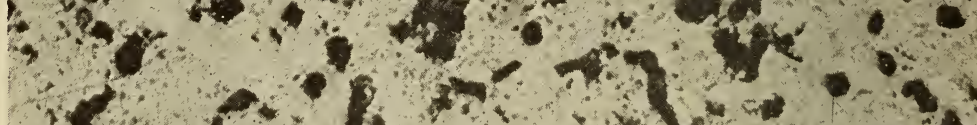

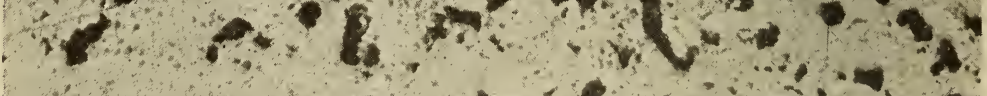

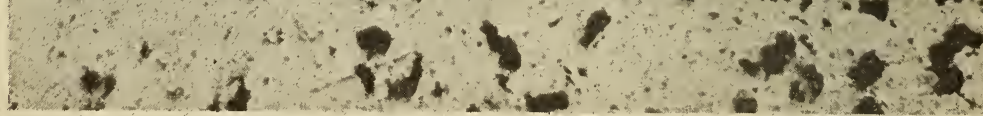

C $\times 500$

FIGURE 30.-Structure of one of the high-speed steels containing titanium as oil quenched from $2,350^{\circ} \mathrm{F}$.

Chemical composition is given in Table $2 ;(a)$, etched with 5 per cent $\mathrm{HNO}_{3}$ in alcohol; (b), unetched; (c), etched in boiling solution of $\mathrm{KMnO}_{4}(4 \mathrm{~g}), \mathrm{NaOH}(4 \mathrm{~g})$ in $100 \mathrm{ml} \mathrm{H} \mathrm{H}_{2} \mathrm{O}$. 
The performance of the high-speed steel tools containing titanium and the customary proportions of carbon was disappointing. As is shown in Figure 28, the cutting speeds decreased both with shallow cuts and under heavy duty as the titanium was increased. The steel with about 0.7 per cent carbon and 1.8 per cent titanium which would not harden also failed to cut at the speeds used in the experiments. Tests at lower speeds might have resulted in a measurable duration of cut, but for all practical purposes the steel referred to did not have cutting properties comparable to high-speed tool steels.

When the carbon in the steels was raised to 1.2 per cent, increase in titanium from about 0.3 to 1.8 per cent resulted in improved performance both under shallow cuts and under heavy duty. However, the performance of tools of steel E96 may not be characteristic of the reported composition for reasons later explained, but in no case did the steels containing titanium give as good performance as the highspeed steels of customary composition without titanium.

It should be noted that increase in the proportions of titanium resulted in an increase in the proportions of aluminum in the high-speed steels. Aluminum has already been shown to have a highly deleterious effect upon the performance of high-speed steel tools, and therefore the changes in the cutting speeds shown in Figure 28 can not be ascribed entirely to titanium.

The reductions in the cutting speeds produced by the different proportions of aluminum found in the titanium high-speed steels can be estimated from data given in Figure 25, and if these reductions in the cutting speed are subtracted from those produced by titanium plus aluminum given in Figure 28 the effects of titanium alone can be estimated. These calculations are incorporated in Table 15 and show that appreciable proportions of titanium exerted a highly deleterious effect upon the cutting speeds, both with shallow cuts and under heavy duty except in the case of the two high-carbon steels.

While the effects of titanium alone, as given in Table 15, are smaller than those shown in Figure 28, the estimated corrections for aluminum did not change the general trends shown in Figure 28.

All of the titanium steels contained characteristic pink or orange colored titanium inclusions, probably nitrides or cyanonitrides. (Figs. 29(b), 29(c), 30(b), 31(b), and 31(c).) The structure shown in Figure $30(a)$ for steel E87, which could not be hardened appreciably by heat treatment, is probably a solid solution of alpha iron, titanium, and aluminum plus a large number of carbides, tungstides, titanium inclusions and possibly other undissolved particles. 
TABLE 15.-Effects of titanium in high-speed tool steels estimated from data given in Figures 25 and 28

\begin{tabular}{|c|c|c|c|c|c|c|c|c|c|}
\hline \multirow{3}{*}{ Steel No. } & \multirow{2}{*}{\multicolumn{3}{|c|}{$\begin{array}{l}\text { Partial chemical } \\
\text { composition } 1\end{array}$}} & \multicolumn{6}{|c|}{ Reduction in cutting speed ${ }^{2}$ produced by- } \\
\hline & & & & \multicolumn{2}{|c|}{$\begin{array}{c}\mathrm{Ti}+\mathrm{Al} \\
\text { (from fig. 28) }\end{array}$} & \multicolumn{2}{|c|}{$\begin{array}{l}\text { Equivalent Al } \\
\text { (from fig. 25) }\end{array}$} & \multicolumn{2}{|c|}{$\mathrm{l}(\mathrm{Ti}+\mathrm{Al})-\mathrm{Al}=\mathrm{T} \mathrm{i}]$} \\
\hline & $\mathrm{C}$ & $\mathrm{Ti}$ & Al & $\begin{array}{c}\text { Shallow } \\
\text { cuts }\end{array}$ & $\begin{array}{c}\text { Heary } \\
\text { duty }\end{array}$ & $\begin{array}{c}\text { Shallow } \\
\text { cuts }\end{array}$ & $\begin{array}{l}\text { Heavy } \\
\text { duty }\end{array}$ & $\begin{array}{c}\text { Shallow } \\
\text { cuts }\end{array}$ & $\begin{array}{l}\text { Heavy } \\
\text { duty }\end{array}$ \\
\hline $\begin{array}{l}\text { E51 } \\
\text { E99- } \\
\text { E87 } \\
\text { E96 } \\
\text { E101 }\end{array}$ & $\begin{array}{c}\text { Per } \\
\text { cent } \\
0.80 \\
.59 \\
.69 \\
1.24 \\
1.20\end{array}$ & $\begin{array}{c}\text { Per } \\
\text { cent } \\
0.24 \\
.41 \\
1.85 \\
1.29 \\
1.80\end{array}$ & \begin{tabular}{c}
$\begin{array}{c}\text { Per } \\
\text { cent }\end{array}$ \\
\hdashline 0.06 \\
.30 \\
.08 \\
.38
\end{tabular} & $\begin{array}{r}6 \\
27 \\
310 \\
63 \\
18\end{array}$ & $\begin{array}{r}-2 \\
10 \\
60 \\
8 \\
4\end{array}$ & $\begin{array}{r}0 \\
3 \\
15 \\
4 \\
20\end{array}$ & $\begin{array}{l}0.5 \\
1.5 \\
2^{5}\end{array}$ & $\begin{array}{r}6 \\
24 \\
295 \\
59 \\
-2\end{array}$ & $\begin{array}{r}-2 \\
9.5 \\
58.5 \\
7.5 \\
2\end{array}$ \\
\hline
\end{tabular}

1 For complete composition and heat treatment of the tools see Table $\hat{z}$.

2 For 90-minute tool life under the conditions indicated in Figures 25 and 28.

3 Would not cut.

As the titanium content of the steels was increased, the number of undissolved particles also increased, as is shown in Figures $29(c)$, $29(f)$, and $30(c)$ for the steels containing 0.6 to 0.8 per cent carbon and in Figures $31(c)$ and $31(f)$ for the steels containing 1.2 per cent carbon. The darkened patches between the grains in the etched sample of steel E101, shown in Figure $31(d)$, are probably due to the aluminum present and resemble features shown in Figure $26(c)$ for high-speed steel containing about 0.8 per cent aluminum without titanium.

The structures shown in Figures 29, 30, and 31 indicate that titanium decreases the dissolving capacity of the austenite for tbe elements which ordinarily are responsible for the characteristic properties of high-speed steels through their solution at bigh hardening temperatures.

However, titanium is known to form carbides very readily, and in the presence of varying amounts of carbon different effects may be produced. In the presence of high carbon the titanium will probably first form carbides, and any titanium remaining may then go directly into solution in the iron. This, of course, assumes that there is an excess of titanium available. In the high-speed steel containing 1.2 per cent carbon and 1.8 per cent titanium (E101) the high carbon restored the ability of the steel to harden upon quenching and gave a tool performance nearly equal to that of highspeed steels of customary composition. However, these benefits were probably not derived from any useful alloying effects of titanium, but probably were produced by putting the titanium in a less harmful condition, (carbides instead of solution in the iron), so that the chromium, tungsten, and vanadium could act in their normal manner. 
The low cutting speed of the high carbon high-speed steel tools containing only 0.29 per cent titanium can not be explained at this time but was probably due either to the high carbon in the absence of appreciable amounts of titanium or to peculiarities of the particular heat from which the tools were prepared. The recovery of titanium in this steel was low, its working properties were poor (fig. 17), and, as has already been pointed out, it probably had areas of segregation.

Titanium may, therefore, be considered to be an undesirable addition to the customary high-speed steel compositions since it decreases the dissolving power of the austenite for those compounds which must be brought into solution to produce the properties characteristic of ordinary high-speed steels. Its interference is lessened, probably through the formation of less harmful carbides (instead of solution as titanium in the austenite), by increasing the carbon content of the steel. The amount of carbon required will probably vary with the titanium content and was in the neighborhood of 1.2 per cent carbon for 1.8 per cent titanium.

\section{STEELS WITH TANTALUM}

During the year 1924, while a study was being made of the chemical composition of heavy-duty lathe tools, rumors were received that promising results were being obtained in England with high-speed steels containing tantalum. While no details were available and no performance records could be obtained at that time, a number of experimental steels were made containing different proportions of tantalum and tested in comparison with high-speed steels of customary composition. The tests were made with deep cuts and coarse feeds, but more recently the same steels were tested under shallow cuts and fine feeds, and a summary of all of the results is now given for the first time.

A report of the preliminary experiments was made in $1925,{ }^{43}$ and discussion of the results brought to light some further information on tantalum in tool steels. One British metallurgist reported ${ }^{44}$ that he had made a series of steels presumably with 0.6 per cent carbon, some chromium, and from 1 to 6 per cent tantalum. The steel with 6 per cent tantalum showed properties somewhat similar to the "red hardness" of ordinary high-speed tool steels. In further work, a steel containing about 6 per cent tungsten and 6 per cent tantalum was said to have had about 75 per cent cutting "efficiency" in comparison with the usual tungsten steels.

43 See footnote 24, p. 863.

" Private communication. 
J. P. Gill ${ }^{45}$ reported that during the years $1920-21$ the firm with which he was associated had spent some time in a study of tantalum in high-speed tool steels. He stated that-

this company probably made up as many as 100 different composition high-speed steels containing tantalum, tungsten, chromium, vanadium, and cobalt. Some of the heats made were as large as 7,000 pounds. Lathe tests were run, many physical tests were made, and it was found that several of the steels compared favorably with some of the regular high-speed steels in commercial use to-day, but these steels were no better than the same steels without tantalum. We did not find any steels that were better than the regular high-speed steels. Many things were learned in regard to the use of tantalum. The manner of introducing the tantalum into the steel and the form of the tantalum in the alloy apparently affected the results. The tantalum steels were found to be very dirty and full of oxides even when melted under the best of conditions. Even in view of this fact, however, the tantalum steels seemed to be tougher than the standard types of high-speed steel.

Studies of tantalum in carbon steels have been reported by Guillet, ${ }^{46}$ Portevin, ${ }^{47}$ and others, ${ }^{48}$ but these investigations do not throw much light upon the subject under discussion. Apparently tantalum up to at least 8 per cent in iron-carbon alloys is in solution in the ferrite, and with carbon up to 0.6 per cent the steels are pearlitic on normal slow cooling and martensitic after quenching. The effects of tantalum on steels which are suitable for cutting tools are not generally known, although a few patents, typified by that granted to F. T. McCurdy, ${ }^{49}$ indicate that tantalum may be useful in this field.

The seven steels containing tantalum that were tested fall into three classes. Steel E23 (Table 2) is a chromium-tantalum steel similar to one previously mentioned as having been made experimentally in England. Steel E42 is a chromium-tungsten-vanadium steel in which about 6 per cent of tungsten was replaced by 6 per cent of tantalum. The steels E43, E44, and E16 contained the usual proportions of special elements except that the vanadium was replaced by different proportions of tantalum. The recults obtained with these three steels suggested that increased carbon might improve the properties, and accordingly two similar steels were made, E45 and E100 (Table 2), with 0.9 and 1.4 per cent carbon, respectively.

A study was first made of the hardness of the different steels after different heat treatments and developed some interesting characteristics. There was no evidence of rehardening on tempering of the chromium-tantalum steel E23, as is shown in Figure 32.

45 Discussion of the report referred to in footnote 24, p. 863.

46 L. Guillet, Sur les proprietes et la constitution des aciers au tantale, Comptes Rendus, 145, p. 327; 1907.

${ }^{47}$ A. M. Portevin, Contribution to the Study of the Special Ternary Steels, Carnegie Scholarship Memoirs, 1, p. 230; 1919.

${ }^{48}$ An Investigation of Tantalum Steels (for G. G. Blackwell Sons \& Co. (Ltd.), Liverpool, England). The Iron \& Coal Trades Rev., 78, p. 933; 1909.

40 United States patent 1449338, Mar. 20, 1923. 


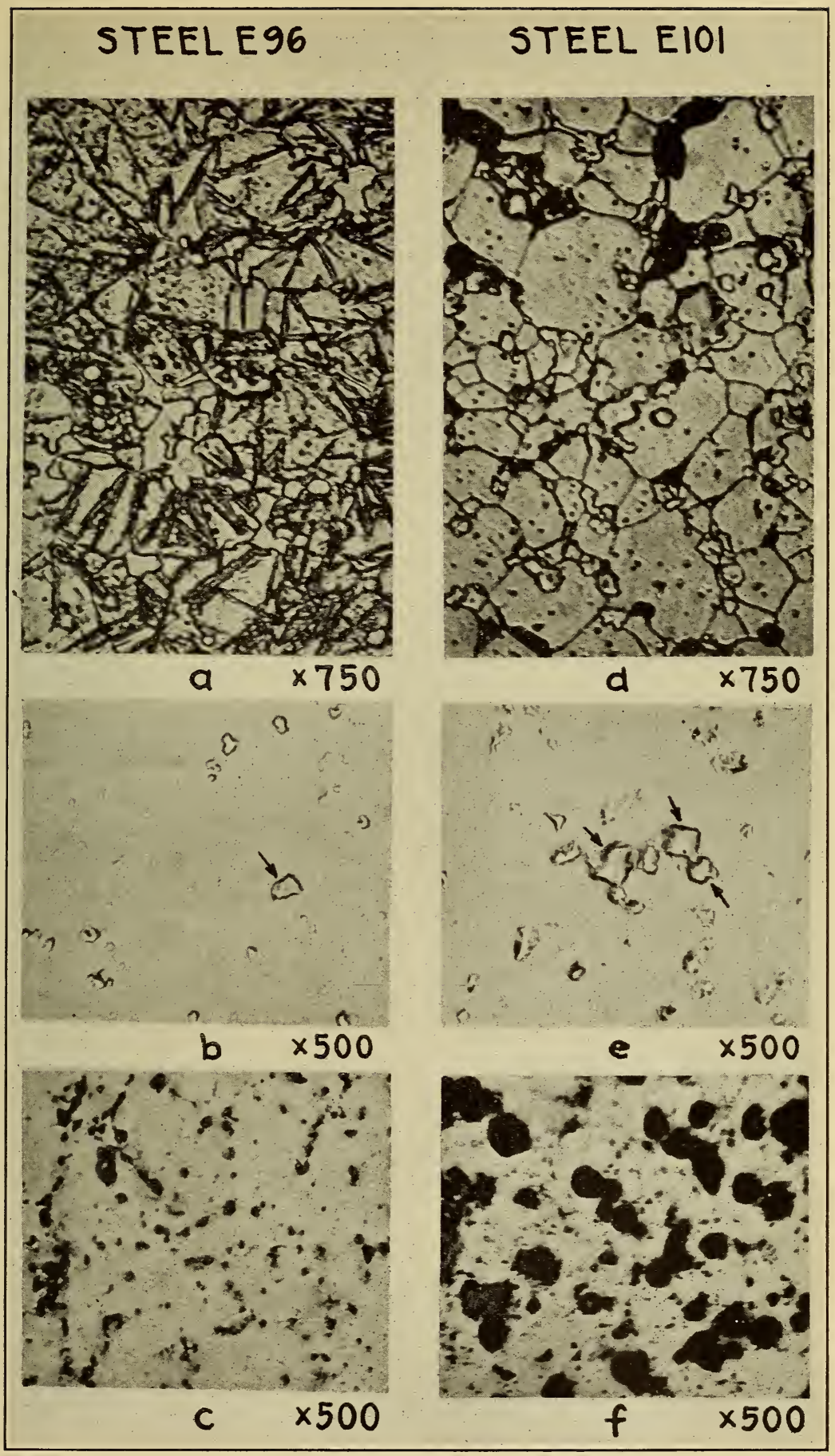

FIGURE 31.-Structures of hardened high-speed steels containing about 1.2 per cent $C$ and different proportions of titanium (and aluminum)

Compositions of the steels are given in Table 2; $(a)$ and $(d)$, etched with 5 per cent $\mathrm{HNO}_{3}$ in alcohol; $(b)$ and $(e)$, unetched; $(c)$ and $(f)$, etched in boiling solution of $\mathrm{KMnO}_{4}(4 \mathrm{~g}), \mathrm{NaOH}(4 \mathrm{~g})$ in $100 \mathrm{ml}$ $\mathrm{H}_{2} \mathrm{O}$. Samples first oil quenched from $2,350^{\circ} \mathrm{F}$. 


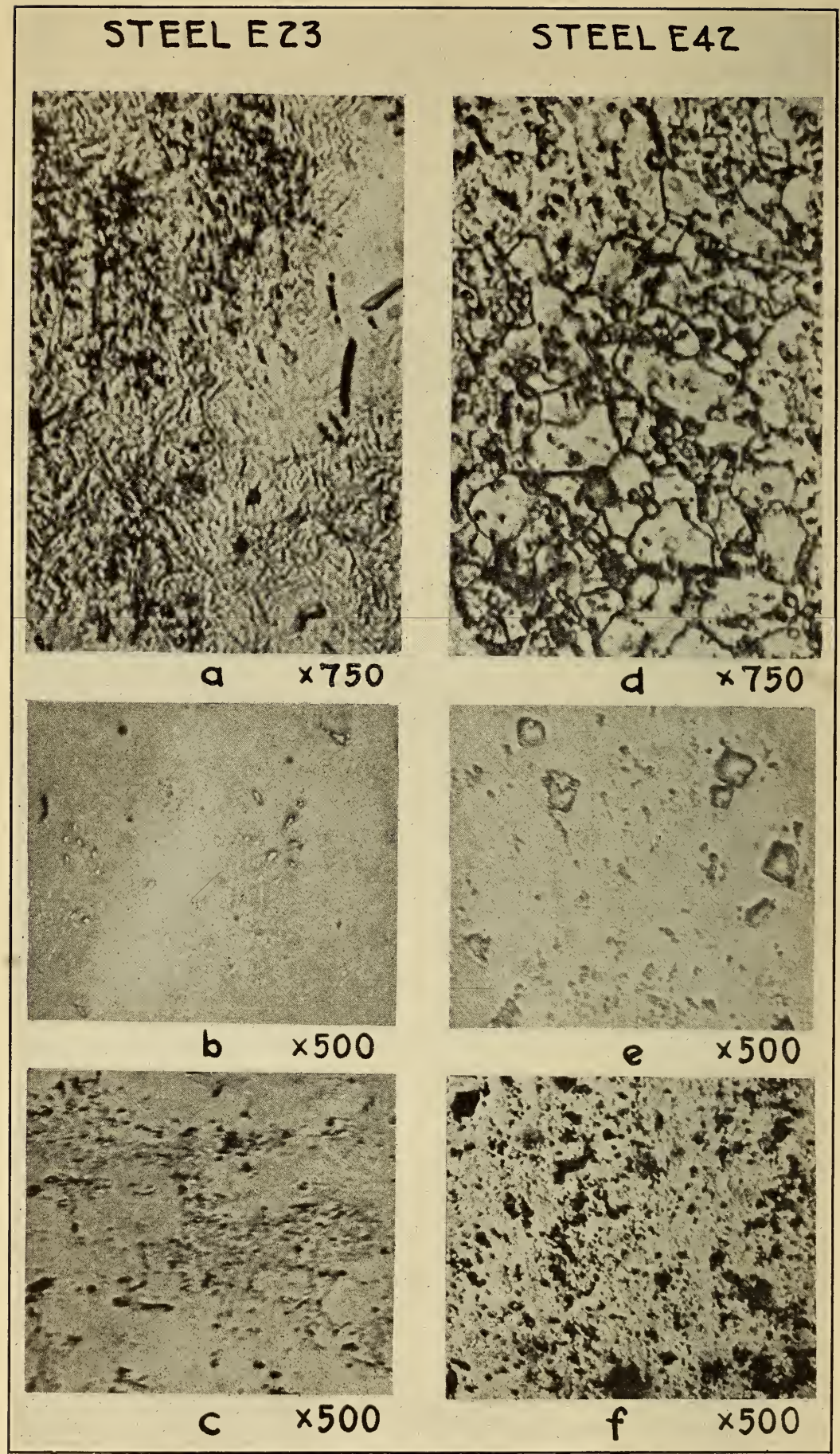

FIgURE 33.-Structures of the chromium-tantalum steel and the chromiumtungsten-tantalum-vanadium steel as oil quenched from $2,350^{\circ} \mathrm{F}$.

Compositions of the steels are given in Table 2; $(a)$ and $(d)$, etched with 5 per cent $\mathrm{HNO}_{3}$ in alcohol; $(b)$ and $(e)$, unetched; $(c)$ and $(f)$, etched in boiling solution of $\mathrm{KMnO}_{4}(4 \mathrm{~g}), \mathrm{NaOH}(4 \mathrm{~g})$ in $100 \mathrm{ml}$ $\mathrm{H}_{2} \mathrm{O}$. 


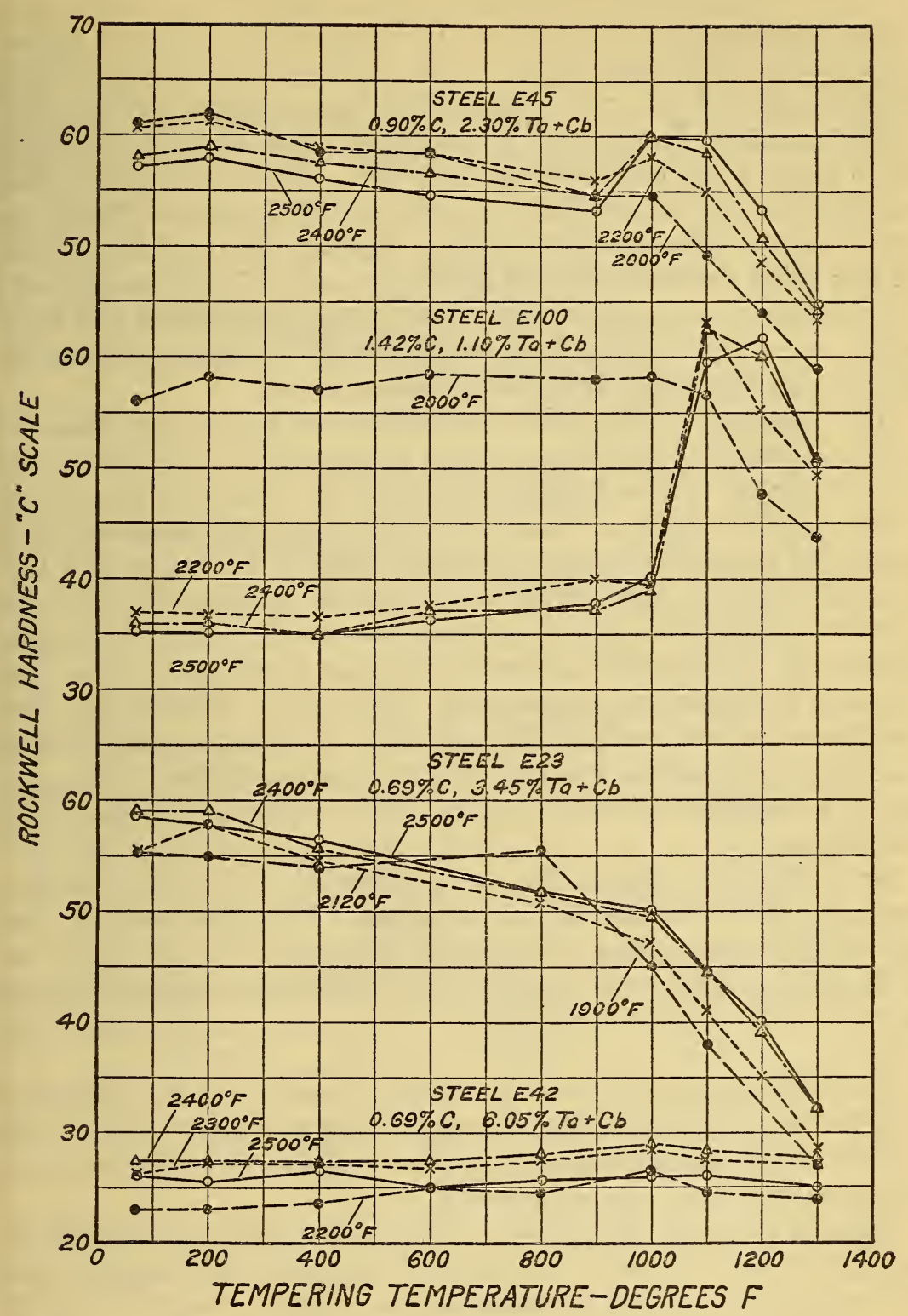

FIGURE 32.-Hardness of some of the high-speed steels containing different proportions of tantalum (+columbium) when subjected to different heat treatments

Compositions of the steels are given in Table 2. Quenching temperatures are shown in the body of the chart. 
The hardened samples appeared to be predominately martensitic with some undissolved particles, probably chromium carbides, as is shown in Figures $33(a),(b)$, and $(c)$. Steel E42 would not harden appreciably under any of the heat treatments employed. These included oil and water quenching from temperatures varying from $1,500^{\circ}$ to $2,500^{\circ} \mathrm{F}$., followed by tempering at different temperatures up to $1,400^{\circ} \mathrm{F}$. for periods up to 195 hours. The long-time tempering was carried out to ascertain whether any precipitation hardening would occur. The structure of this steel when quenched from $2,350^{\circ}$ F. into oil is shown in Figures $33(d),(e)$, and $(f)$, and comprised a large number of undissolved particles, probably carbides and tungstides, in a matrix of alpha iron (Rockwell $\mathrm{C}$ hardness about 27) presumably containing tantalum in solid solution.

The hardness of the steels containing the usual proportions of carbon, chromium, and tungsten (low tungsten-high vanadium steels) was not greatly affected under different heat treatments by 0.75 per cent or less of tantalum, except that the maximum rehardening on tempering occurred at about $1,000^{\circ}$ to $1,050^{\circ} \mathrm{F}$. instead of at $1,100^{\circ}$ F., and that the hardness of the tempered samples did not quite equal the highest hardness produced in the untempered samples. Also in the untempered samples the hardness tended to decrease with increase in quenching temperature. (Fig. 34.) With 5 per cent tantalum the hardness was less than that of the high-speed steels of customary composition when subjected to comparable heat treatments and the hardness was more largely dependent upon the quenching temperature.

As is shown in Figure 35, the number of undissolved particles increased with increase in the tantalum. This was probably not due to any combination of tantalum and carbon but to a decrease in the dissolving power of the austenite for the chromium and tungsten carbides, or tungstides, produced by the tantalum in solution in the iron.

The hardness and the structures (figs. 32 and 36) of the chromium tungsten tantalum steel E45 containing 0.9 per cent carbon were approximately the same as those of the chromium tungsten tantalum steels with 0.6 to 0.7 per cent carbon.

Perhaps the most interesting of the steels containing tantalum in addition to the customary amounts of chromium and tungsten was the one containing 1.4 per cent carbon. (E100, Table 2.) As is shown in Figure 32, this steel had a Rockwell C scale hardness of only about 36 when oil quenched from temperatures between $2,200^{\circ}$ and $2,500^{\circ} \mathrm{F}$. When hardened from a lower temperature, $2,000^{\circ} \mathrm{F}$., its hardness was about 56 and was not appreciably changed upon subsequent tempering at temperatures up to $1,100^{\circ} \mathrm{F}$. 
The samples which did not harden when oil quenched from $2,200^{\circ}$ to $2,500^{\circ} \mathrm{F}$. did not harden appreciably when subsequently tempered at temperatures up to $1,000^{\circ} \mathrm{F}$., but with increase in tempering temperature to $1,100^{\circ} \mathrm{F}$. showed a surprisingly large increase in the hardness. This increase on the Rockwell $\mathbf{C}$ scale was from about 40 to 62 , a difference of 22 points. The untempered samples showed

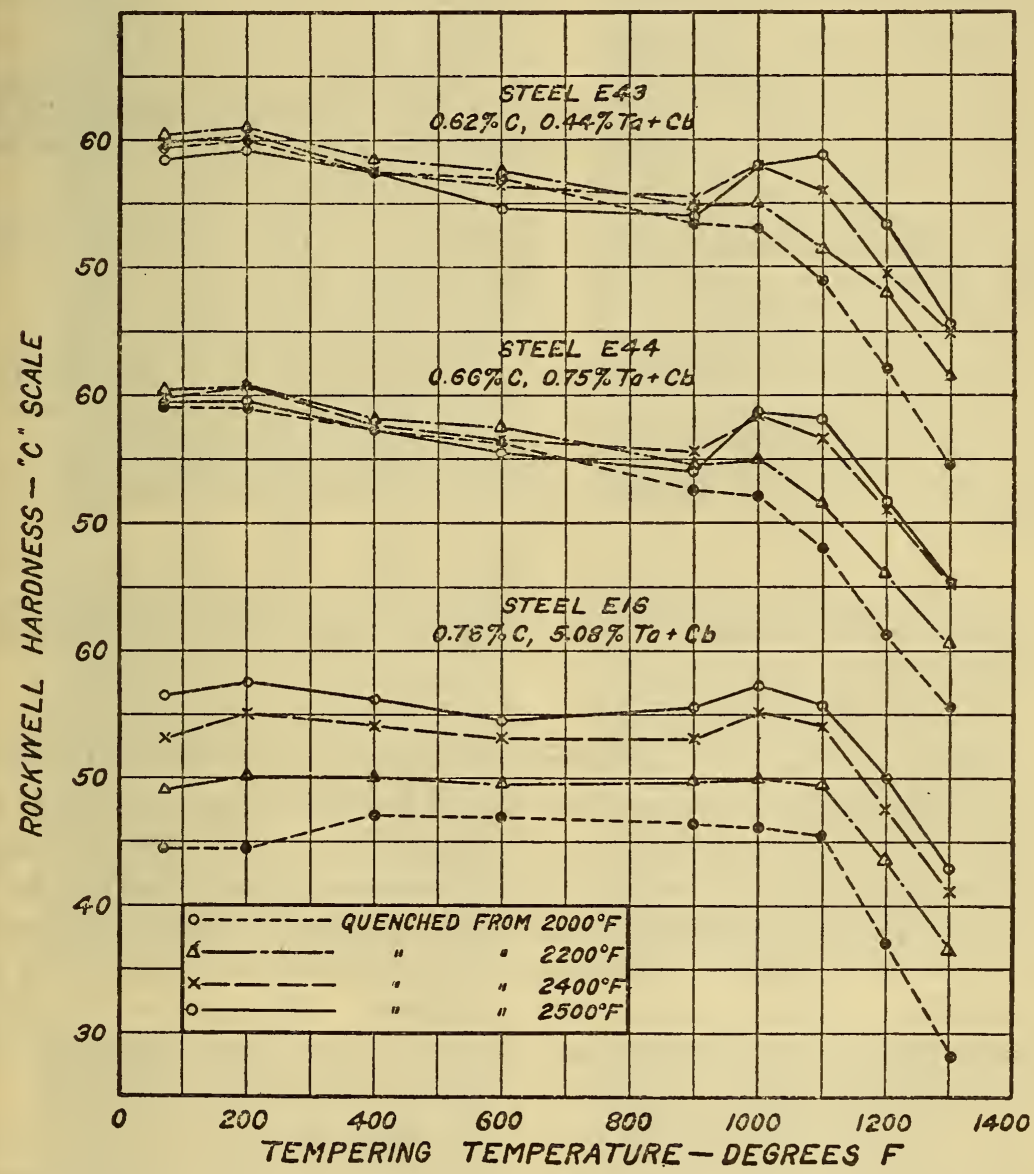

FIGURE 34.-Hardness of some of the high-speed steels containing different proportions of tantalum (+columbium) when subjected to different heat treatments

Compositions of the steels are given in Table 2.

an austenitic matrix with numerous undissolved particles at the austenite grain boundaries, as is shown in Figures $36(d),(e)$, and $(f)$.

None of the steels containing tantalum showed as good performance as the high-speed steels of customary compositions, either with shallow cuts and fine feeds or under heavy duty. Steel E42, which would not harden, also failed to cut. Likewise, the chromium-tantalum 
steel E23 did not show cutting properties comparable to those of the ordinary high-speed steels. The results of the lathe tests with these steels are summarized in Table 16.

TABLE 16.-Summary of the lathe tests on some of the steels containing tantalum $(+$ columbium $)$

TESTS WITH SHALLOW CUTS (0.010 INCH DEPTH, 0.0115 IN./REV. FEED, 350 FT./MIN. SPEED)

\begin{tabular}{|c|c|c|c|c|c|c|c|c|c|c|c|}
\hline \multirow{2}{*}{ Steel No. } & \multicolumn{5}{|c|}{ Chemical composition } & \multirow{2}{*}{$\begin{array}{c}\text { Oil } \\
\text { quenched } \\
\text { from- }\end{array}$} & \multirow{2}{*}{$\begin{array}{l}\text { Tem- } \\
\text { pered } \\
\text { at- }\end{array}$} & \multirow{2}{*}{$\begin{array}{l}\text { Tests } \\
\text { on } \\
\text { forging } \\
\text { No. }\end{array}$} & \multirow{2}{*}{$\begin{array}{l}\text { Num- } \\
\text { ber of } \\
\text { tools } \\
\text { tested }\end{array}$} & \multirow{2}{*}{$\begin{array}{l}\text { A verage } \\
\text { tool life }\end{array}$} & \multirow{2}{*}{$\begin{array}{l}\text { Cutting } \\
\text { speed for } \\
90 \text {-minute } \\
\text { tool life }\end{array}$} \\
\hline & $\mathrm{C}$ & $\mathrm{Cr}$ & $\mathrm{W}$ & $\mathrm{V}$ & $\begin{array}{c}\mathrm{Ta} \\
(+\mathrm{Cb})\end{array}$ & & & & & & \\
\hline $\mathrm{E} 97_{-}$ & $\begin{array}{l}\text { P. ct. } \\
0.64\end{array}$ & $\begin{array}{l}\text { P. ct. } \\
\text { 3. } 41\end{array}$ & $\begin{array}{l}\text { P. ct. } \\
\text { 13. } 02\end{array}$ & $\begin{array}{l}\text { P. ct. } \\
\text { 1. } 99\end{array}$ & P.ct. & ${ }^{\circ} F$. & ${ }^{\circ} \mathrm{F}$, 100 & 41 & 8 & $\begin{array}{r}\text { Minutes } \\
22.9\end{array}$ & Ft./min. \\
\hline $\begin{array}{l}\text { E23. } \\
\text { E42. }\end{array}$ & $\begin{array}{l}.69 \\
.69\end{array}$ & $\begin{array}{l}4.28 \\
4.23\end{array}$ & 8.20 & 1.58 & $\begin{array}{l}3.45 \\
6.05\end{array}$ & $\begin{array}{l}2,350 \\
(2)\end{array}$ & 650 & $\begin{array}{l}41 \\
41\end{array}$ & 5 & 0 & \\
\hline 9100 & 1.42 & 3.37 & 13. 03 & .10 & 1.10 & 2,350 & 1,000 & 41 & $\overline{7}$ & .2 & \\
\hline
\end{tabular}

HEAVY DUTY TESTS (3/16 INCH DEPTH, 0.028 IN./REV. FEED, 85 FT./MIN. SPEED)

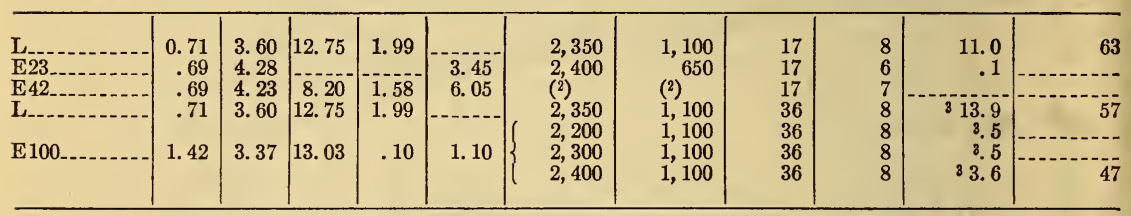

1 Computed from average tool life by means of equation (1) of the text with $n=1 / 10$ for shallow cuts and $n=1 / 7$ for deep cuts.

2 Would not harden.

3 Tests made at 75 feet per minute.

The high carbøn, chromium-tungsten-tantalum steel E100 (Table 2) which showed the very large increase in hardness when tempered at $1,100^{\circ} \mathrm{F}$. after quenching from high temperatures, failed to show any promise for lathe tools for either shallow cuts or heavy duty. As is shown in Table 16, the tools failed in less than one minute, whereas the high-speed steels of customary composition cut for periods of 10 to 22 minutes under comparable conditions. The best tool life (3.6 minutes) in rough turning was obtained when steel E100 was oil quenched from $2,400^{\circ} \mathrm{F}$. and subsequently tempered at $1,100^{\circ} \mathrm{F}$.

The four high-speed steels containing 0.6 to 0.9 per cent carbon, in which the 2 per cent vanadium was replaced by different proportions tantalum, gave the best tool performance of any of the steels containing tantalum, but in no case was this as good as the performance of the customary chromium-tungsten-vanadium steel. As is shown in Figure 37, the cutting speeds of the chromium-tungsten-tantalum steels decreased with increase in the proportion of tantalum.

Tantalum does not appear to be promising as a substitute for vanadium or as an alloying element in the customary chromiumtungsten high-speed steels for lathe tools. It acted in a manner similar to aluminum and titanium in that it appeared to decrease 


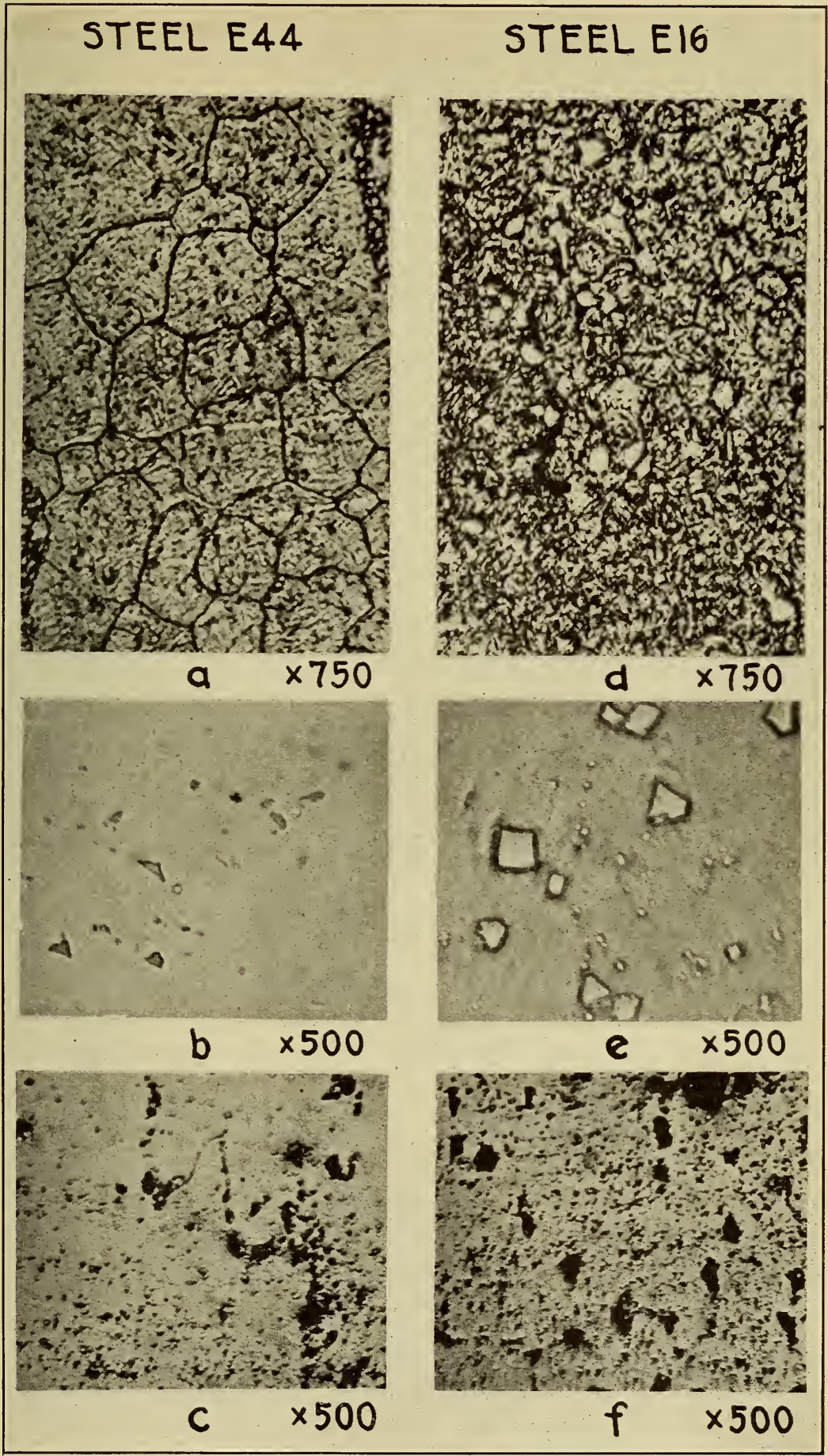

FIgURE 35.-Structures of two of the chromium-tungsten-tantalum steels as oil quenched from $2,350^{\circ} \mathrm{F}$.

Compositions of the steels are given in Table 2; $(a)$ and $(d)$, etched with 5 per cent $\mathrm{HNO}_{3}$ in alcohol; $(b)$ and (e), unetched; $(c)$ and $(f)$, etched in boiling solution of $\mathrm{KMnO}_{4}(4 \mathrm{~g}), \mathrm{NaOH}(4 \mathrm{~g})$ in $100 \mathrm{ml}$ $\mathrm{H}_{2} \mathrm{O}$. 


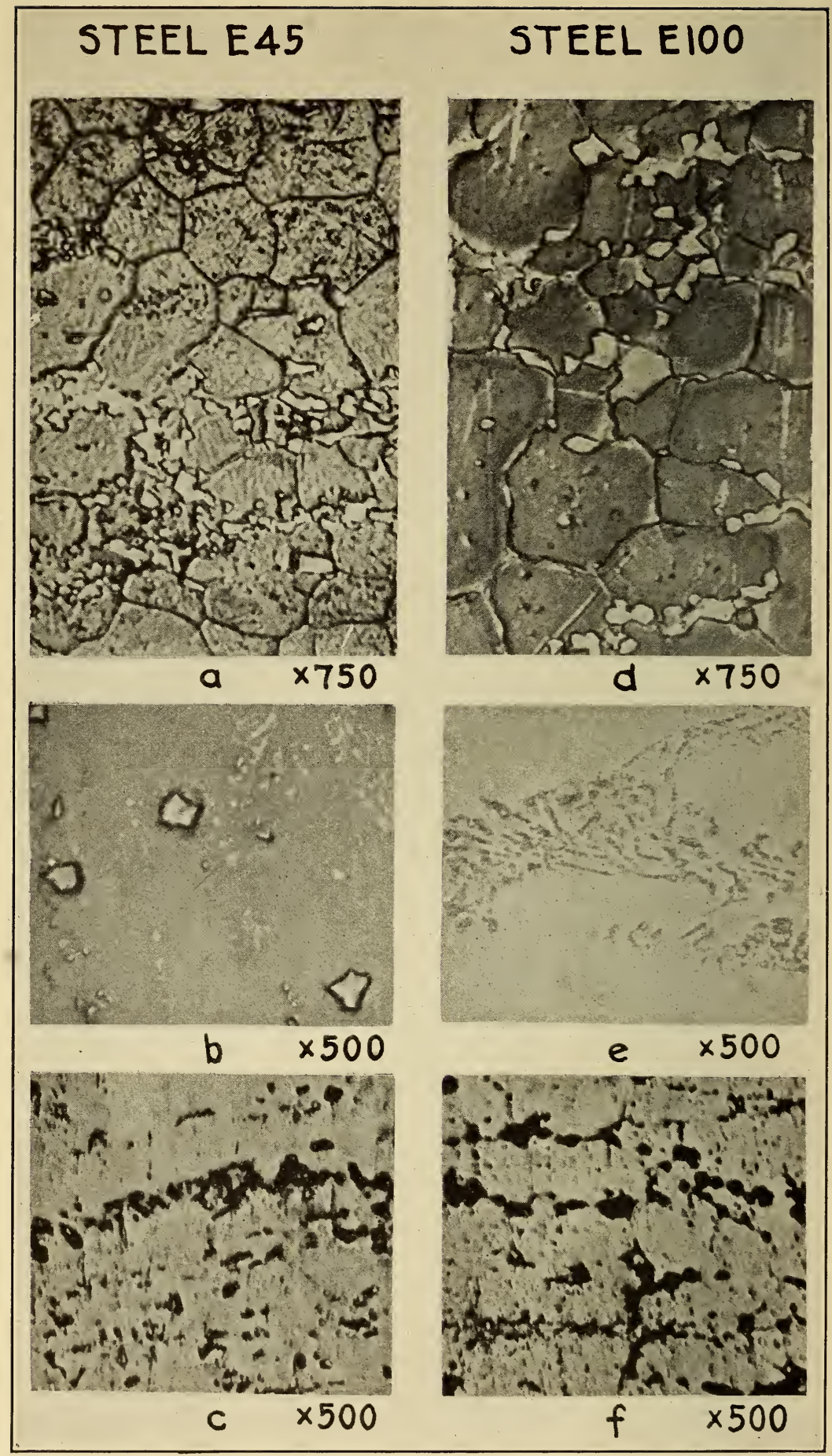

FIGURE 36.-Structures of two of the high-carbon steels containing chromium, tungsten, and tantalum when oil quenched from $2,350^{\circ} \mathrm{F}$.

Compositions of the steels are given in Table 2; $(a)$ and (d), etched with 5 per cent $\mathrm{HNO}_{3}$ in alcohol; $(b)$ and $(e)$, unetched; $(c)$ and $(f)$, etched in boiling solution of $\mathrm{KMnO}_{4}(4 \mathrm{~g}), \mathrm{NaOH}(4 \mathrm{~g})$ in $100 \mathrm{ml}$ $\mathrm{H}_{2} \mathrm{O}$. 
the dissolving power of the austenite for the chromium and tungsten compounds and so decreased the hardness and cutting speeds of the quenched lathe tools.

\section{STEELS WITH HIGH PHOSPHORUS OR SULPHUR}

Phosphorus and sulphur are present in varying proportions in all commercial steels, and therefore it seemed desirable to determine their effects upon lathe-tool performance in connection with the study of impurities in high-speed steels for shallow cuts, already described. Furthermore, relatively large proportions of phosphorus or sulphur were inadvertently introduced, through one of the lots of ferrovanadium, into some of the high-speed steels containing nickel or cobalt, and it became impracticable to interpret the results of the lathe tests

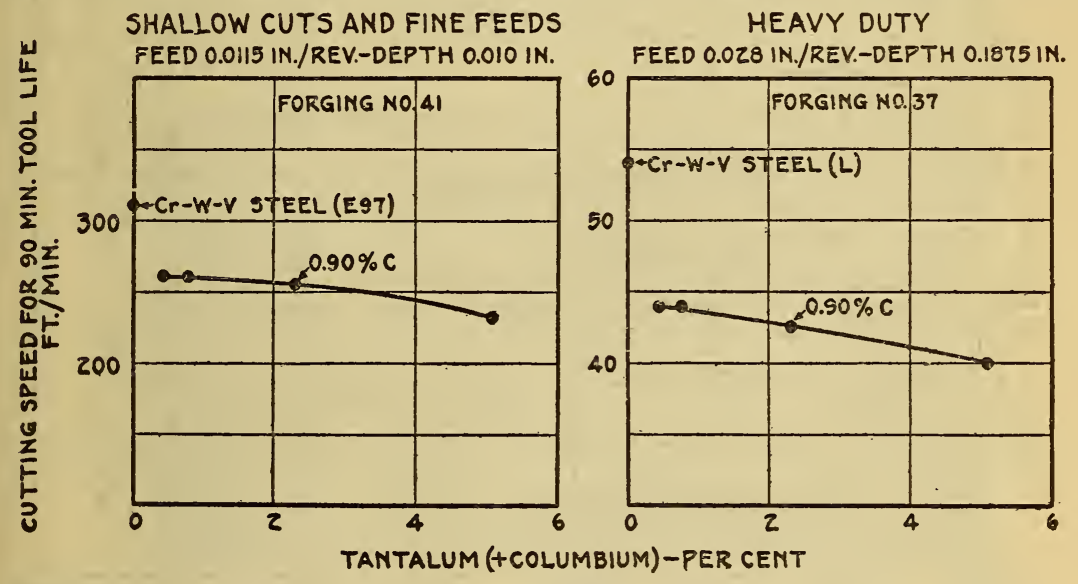

FIGURE 37.-Effect of tantalum (+ columbium) on the cutting speed of highspeed steel tools under shallow cuts and under heavy duiy

Compositions of the tools and their heat treatment are given in Table 2; properties of the forgings are given in Table 3. All tests were made dry.

with these steels without information on the effects of the phosphorus and sulphur present.

As a result of their extended experiments with roughing tools, Taylor and coworkers ${ }^{50}$ came to the conclusion-

that high phosphorus and sulphur are much less injurious to high-speed tools than they were to the carbon tools. However, these elements still exert a somewhat injurious influence upon the steel, and we therefore recommend, inasmuch as the presence of chromium and tungsten in large quantities necessarily render high-speed tools very expensive, that the best qualities of low phosphorus and low sulphur iron should be used in their manufacture.

These views have received the support of a majority of the American manufacturers of high-speed tool steels, as is shown by the results 
of a survey made during $1922^{51}$ of 66 lots representing 39 commercial brands on the American market. The average proportions of phosphorus and sulphur were 0.023 and 0.027 per cent, respectively, while the ranges were 0.004 to 0.051 per cent phosphorus and 0.009 to 0.061 per cent sulphur.

Comparison of the results in Figure 38 with those for steel E97 in Figure 23 shows that the Rockwell hardness of the high-speed steels was not appreciably affected by 0.058 per cent added phosphorus or 0.215 per cent added sulphur. However, the high-sulphur steels showed a large number of sulphide inclusions (figs. $39(a)$ and (b),

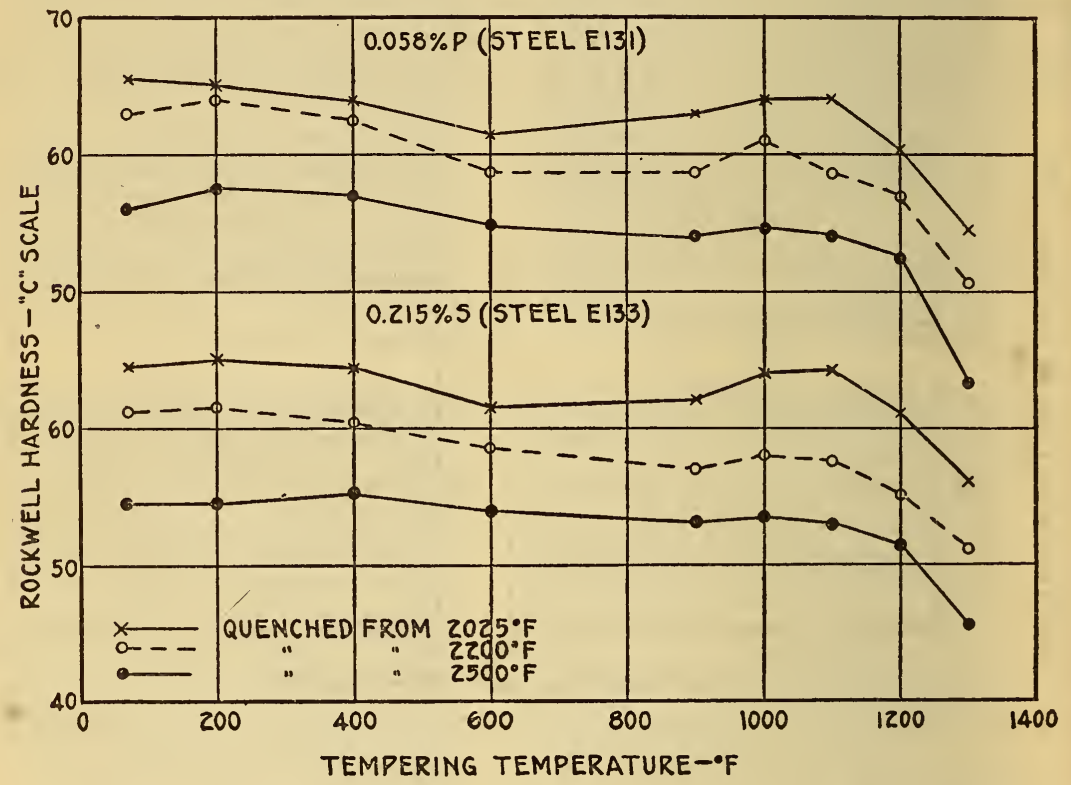

FIGURE 38.-Hardness of the high-speed steels containing high phosphorus or high sulphur when subjected to different heat treatments

Compositions of the steels are given in Table 2.

and 40), and there was evidence of phosphide-rich areas in the steel with 0.058 per cent phosphorus (fig. $39(c)$ ).

The sulphide inclusions in the chromium-tungsten-vanadium steels were probably sulphides of both manganese and iron, since the 0.39 per cent manganese in steel E133 is not sufficient to take care of all of the 0.215 per cent sulphur. Similar sulphide inclusions were found in the high-sulphur high-speed steels containing nickel, although they did not have as smooth boundaries as in the steels without nickel and were interspersed with or broken up by white constituents, presumably the carbides and tungstides. It is possible

31 H. J. French and Jerome Strauss, Lathe Breakdown Tests of Some Modern High-Speed Tool Steels, B. S. Tech. Paper No. 228; 1923. 


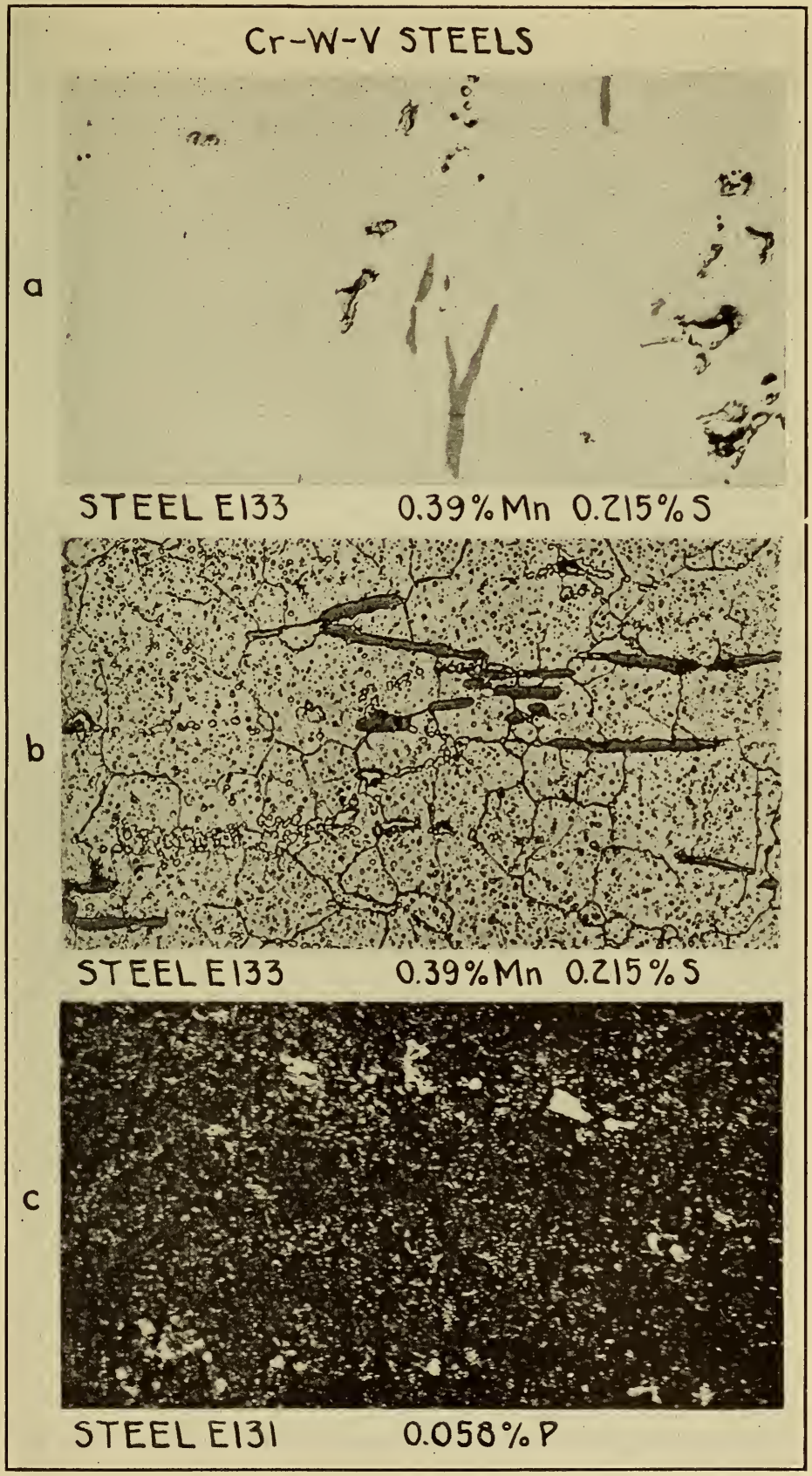

FIGURE 39.-Structures of hardened high-speed steels containing high phosphorus or high sulphur. $\times 500$

Samples oil quenched from $2,350^{\circ} \mathrm{F}$., not tempered; (a), unetched; $(b)$, etched with 5 per cent $\mathrm{HNO}_{3}$ in alcohol; (c), etched with stead's reagent. 


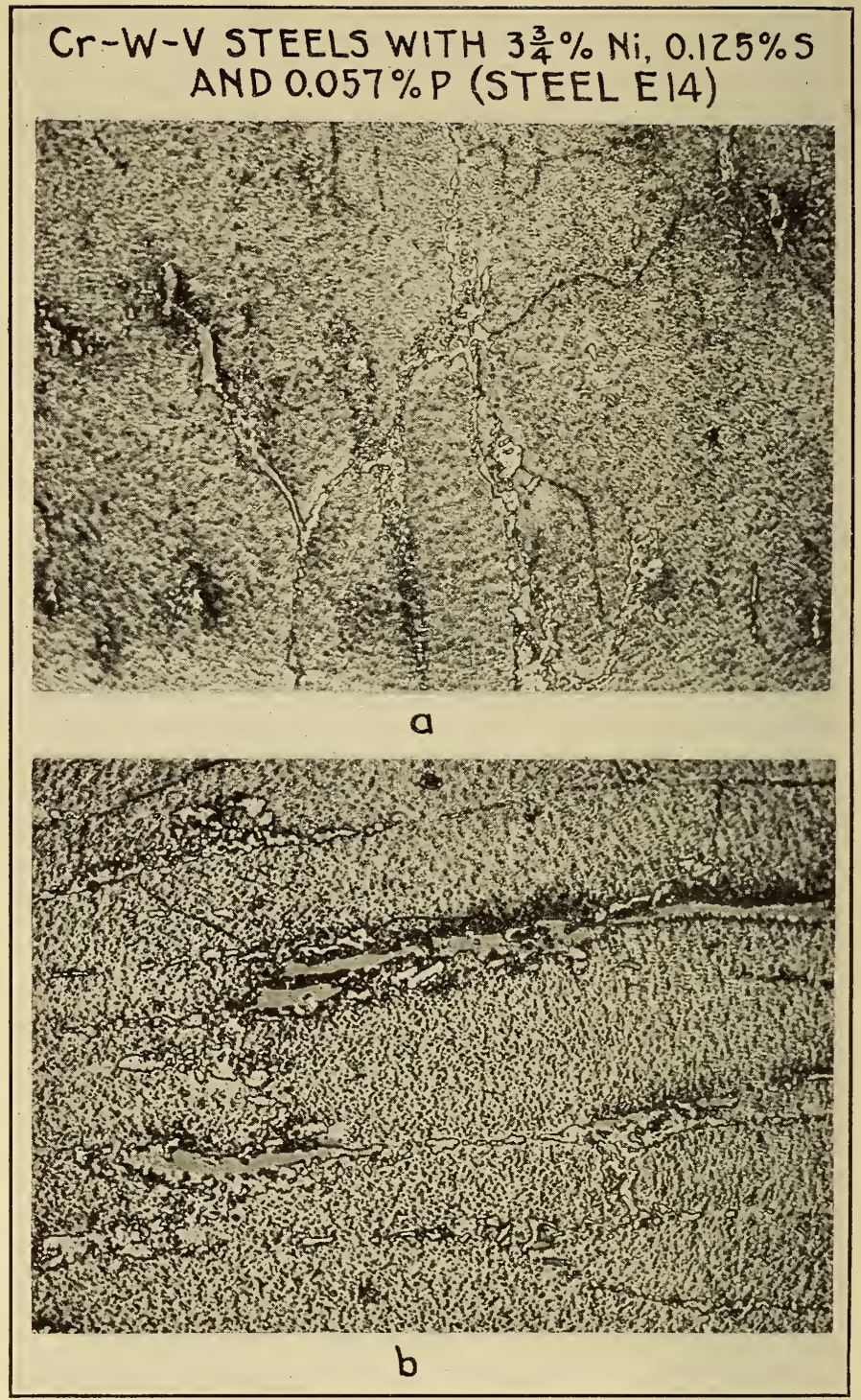

FIgURE 40.-Structures of hardened high-speed steel containing 33/4 per cent nickel and high phosphorus and sulphur. $\times 500$

Samples oil quenched from $2,350^{\circ} \mathrm{F}$., not tempered; (a), etched with 5 per cent $\mathrm{HNO}_{3}$ in alcohol; $(b)$, etched with 2 per cent $\mathrm{HF}$ in water. 
that some of the sulphur has combined with the nickel in the highspeed steels containing this latter element, but definite evidence is lacking that this is so, and the significance, if any, of these differences in structural characteristics is not now apparent. The feature of principal interest is that evidence was obtained in the lathe tests that high sulphur was somewhat more detrimental in the high-speed steels with nickel than in those without.

In the lathe tests under heavy duty and also those under shallow cuts (summarized in fig. 41) the steel with 0.058 per cent phosphorus (E131, Table 2) and the steels with 0.135 and 0.215 per cent sulphur showed comparable performance to the steels with much lower proportions of these elements (E129 and E97). Similarly, a cobalt

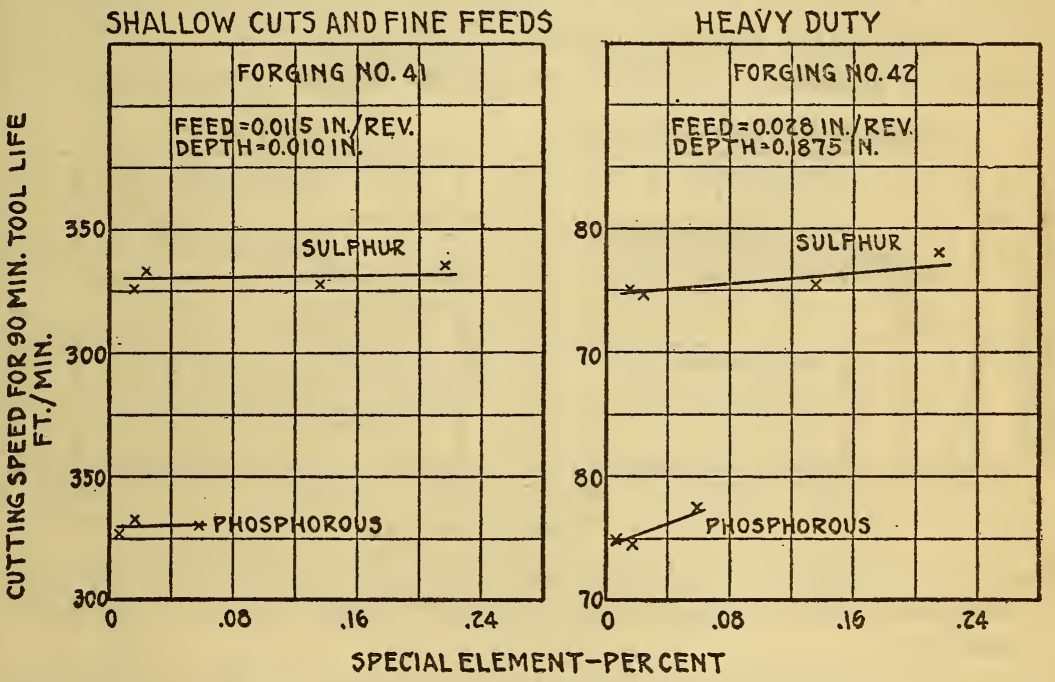

FIGURE 41.-Effects of phosphorus and sulphur on the cutting speeds of high-speed steel tools under shallow cuts and under heavy duty

Compositions of the tools and their heat treatments are given in Table 2; properties of the forgings are given in Table 3 . All tests were made dry.

high-speed steel with both high phosphorus and high sulphur (E15) had a cutting speed equal to that of a similar steel with low phosphorus and sulphur (steel A, Table 2). On the other hand, the nickel-bearing high-speed steel with 0.057 per cent phosphorus and 0.125 per cent sulphur, had a lower cutting speed than a similar steel with about 0.02 per cent of each of these elements.

It may, therefore, be said that phosphorus up to about 0.06 per cent and sulphur up to 0.215 per cent do not appear to be injurious, from the viewpoint of lathe tool performance, when present individually or together, in the customary chromium-tungsten-vanadium steels, with or without cobalt. However, high sulphur tended to lower the cutting speeds in the presence of nickel. 
Because of the possibility of segregation of the phosphorus and the introduction of numerous sulphide inclusions in high-sulphur steels these two elements may react disadvantageously by promoting lack of uniformity and localized weaknesses. Therefore, they can advisably be kept within low limits for all high-speed steel lathe tools.

\section{STEELS WITH NICKEL}

The close proximity of nickel and cobalt in the periodic system of the elements and recognition of the benefits derived from cobalt has frequently raised the question of substituting nickel for cobalt in high-speed tool steels.

Previously reported tests with roughing tools ${ }^{52}$ showed that the addition of about $3 \frac{3}{4}$ per cent of nickel to the customary chromiumtungsten-vanadium steels produced effects similar to those from like amounts of cobalt. However, somewhat higher temperatures had
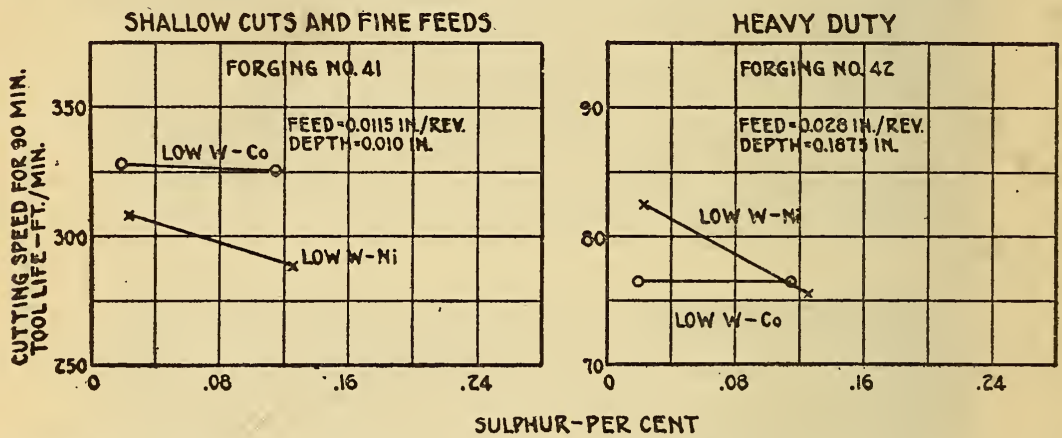

FIGURE 42.-Effects of sulphur on the cutting speeds of high-speed steel tools containing nickel or cobalt when tested under shallow cuts and also under heavy duty

Compositions of the tools and their heat treatments are given in Table 2; properties of the forgings are given in Table 3. All tests were made dry.

to be used in hardening the nickel steels than in the steels without nickel to produce the best tool performance, and in this respect nickel and cobalt acted similarly. On the other hand, it was more difficult to put the high-speed steels with nickel into a machinable condition than it was with steels containing cobalt or steels without nickel or cobalt, unless an adjustment was made in the carbon content. With decrease in carbon from 0.6 or 0.7 to 0.5 per cent, the steels with nickel could themselves be readily machined while the tool performance under heavy duty remained substantially the same.

These tests were all made under heavy duty, and two of the nickel steels contained high phosphorus or sulphur, or both. For this reason the rough turning tests were repeated on steels containing low proportions of phosphorus and sulphur, and the results are included in Table 17 with those obtained under shallow cuts and fine feeds.

\footnotetext{
${ }^{32}$ H. J. French and T. G. Digges, Experiments with Nickel, Tantalum, Cobalt, and Molybdenumin High-Speed Steels, Trans. Am. Soc. Steel Treat., 8, p. 861; 1925.
} 


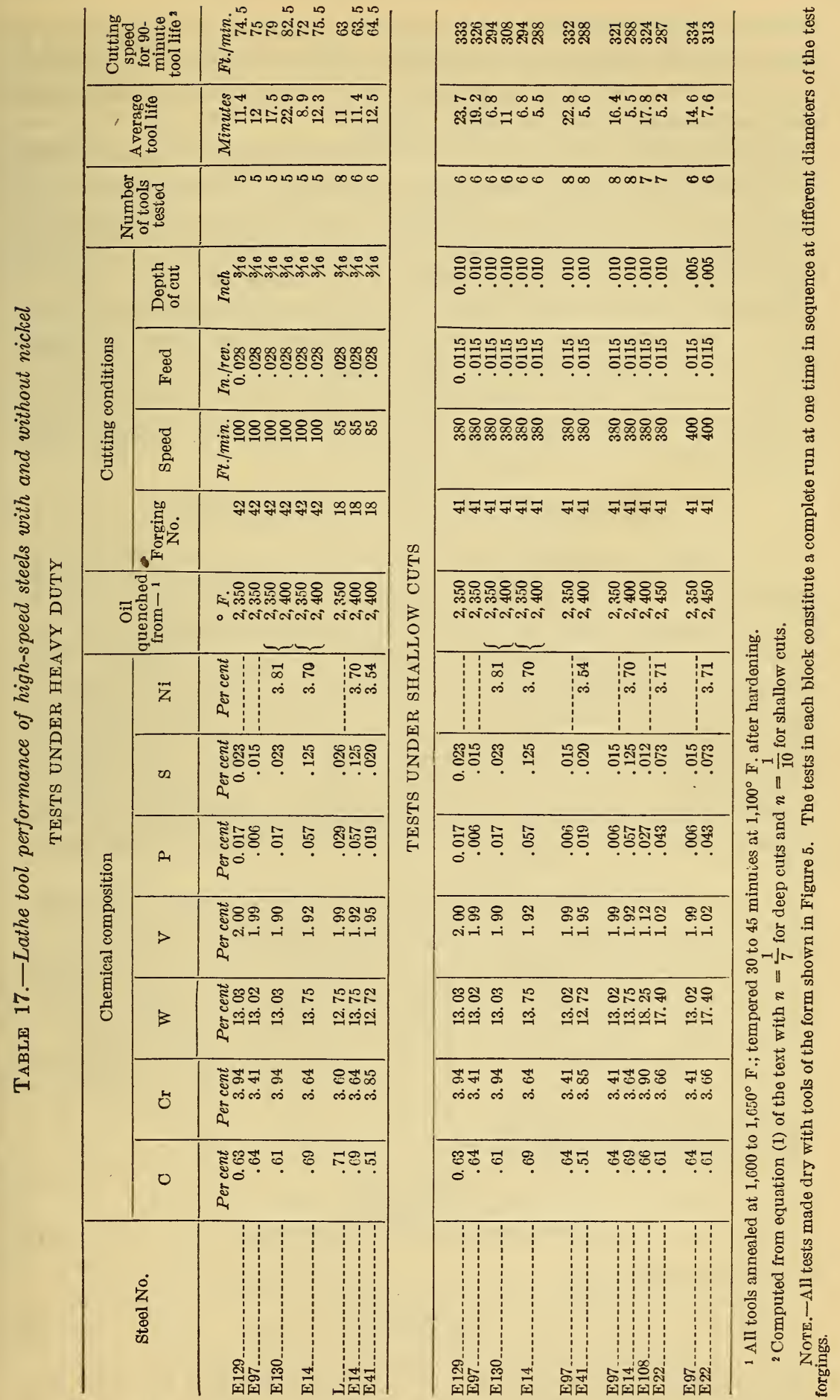


The results in Table 17 show that the addition of $3 \frac{3}{4}$ per cent of nickel to the customary chromium-tungsten-vanadium steels was beneficial for the rough turning tools but detrimental to the tools used under shallow cuts and fine feeds.

In the rough turning tools the addition of nickel, together with a $50^{\circ} \mathrm{F}$. increase in the quenching temperature, produced an appreciable improvement in the performance of the high-speed steels, but the same tools were not as good under shallow cuts as the tools free from nickel which were hardened at lower temperatures.

The fact already mentioned that the high-speed steels with nickel could not themselves be readily machined, even after prolonged annealing, suggested lowering the carbon content from around 0.6 or 0.7 to 0.5 per cent. This did not affect the performance of the roughing tools appreciably, as is shown in Table 17, but was detrimental in the tools used under shallow cuts.

\section{SUMMARY AND CONCLUSIONS}

1. A method is described for testing lathe tools under shallow cuts and fine feeds. It is based upon the fact that when two tools are set at equal depths in one tool holder the second or "trailing" tool will not cut so long as the "leader" or cutting tool shows no wear. With the carbon and high-speed steel tools used, the second tool began to cut when the leader had worn 0.001 to 0.002 inch, and at this point the leader or test tool was considered to have failed. All subsequent comments on turning with shallow cuts and fine feeds are based on this end point, but greater wear can be made to represent tool failure by using a shallower setting for the second tool than for the cutting tool.

2. Tests were made dry at different cutting speeds, feeds, and depths of cut on nickel steel forgings with tensile strengths of 80,000 to $100,000 \mathrm{lbs}$./in. ${ }^{2}$ to give a broad background for the interpretation of the results of tests of different tool steels, first heat treated in various ways. The results could be represented approximately by the following equations, in which $V$ is the cutting speed, $T$ the tool life, $F$ the feed, $D$ the depth of cut, $A$ the area of cut (=DF), $c, K$, $K_{1}, K_{2}$, and $n$ are constants.

For high-speed steel tools

$$
\begin{gathered}
V T^{\frac{1}{10}}=c \\
V=K_{1}-K_{2}(D F)=K_{1}-K_{2} A
\end{gathered}
$$

For carbou steel tools

$$
V=\frac{K}{D F}=\frac{K}{A}
$$

These equations are not to be construed to represent the true laws of cutting, since the cutting speed is probably not affected equally by 
variations in the feed and the depth of cut. However, they represent approximately the results of the experiments made with the depths of cut of 0.005 to 0.020 inch and feeds of 0.0115 to 0.0204 in./rev.

3 . In the tests of short duration, where tool failure occurred in about 2 to 10 minutes, the tool life was increased somewhat more by the use of water than by lard oil, but in tests of about 50 minutes duration, under the same feed and depth of cut but lower cutting speeds, these two liquids produced effects of the same magnitude. The increases in tool life from the use of these liquids were not large in any case, but the finish on the work piece at the end of the cut was better with the liquids than without.

4. Tests with tools of different forms and angles showed that the successful application of the described method of test was not dependent upon having the broad-nose tool used in a majority of the experiments. Tools with a plan angle of $65^{\circ} \mathrm{had}$ a longer life than the broad-nose tools, but the finish produced on the nickel steels in dry turning did not appear to be as good. The best tool life with the broad-nose tools was obtained with a back slope of $30^{\circ}$; a side slope of $0^{\circ}$ was better than $8^{\circ}$.

5. The cutting speed of quenched carbon steel tools was not affected appreciably by variations in carbon content from 0.75 to 1.3 per cent nor by subsequent tempering at temperatures up to $375^{\circ} \mathrm{F}$., which did not lower the hardness; the cutting speed of the carbon steel tools was equal approximately to that of a quenched "oil hardening" tool steel and only slightly lower than the cutting speed of a steel containing 1.3 per cent carbon and $23 / 4$ per cent tungsten.

6. The cutting speed of carbon steel tools was lower in all cases than that of high-speed steel tools, but the differences between the two decreased with decrease in the areas of cut in dry turning.

7. The heat treatments which resulted in the best roughing tool performance for high-speed steels of customary compositions also resulted in superior performance under shallow cuts and fine feeds. These treatments comprised oil quenching from the highest practical temperatures followed by tempering to convert the larger part of the retained austenite to martensite.

8. Of 12 elements added in different proportions to chromiumtungsten or chromium-tungsten-vanadium high-speed steels only one-cobalt-produced decidedly beneficial results. Molybdenum and nickel offered promise under certain conditions, while the remainder either had a negligible effect or were definitely deleterious from one viewpoint or another.

9. Cobalt improved the performance of the high-speed steel tools both under shallow cuts and under heavy duty, but the maximum benefits were obtained only with high hardening temperatures. The percentage gain from the addition of cobalt was somewhat greater 
in rough turning than with shallow cuts and fine feeds, but increase in cobalt above about 5 per cent did not produce improvements commensurate with those resulting from $3: 5$ to 5 per cent and high hardening temperatures.

10. Replacement of part or all of the tungsten in high-speed steels by molybdenum, in the ratio of 1 part molybdenum to $2 \frac{1}{2}$ parts of tungsten, produced steels having performance comparable to that of the tungsten steels. Such substitution should be useful in case of a depleted tungsten supply but is not advocated at the present time, since there was some evidence of irregular performance in the high molybdenum steels, and their hot working properties did not seem to be as good as those of the tungsten steels. However, a steel with 7 per cent molybdenum and no tungsten had one advantage over the tungsten steels for roughing tools in that its hardness and performance were not so largely affected by variations in the hardening temperatures.

11. The addition of $3 \frac{3 / 4}{4}$ per cent of nickel to the customary chromiumtungsten-vanadium steels was beneficial for the rough turning tools, particularly when combined with a $50^{\circ} \mathrm{F}$. increase in the hardening temperatures, but was detrimental to the tools used under shallow cuts and fine feeds and adversely affected the machining properties of the high-speed steel itself. Lowering the carbon from 0.6 or 0.7 to 0.5 per cent improved the machining properties without affecting the performance of the roughing tools but was detrimental to the tools used under shallow cuts.

12. Each of the four elements-arsenic, antimony, copper, and tin-adversely affected the tool performance of high-speed steels under shallow cuts, and the magnitude of the decrease became greater as the proportions of these elements increased. Copper was the least harmful; next in order came tin, while arsenic and antimony were the most objectionable.

13. The effects of these four elements upon the performance of roughing tools did not necessarily correspond to those observed with shallow cuts. The 0.8 per cent arsenic addition lowered the cutting speed, but the addition of 0.4 per cent antimony or 0.5 per cent or less of tin had no measurable effect. Higher proportions of tin lowered the cutting speeds. The high-speed steels containing 0.36 to 1.77 per cent copper showed slightly better performance than the corresponding steels without copper.

14. The steels containing 0.4 per cent antimony, 0.8 per cent or more of copper, or 0.8 per cent arsenic did not have good hot working properties, (illustrated by numerous corner cracks on the bars), while those containing 1.7 per cent antimony or 1.8 per cent tin showed a high degree of hot shortness and could not be forged or rolled. Also, 
the steel with 1.77 per cent copper could itself be machined only with difficulty in the annealed condition.

15. Phosphorus up to about 0.06 per cent and sulphur up to 0.215 per cent did not appear to be injurious, from the viewpoint of lathetool performance of the customary chronium-tungsten-vanadium steels, with or without cobalt. However, high sulphur tended to lower the cutting speeds in the presence of $3 \frac{3 / 4}{4}$ per cent nickel. Because of the possibility of segregation of the phosphorus and the introduction of numerous sulphide inclusions in high-sulphur steels these two elements can advisedly be kept within low limits for all highspeed steel lathe tools.

16. Aluminum adversely affected the performance of the high-speed steel tools both with shallow cuts and under heavy duty. It was one of the few metals considered which, in proportions around 0.3 per cent, produced a measurable decrease in the cutting speeds in rough turning. This decrease became greater as the proportion of the aluminum was increased, and with 0.8 per cent the drop in cutting speed was greater than that produced by equal proportions of any of the other elements considered. These changes were accompanied by decrease in the hardness of the quenched steels probably through decrease in the dissolving capacity of the aluminum-iron solid solution for carbon, chromium, tungsten, and vanadium. With 0.8 per cent aluminum there was also evidence of a low melting eutectic in samples quenched from $2,350^{\circ} \mathrm{F}$.

17. Titanium was another of the elements which appeared to lower the dissolving capacity of the austenite, and as a result the hardness and the cutting speeds of the high-speed steel tools decreased with increase in the titanium. Its interference was lessened, probably through the formation of less harmful carbides, instead of solution as titanium in the austenite, by increasing the carbon content of the steel.

18. Tantalum did not appear to be promising as a substitute for vanadium or as an alloying element in the customary chromiumtungsten high-speed steels for lathe tools. It acted in a manner similar to aluminum and titanium in that it appeared to decrease the dissolving power of the austenite for the chromium and tungsten compounds and so decreased the hardness and cutting speeds of the quenched lathe tools.

\section{ACKNOWLEDGMENTS}

Acknowledgments are due to a number of the authors' associates as follows: To C. F. Raab, machinist, whose care in grinding all of the tools and help in carrying out many of the lathe tests contributed appreciably to the consistent results obtained; to W. V. Magruder, 
laboratory aid, for carrying out many of the heat treatments, hardness, and lathe tool tests; to H. K. Herschman, associate metallurgist, and S. J. Rosenberg, assistant metallurgist, for the preparation of the micrographs; and to H. Bright, associate chemist, for the chemical analysis of the tools.

Washington, April 12, 1929. 